IVAN MIGUEL TRINDADE

MODELAGEM, CONTROLE E OTIMIZAÇÃO DE CONSUMO DE COMBUSTÍVEL PARA UM VEÍCULO HÍBRIDO ELÉTRICO SÉRIE-PARALELO

São Paulo 
IVAN MIGUEL TRINDADE

MODELAGEM, CONTROLE E OTIMIZAÇÃO DE CONSUMO DE COMBUSTÍVEL PARA UM VEÍCULO HÍBRIDO ELÉTRICO SÉRIE-PARALELO

Dissertação apresentada à Escola Politécnica da Universidade de São Paulo para obtenção do título de Mestre em Ciências

São Paulo 
IVAN MIGUEL TRINDADE

\title{
MODELAGEM, CONTROLE E OTIMIZAÇÃO DE CONSUMO DE COMBUSTÍVEL PARA UM VEÍCULO HÍBRIDO ELÉTRICO SÉRIE-PARALELO
}

\author{
Dissertação apresentada à Escola \\ Politécnica da Universidade de São \\ Paulo para obtenção do título de Mestre \\ em Ciências \\ Área de concentração: Engenharia de \\ Controle e Automação Mecânica \\ Orientador: Prof. Dr. Agenor de Toledo \\ Fleury
}

São Paulo 
Este exemplar foi revisado e corrigido em relação à versão original, sob responsabilidade única do autor e com a anuência de seu orientador.

São Paulo, de de

Assinatura do autor:

Assinatura do orientador:

Catalogação-na-publicação

Trindade, Ivan Miguel Trindade

MODELAGEM, CONTROLE E OTIMIZAÇÃO DE CONSUMO DE COMBUSTÍVEL PARA UM VEÍCULO HÍBRIDO ELÉTRICO SÉRIE-PARALELO /

I. M. T. Trindade -- versão corr. -- São Paulo, 2016. $115 \mathrm{p}$.

Dissertação (Mestrado) - Escola Politécnica da Universidade de São Paulo. Departamento de Engenharia Mecânica.

1.VEÍCULOS 2.CONTROLE ÓTIMO 3.PROGRAMAC̃̃O DINÂMICA 4.VEÍCULOS HÍBRIDOS ELÉTRICOS I.Universidade de São Paulo. Escola Politécnica. Departamento de Engenharia Mecânica Il.t. 
Dedico este trabalho aos meus pais, Kátia Faiçal Miguel Trindade e Auro Trindade, e a meu irmão, Lucas Miguel Trindade, que sempre foram essenciais nas minhas escolhas e nas minhas conquistas. 


\section{AGRADECIMENTOS}

À Escola Politécnica da USP, pela formação como profissional e pelo ambiente de alto nível que me possibilitou evoluir como pessoa durante a graduação.

Ao meu orientador, Prof. Dr. Agenor de Toledo Fleury, pela orientação e aprendizagem nos últimos anos. Nesse tempo, percebi o quão humilde e paciente ele é, sobretudo para repassar os seus tão valiosos conhecimentos e experiências adquiridos em anos de engenharia.

Às diversas pessoas que participaram com sugestões, dicas e experiências para o desenvolvimento desta dissertação. Em especial, à minha prima Tatiana Miguel Rodrigues pela ajuda na reta final e pelo exemplo sendo a primeira mestre na família.

$\mathrm{E}$, finalmente, à minha família, por todo o apoio incondicional como de costume e interesse para que eu tivesse dedicação com esta dissertação. 


\section{RESUMO}

O principal objetivo dos veículos híbridos é diminuir o consumo de combustível em relação a veículos convencionais. Para isso, existe a necessidade de realizar a integração dos diferentes sistemas do trem-de-força e coordenar o seu funcionamento através de estratégias de controle. Tais estratégias são desenvolvidas e simuladas em conjunto com um modelo computacional da planta do veículo antes de serem aplicadas em uma unidade de controle eletrônica. O presente estudo tem como objetivo analisar o gerenciamento de energia em um veículo híbrido elétrico não-plugin do tipo série-paralelo visando à diminuição de consumo de combustível. O método de otimização global é utilizado para encontrar as variáveis de controle que resultam no mínimo consumo de combustível em um determinado ciclo de condução. Na primeira etapa, um modelo computacional da planta do veículo e da estratégia de controle não-ótima são criados. Os resultados obtidos da simulação são então comparados com dados experimentais do veículo operando em dinamômetro de chassis. A seguir, o método de otimização global é aplicado ao modelo computacional utilizando programação dinâmica e tendo como objetivo a minimização do consumo de combustível total ao final do ciclo. Os resultados mostram considerável redução do consumo de combustível utilizando otimização global e tendo como variável de controle não só a razão de distribuição de torque mas também os pontos de operação do motor de combustão. Os modelos computacionais criados nesse trabalho são disponibilizados e podem ser usados para o estudo de diferentes estratégias de controle para veículos híbridos.

Palavras chave: Veículo híbrido elétrico. Estratégia de Controle. Controle ótimo global. Programação dinâmica. 


\begin{abstract}
The main goal of hybrid electric vehicles is to decrease engine emission and fuel consumption levels. In order to realize this, one must perform the powertrain system integration and coordinate its operation through supervisory control strategies. These control strategies are developed in a simulation environment containing the plant model of the powertrain before they can be implemented in a real-time control unit. The goal of this work is to analyze the energy management strategy which minimizes the fuel consumption in a series-parallel non-plugin hybrid electric vehicle. Global optimization is used for finding the control variables that result in the minimum fuel consumption for a specific driving cycle. In a first stage, a computational model of vehicle plant and non-optimal control strategy are created. The results from the simulation are compared against experimental data from chassis dynamometer tests. Next, a global optimization strategy is applied using dynamic programming in order to minimize total fuel consumption at the end of the driving cycle. The results from the optimization show a considerable fuel consumption reduction having as control variables not only the torque-split strategy but also the engine operating points. As contribution from this work, the computational models are made available and can be used for analyzing different control strategies for hybrid vehicles.
\end{abstract}

Keywords: Hybrid electric vehicle. Control strategy. Global optimal control. Dynamic programming. 


\section{LISTA DE FIGURAS}

Figura 1.1- Fases da regulamentação de controle de emissões do PROCONVE para veículos leves (MINISTÉRIO DO MEIO AMBIENTE, 2015). .3

Figura 1.2 - Características da matriz energética brasileira (MINISTÉRIO DE MINAS E ENERGIA, 2015). .5

Figura 1.3 - Topologia série de um VHE 8

Figura 1.4 - Configuração do tipo paralelo. .8

Figura 1.5 - Configuração do tipo série-paralelo ou power-split.

Figura 2.1 - Classificação das estratégias de controle para veículos híbridos elétricos. Adaptado de Salmasi (2007).

Figura 2.2 - Exemplo de lógica difusa para um veículo híbrido paralelo. Adaptado de Rajagopalan et al. (2003). .15

Figura 2.3 - Conceito de controle preditivo baseado em reconhecimento do padrão de condução. Adaptado de Lin et al., (2004).

Figura 3.1 - Ilustração do trem-de-força do veículo adotado. .22

Figura 3.2 - Diagrama de alavancas da engrenagem planetária. .24

Figura 3.3 - Modos de operação do sistema série-paralelo. .27

Figura 3.4 - Mapa de torque e potência máximos do MCI. .29

Figura 3.5 - Mapa de consumo específico do MCI em [g/kWh] e curva de operação ótima 
Figura 3.6 - Linha de operação ótima obtida da simulação e a partir de resultados experimentais de Kim; Rousseau e Rask (2012).

Figura 3.7 - Diagrama do modelo computacional do motor de combustão. 33

Figura 3.8 - Variação de tensão no terminal da bateria para a simulação. Dados experimentais são provenientes de Gray e Shirk (2013) e indicam o comportamento da bateria no início e fim da vida útil. 35

Figura 3.9 - Diagrama do modelo computacional da bateria. 36

Figura 3.10 - Mapa de eficiência para o MG2. 37

Figura 3.11 - Diagrama do modelo computacional do MG2. 38

Figura 3.12 - Diagrama do modelo computacional do piloto. .40

Figura 3.13 - Diagrama do modelo computacional da dinâmica veicular. .41

Figura 4.1 - Potência da bateria em função do seu estado de carga (KIM; ROUSSEAU e RASK, 2012). 44

Figura 4.2 - Resultados experimentais obtidos por Argonne National Laboratory (2013) para a potência trativa acima da qual o MCI é ligado. .45

Figura 4.3 - Nível superior do modelo computacional do veículo em Matlab/Simulink. 46

Figura 5.1 - Velocidade do veículo (acima) e erro do controlador do piloto (abaixo) para a simulação do modelo não-ótimo. .48

Figura 5.2 - Comparação da rotação do MCI para simulação do modelo não-ótimo com a rotação obtida nos testes efetuados por Argonne National Laboratory (2013) 
Figura 5.3 - Comparação da corrente elétrica da bateria para simulação do modelo não-ótimo com a corrente elétrica obtida nos testes efetuados por Argonne National Laboratory (2013). .50

Figura 5.4 - Comparação do estado de carga (SOC) da bateria (acima) e do consumo de combustível (abaixo) para simulação do modelo não-ótimo com os resultados de testes efetuados por Argonne National Laboratory (2013).

Figura 6.1 - Exemplo de tabela contendo valores ótimos da função custo da programação dinâmica para cada valor da variável de estado e instante de tempo. (VAGG, 2014). 56

Figura 6.2 - Resultado do caso 1 para o SOC da bateria. O gráfico de contorno mostra todas as soluções de controle ótimo possíveis resultantes da otimização global.

Figura 6.3 - Razão de distribuição de torque em função da demanda de potência (acima) e velocidade (abaixo) para a caso 1 da programação dinâmica. .61

Figura 6.4 - Consumo de combustível acumulado resultante do caso 1 da programação dinâmica

Figura 6.5 -Resultado da caso 2 para o SOC da bateria. O gráfico de contorno mostra todas as soluções de controle ótimo possíveis resultantes da otimização global.

Figura 6.6 - Razão de distribuição de torque em função da demanda de potência (acima) e velocidade (abaixo) para o caso 2 da programação dinâmica. .64

Figura 6.7 - Pontos de operação do MCI durante para os dois casos da programação dinâmica

Figura 6.8 - Consumo de combustível resultante do caso 2 da programação dinâmica. .66 
Figura 7.1 - Comparação do resultado para o SOC da bateria proveninente da programação dinâmica - caso 1 - com os resultados de testes com o veículo estudado. .69

Figura A.1 - Diagrama de corpo livre para componentes da engrenagem planetária: a) engrenagem solar, b) braço planetário e c) engrenagem anular. ...81

Figura A.2 - Diagrama de corpo livre para a) MG1, b) MCI e c) MG2. 82

Figura B.1 - Diagrama do nível superior do sistema de controle .84

Figura B.2 - Diagrama do sub-módulo de estados de operação do sistema. .85

Figura B.3 - Diagrama da máquina de estados do sub-módulo de estados de operação do sistema. .86

Figura B.4 - Diagrama do sub-módulo do sistema de controle do MG1. .87

Figura B.5 - Diagrama do sub-módulo do sistema de controle do MG2. .88

Figura B.6 - Diagrama do sub-módulo do sistema de controle do MCI. 89

Figura D.1 - Resultados adicionais para a simulação do modelo com controle não ótimo.

Figura E.1 - Resultados adicionais do caso 1 da programação dinâmica. .92

Figura E.2 - Resultados adicionais do caso 2 da programação dinâmica. .93 


\section{LISTA DE TABELAS}

Tabela 5.1 - Resultados comparativos da simulação de validação......................51

Tabela 6.1 - Parâmetros dos dois casos da programação dinâmica. ...................59

Tabela 6.2 - Resultados do caso 1 da programação dinâmica. ............................62

Tabela 6.3 - Resultados do caso 2 da programação dinâmica. ..........................66

Tabela A.1 - Especificações do sistema adotado. .......................................... 80

Tabela C.1 - Dados estatísticos referentes ao ciclo de condução da norma NBR 6601. 


\section{LISTA DE SIGLAS}

$\begin{array}{ll}\text { A } & \text { Engrenagem anular } \\ \text { AC } & \text { Corrente Alternada } \\ \text { BP } & \text { Braço planetário } \\ \text { BSFC } & \text { Brake Specific Fuel Consumption, ou consumo específico de } \\ & \text { combustível } \\ \text { CA } & \text { Circuito Aberto } \\ \text { CAN } & \text { Controller Area Network } \\ \text { CC } & \text { Corrente contínua } \\ \text { COO } & \text { Curva de Operação Ótima } \\ \text { GPS } & \text { Global Positioning System, ou sistema de posicionamento } \\ & \text { global } \\ \text { IPI } & \text { Imposto Sobre Produtos Industrializados } \\ \text { IPVA } & \text { Imposto Sobre a Propriedade de Veículos Automotores } \\ \text { MCI } & \text { Motor de Combustão Interna } \\ \text { MG1 } & \text { Motor Gerador 1 } \\ \text { MG2 } & \text { Motor Gerador 2 } \\ \text { PCI } & \text { Poder Calorífico Inferior } \\ \text { PD } & \text { Programação Dinâmica } \\ \text { SOC } & \text { Stato Charge ou estado de carga da bateria } \\ \text { VHE } & \text { Veíbrido Elétrico } \\ & \text { Mero }\end{array}$




\section{LISTA DE SÍMBOLOS}

\begin{tabular}{|c|c|}
\hline$A$ & Área frontal do veículo \\
\hline$b s f c$ & Consumo específico de combustível \\
\hline C & Capacidade de carga da bateria \\
\hline$C_{0}$ & Coeficiente do torque de atrito do motor de combustão \\
\hline$C_{1}$ & $\begin{array}{l}\text { Coeficiente do torque de atrito do motor de combustão } \\
\text { relacionado à pressão de combustão }\end{array}$ \\
\hline$C_{2}$ & $\begin{array}{l}\text { Coeficiente do torque de atrito do motor de combustão } \\
\text { relacionado à sua velocidade angular }\end{array}$ \\
\hline$C_{3}$ & $\begin{array}{l}\text { Coeficiente do torque de atrito do motor de combustão } \\
\text { dependente ao quadrado da sua velocidade angular }\end{array}$ \\
\hline$C_{d}$ & Coeficiente de arrasto aerodinâmico \\
\hline$c_{R}$ & Coeficiente de resistência ao rolamento do pneu \\
\hline$F$ & Força entre engrenagem planeta e braço planetário \\
\hline$g$ & Aceleração da gravidade \\
\hline$G$ & Custo associado ao instante final da programação dinâmica \\
\hline$H$ & Função custo instantânea da programação dinâmica \\
\hline$i_{D}$ & Relação de redução do diferencial somada com a redução final \\
\hline$i$ & Relação de redução entre engrenagem anular e solar \\
\hline$I$ & Corrente elétrica nos terminais da bateria \\
\hline$I_{A}$ & Momento de inércia da engrenagem anular \\
\hline$I_{B P}$ & Momento de inércia do braço planetário \\
\hline$I_{L}$ & Corrente elétrica parasita da bateria \\
\hline$I_{M C I}$ & Momento de inércia do motor de combustão \\
\hline & Momento de inércia do motor-gerador 1 \\
\hline
\end{tabular}




\begin{tabular}{|c|c|}
\hline$I_{M G 2}$ & Momento de inércia do motor-gerador 2 \\
\hline$I_{S}$ & Momento de inércia da engrenagem solar \\
\hline$I_{T R}$ & Momento de inércia equivalente do eixo das rodas \\
\hline$J$ & Função custo total da programação dinâmica \\
\hline$J^{*}$ & $\begin{array}{l}\text { Trajetória ótima da função custo total da programação } \\
\text { dinâmica }\end{array}$ \\
\hline$k$ & Índice de tempo discreto \\
\hline$K_{i, c}$ & Ganho integral do controlador do piloto \\
\hline$K_{i, M G 1}$ & Ganho integral do controlador do MG1 \\
\hline$K_{p, c}$ & Ganho proporcional do controlador do piloto \\
\hline$K_{p, M G 1}$ & Ganho proporcional do controlador do MG1 \\
\hline$l$ & Deslocamento do pistão \\
\hline$\dot{m}_{\text {comb }}$ & Vazão em massa de combustível \\
\hline$m_{\text {rodas }}$ & $\begin{array}{l}\text { Inércia translacional equivalente de todos os componentes } \\
\text { rotacionais do veículo calculada no eixo das rodas }\end{array}$ \\
\hline M & Massa do veículo \\
\hline$N$ & Instante final de tempo discreto \\
\hline$N_{A}$ & Número de dentes da engrenagem anular \\
\hline$N_{k}$ & Número total de espaços discretos de tempo \\
\hline$N_{S}$ & Número de dentes da engrenagem solar \\
\hline$N_{u}$ & Número total de espaços discretos da variável de controle \\
\hline$N_{x}$ & Número total de espaços discretos da variável de estado \\
\hline$P_{b a t}$ & Potência da bateria \\
\hline$P_{\text {comb }}$ & Pressão de combustão \\
\hline$P_{d e m}$ & Demanda de potência nas rodas \\
\hline$P_{M C I}$ & Potência do motor a combustão \\
\hline$P_{M G 1}$ & Potência do motor-gerador 1 \\
\hline
\end{tabular}




\begin{tabular}{|c|c|}
\hline$P_{M G 2}$ & Potência do motor-gerador 2 \\
\hline$Q_{P C I}$ & Poder calorífico interior \\
\hline$r_{A}$ & Raio da engrenagem anular \\
\hline$r_{p}$ & Raio do pneu \\
\hline$r_{S}$ & Raio da engrenagem solar \\
\hline$r_{\text {torque }}$ & Razão de distribuição de torque \\
\hline$R_{i}$ & Resistência interna da bateria \\
\hline$R_{L}$ & Resistência parasita da bateria \\
\hline$S O C_{\text {final, } \max }$ & Valor máximo do SOC ao final do ciclo \\
\hline$S O C_{f i n a l, \text { min }}$ & Valor mínimo do SOC ao final do ciclo \\
\hline$S O C_{\min }$ & Valor mínimo do SOC durante o ciclo \\
\hline$S O C_{\max }$ & Valor máximo do SOC durante o ciclo \\
\hline$t$ & Instante de tempo \\
\hline$t_{s}$ & Passo de tempo da simulação \\
\hline$T$ & Instante de tempo final da simulação \\
\hline$T_{a n t, p}$ & Torque de antecipação do controlador do piloto \\
\hline$T_{c, p}$ & Torque de saída do controlador do piloto \\
\hline$T_{\text {dem }}$ & Demanda de torque nas rodas \\
\hline$T_{\text {freio }}$ & Demanda de torque no freio mecânico \\
\hline$T_{A}$ & Torque de reação na engrenagem anular \\
\hline$T_{B P}$ & Torque de reação no braço planetário \\
\hline$T_{M C I}$ & Torque do motor de combustão \\
\hline$T_{M C I, \text { atrito }}$ & Torque de atrito do motor de combustão \\
\hline$T_{M C I, \max }$ & Torque máximo do motor de combustão durante o ciclo \\
\hline$T_{M C I, \min }$ & orque mínimo do motor de combustão durante o ciclo \\
\hline
\end{tabular}


$T_{M G 1}$

$T_{M G 1, \max }$

$T_{M G 2}$

$T_{R E S}$

$T_{S}$

$u$

$u^{*}$

V

$\checkmark$

$V_{C A}$

$V_{M C I}$

$V_{\text {ref }}$

$V_{T}$

$\omega_{A}$

$\omega_{B P}$

$\omega_{M C I}$

$\omega_{M C I, \max }$

$\omega_{M C I, \min }$

$\omega_{M C I, r e f}$

$\omega_{M G 1}$

$\omega_{M G 2}$

$\omega_{p}$

$x$

$x *$

Torque do motor-gerador 1

Torque máximo do motor-gerador 1

Torque do motor-gerador 2

Torque das resistência ao movimento do veículo

Torque de reação na engrenagem solar

Variável de controle da programação dinâmica

Trajetória ótima da variável de controle

Velocidade do veículo

Função retorno da programação dinâmica

Tensão da bateria em circuito aberto

Deslocamento volumétrico do motor a combustão

Velocidade do veículo de referência para o modelo do piloto

Tensão nos terminais da bateria em circuito fechado

Velocidade angular no eixo da engrenagem anular

Velocidade angular no eixo do braço planetário

Velocidade angular do motor de combustão

Velocidade angular máxima do motor a combustão quando este estiver ligado

Velocidade angular mínima do motor a combustão quando este estiver ligado

Velocidade angular de referência do motor de combustão para o modelo do controlador do motor-gerador 1

Velocidade angular do motor-gerador 1

Velocidade angular do motor-gerador 2

Velocidade angular do pneu

Variável de estado da programação dinâmica

Trajetória ótima da variável de estado da programação dinâmica 
$\eta_{M G 1}$

$\eta_{M G 2}$

$\eta_{F}$

$\eta_{M C I}$

$\rho_{a r}$

$\tau_{M G 1}$
Eficiência do motor-gerador 1

Eficiência do motor-gerador 2

Eficiência da transmissão do veículo

Eficiência térmica do motor de combustão

Densidade do ar

Constante de tempo do controlador do motor-gerador 1 


\section{SUMÁRIO}

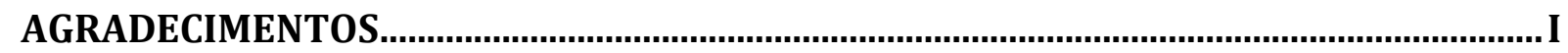

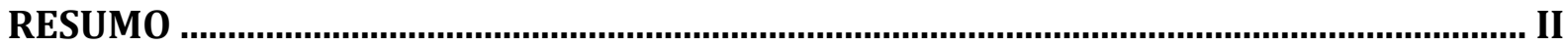

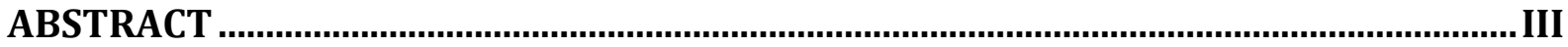

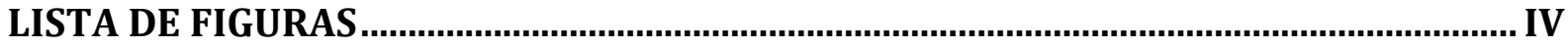

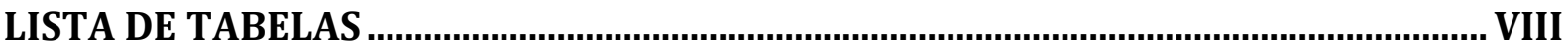

LISTA DE SIGLAS

LISTA DE SÍMBOLOS.........................................................................................................

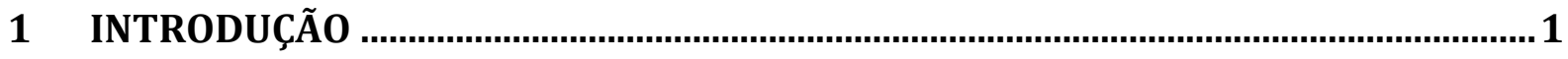

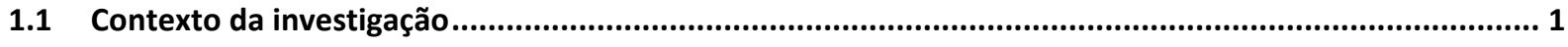

1.2 Panorama para a introdução de veículos híbridos e elétricos ........................................................ 3

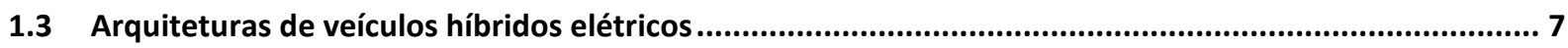

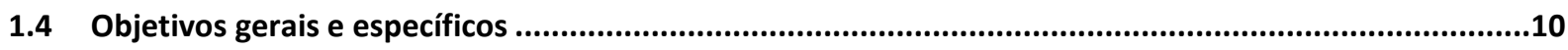

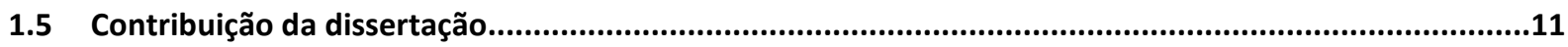

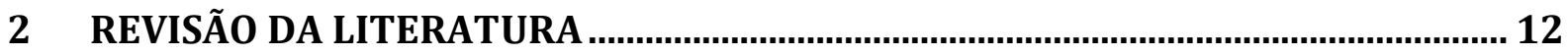

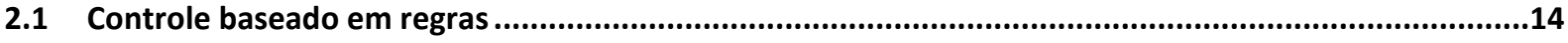

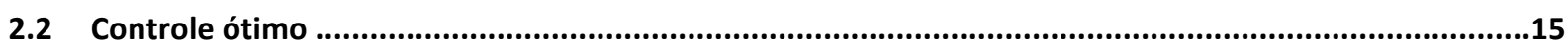

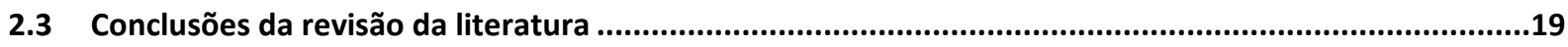

3 MODELAGEM DO VEÍCULO HÍBRIDO ELÉTRICO ............................................... 21 


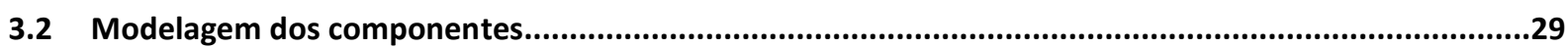

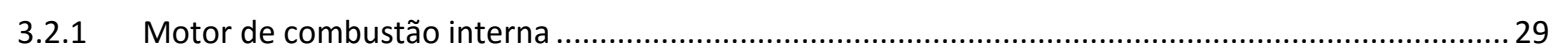

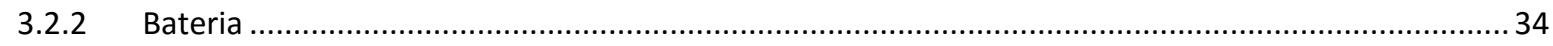

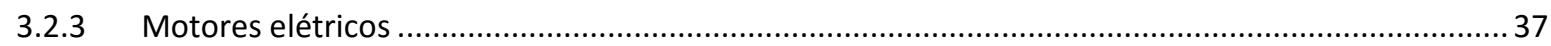

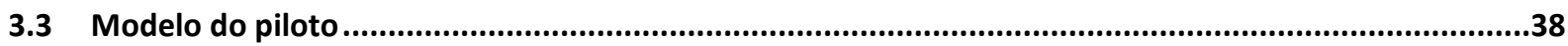

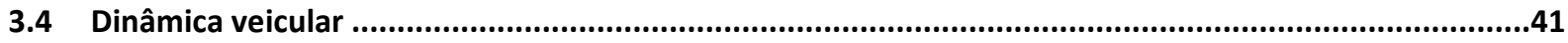

4 ESTRATÉGIA DE CONTROLE BASEADA EM REGRAS …....................................... 42

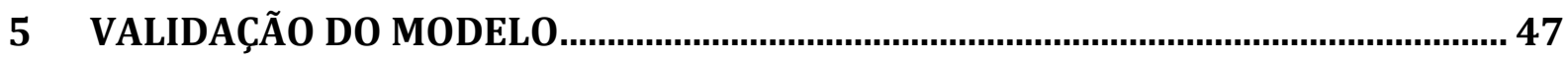

\section{OTIMIZAÇÃO GLOBAL DO CONSUMO DE COMBUSTÍVEL USANDO}

PROGRAMAÇÃO DINÂMICA...................................................................................... 53

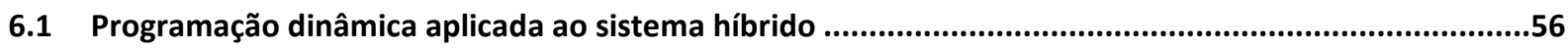

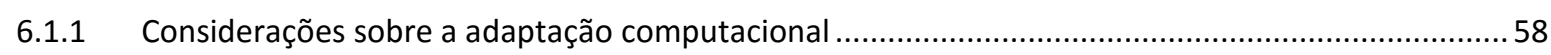

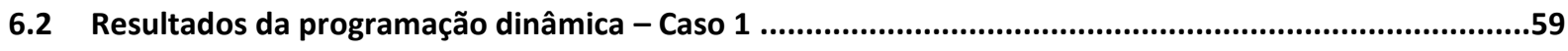

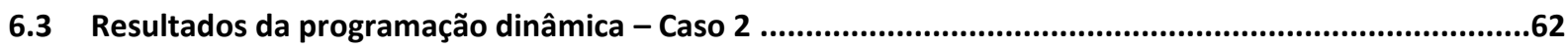

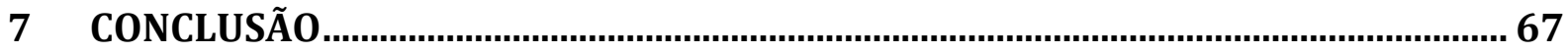

7.1 Modelo da planta do veículo e controle baseado em regras ...........................................................67

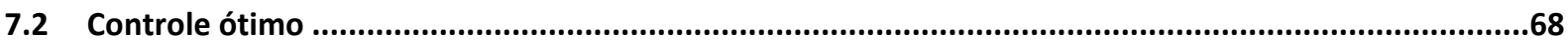

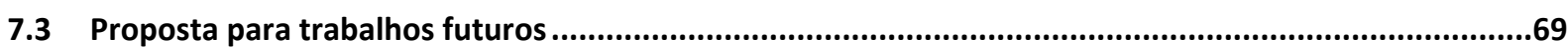

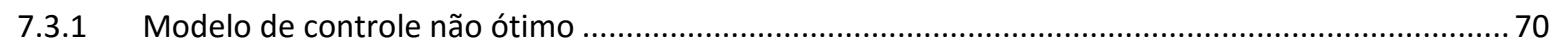

7.3.2 Otimização global aplicada a veículos flex ............................................................................ 70

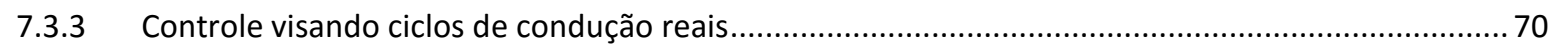

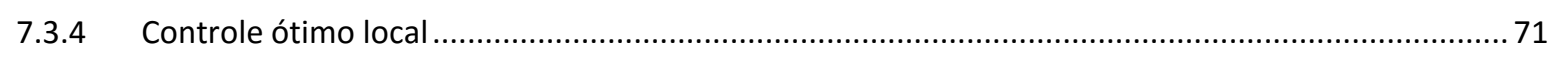

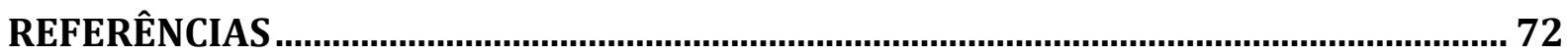


ANEXO A - DADOS DO VEÍCULO. 80

APÊNDICE A - MODELAGEM DA DINÂMICA NA ENGRENAGEM PLANETARIA. 81

APÊNDICE B - DIAGRAMAS DO MODELO COMPUTACIONAL PARA O SISTEMA DE CONTROLE

APÊNDICE C - DADOS DO CICLO DA NORMA NBR 6601 90

APÊNDICE D - RESULTADOS DE SIMULAÇÃO DO MODELO COM CONTROLE NÃOÓTIMO 91

APÊNDICE E - RESULTADOS DA PROGRAMAÇÃO DINÂMICA 92 


\section{INTRODUÇÃO}

\subsection{Contexto da investigação}

Desde seu surgimento, no século XIX, motores de combustão interna foram responsáveis por propiciar uma nova era na história da indústria e transporte. Da mesma forma, o veículo automotor revolucionou a sociedade moderna e o seu conceito de locomoção. A indústria de automóveis, juntamente com a sua cadeia de suprimentos para produção e circulação de veículos, passou a influenciar fortemente o cenário econômico mundial. O petróleo se tornou uma mercadoria estratégica no mercado internacional, atraindo até mesmo interesses geopolíticos para a sua comercialização e sendo fator de grande importância na economia global.

No Brasil, a evolução da frota de veículos atingiu 42 milhões de unidades em 2014. Já o número de habitantes por veículo foi de 5,3, em contraste ao de 8,4 correspondente a 2003 (ANFAVEA, 2015). Em 2014, a indústria automobilística brasileira gerou um faturamento líquido de mais de $\mathrm{R} \$ 98$ bilhões (ANFAVEA, 2015), sendo responsável por 23\% do PIB industrial desse ano (MINISTÉRIO DO DESENVOLVIMENTO, INDÚSTRIA E COMÉRCIO EXTERIOR, 2014). Esse desempenho da indústria automobilística impulsiona ainda a produção industrial de outros setores como aço e derivados, materiais eletrônicos, plástico e borracha.

No entanto, tal avanço tecnológico também trouxe desvantagens, mais especificamente quanto a problemas para a saúde e ao meio ambiente acarretados pela emissão de poluentes. O crescimento elevado do mercado automobilístico no país faz com que as emissões veiculares sejam de grande interesse público e governamental. Atualmente, o setor de transportes é responsável por mais de $38 \%$ da emissão total de dióxido de carbono $\left(\mathrm{CO}_{2}\right)$ no setor de energia (MINISTÉRIO DA CIÊNCIA, TECNOLOGIA E INOVAÇÃO, 2013). Ainda, de acordo com IPCC (2007), o setor de transportes foi responsável 
por $13 \%$ das emissões de gases de efeito estufa em nível global no ano de 2007. Nas zonas urbanas do Brasil, a emissão veicular é o principal responsável pela poluição, contribuindo para 80\% do total (DOMINGUES e PECORELLI-PERES, 2012). Isso corrobora a grande atenção a ser dada ao controle de emissões de automóveis em centros urbanos.

A respeito de problemas associados à emissão de poluentes, pode-se citar o efeito estufa, o aparecimento de neblina com fumaça em cidades e problemas de saúde no sistema respiratório (COMPANHIA AMBIENTAL DO ESTADO DE SÃO PAULO, 2011). Em nível global, o protocolo de Kyoto, ratificado em 1997, definiu metas de redução de emissões para os países desenvolvidos, incluindo medidas para limitação de emissões no setor de transporte. No Brasil, o CONAMA (Conselho Nacional do Meio Ambiente), órgão deliberativo do Sistema Nacional do Meio Ambiente, criou, em 1986, o PROCONVE (Programa de Controle de Poluição do Ar por Veículos Automotores) através da resolução CONAMA n ${ }^{\circ} 18$ (IBAMA, 2011). Este programa é coordenado pelo IBAMA (Instituto Brasileiro do Meio Ambiente e dos Recursos Naturais Renováveis) e define os limites de emissões veiculares que atendam aos padrões de qualidade do ar instituídos pelo PRONAR (Programa Nacional de Controle de Qualidade do Ar).

A Figura 1.1 mostra a evolução das leis de emissões no Brasil para veículos leves desde a implementação da primeira fase de controle de emissões, L-1, em 1988, até a fase L-6, iniciada em 2014. Devido a essas regulamentações, entre o período de 1992 e 2012 houve uma diminuição significativa na emissão de poluentes correspondente a 76,2\% para monóxido de carbono (CO), 71,6\% para hidrocarbonetos não-metano (NMHC) e 39\% para material particulado (MP) (MMA, 2014). Embora tais níveis tenham caído, o grande aumento da frota de veículos no país não possibilitou a diminuição de emissões de $\mathrm{CO}_{2}$ e óxidos de nitrogênio (NOX), que aumentaram em 100\% e 5,7\%, respectivamente. 

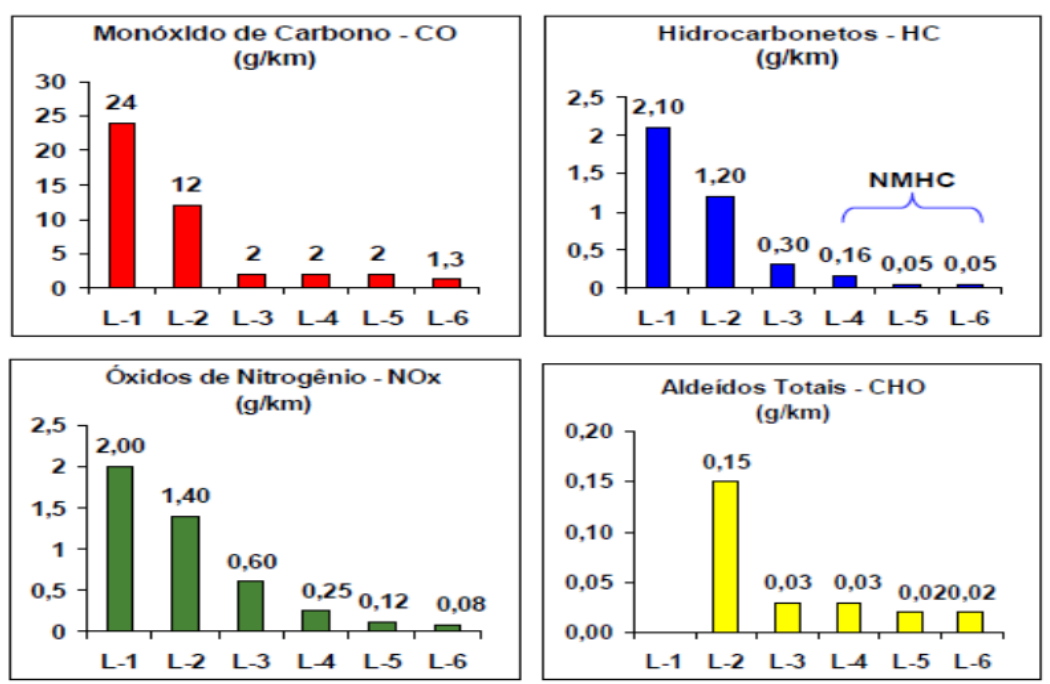

Figura 1.1- Fases da regulamentação de controle de emissões do PROCONVE para veículos leves (MINISTÉRIO DO MEIO AMBIENTE, 2015).

Nos últimos anos, medidas para incentivar o aumento da eficiência energética, e consequente diminuição dos níveis de $\mathrm{CO}_{2}$, passaram a ser implementadas. A exemplo dos EUA, onde existem não apenas regulamentações para os limites de emissões como também para níveis de consumo de combustível, o Brasil implantou, em 2008, através do INMETRO, o Programa Brasileiro de Etiquetagem veicular (PBE). O principal objetivo desse programa é fornecer dados para o consumidor para comparação da eficiência energética de veículos. Contudo, o PBE não é uma diretriz de regulamentação e, por isso, não impõe penalidades a montadoras que produzam veículos com baixa eficiência energética e nem impossibilita a homologação desses veículos, embora sobretaxe sensivelmente o preço do veículo ao consumidor.

\subsection{Panorama para a introdução de veículos híbridos e elétricos}

O alto consumo de petróleo na indústria e no setor automotivo tem gerado debates e discussões nas últimas décadas sobre a quantidade de petróleo disponível no mundo. A maior quantidade de reservas está no Oriente Médio, o que atrai interesses políticos em uma região já politicamente instável (EHSANI; GAO e EMADI, 2010). Greene (2002) estima que a produção de petróleo no 
mundo poderá ter um pico em 2040 antes de entrar em declínio, momento no qual a disponibilidade das reservas passa a depender fortemente dos chamados óleos não-convencionais, obtidos através de métodos de extração não comumente utilizados. A demanda crescente de petróleo e o provável aumento dos custos de extração podem gerar um cenário insustentável no futuro, com preços demasiadamente elevados para derivados de petróleo.

Esse cenário tem fomentado a procura de alternativas para o uso de combustíveis fósseis, onde os principais candidatos são os biocombustíveis e a utilização de veículos híbridos e elétricos. No caso do Brasil, a produção e utilização de etanol para uso automotivo começou na década de 1970, impulsionada pela crise do petróleo, e fez do país um dos mais bem sucedidos na utilização de biocombustíveis para o transporte. Em níveis tecnológicos, o uso do etanol ainda incentivou a criação dos motores flex. Com isso, o consumo de etanol cresceu significativamente ao longo dos últimos 40 anos e foi equivalente a $33 \%$ do consumo total de combustível no ano de 2013 (UNICA, 2014). Apesar do panorama favorável, a variação dos preços do etanol tem se mostrado o maior entrave para que este se concretize como uma vantagem financeira real frente à gasolina.

No cenário global, a utilização de biocombustíveis não se mostrou tão promissora quanto no Brasil devido em parte à alta energia demandada para a produção a partir de culturas como beterraba e milho (UNIÃO DA INDÚSTRIA DE CANADE-AÇÚCAR, 2008). No entanto, não menos promissora que o etanol, outra solução foi a utilização de propulsão elétrica e híbrida no sistema de trem-deforça de veículos.

Veículos híbridos são aqueles em que a energia para propulsão é proveniente de mais de uma fonte ou sistema de armazenagem. Por exemplo, um veículo híbrido elétrico (VHE) contém um ou mais motores elétricos e um sistema de armazenamento de energia elétrica além do motor de combustão. Essa tecnologia 
passou a ser grande foco de pesquisa da indústria automobilística internacional no final da década de 90 e é o tema principal desta dissertação.

A tecnologia de VHE é tão antiga quanto o veículo automotor. Ehsani; Gao e Emadi (2010) exemplificam inúmeros exemplos de veículos híbridos e elétricos no começo do século $\mathrm{XX}$, mas que perderam força devido à vasta disponibilidade de petróleo e facilidade de armazenamento de energia com combustíveis líquidos. Baran e Legey (2010) citam os EUA como os principais responsáveis por incentivar a pesquisa e desenvolvimento da tecnologia de veículos híbridos e elétricos, buscando obter segurança estratégica no setor de energia e tornar-se um líder nesse setor.

A Figura 1.2 mostra alguns dados sobre a matriz energética brasileira provenientes de Ministério de Minas e Energia (2015). Observa-se que a maior parte da energia total gerada é dependente de petróleo e fontes não renováveis. No entanto, as fontes renováveis são responsáveis por mais de $70 \%$ da geração de energia elétrica do país, o que faz a matriz energética brasileira ser extremamente vantajosa para a utilização de veículos elétricos e híbridos, ainda mais se comparada com países onde a geração de energia elétrica é majoritariamente proveniente de fontes não renováveis (MINISTÉRIO DE MINAS E ENERGIA, 2015).

\section{Geração total de energia}

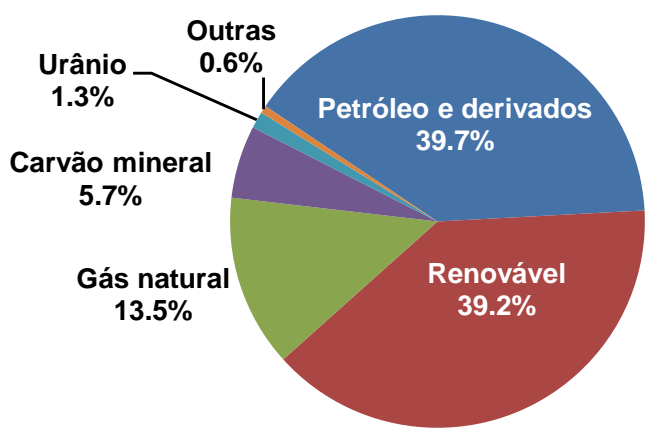

\section{Geração de energia elétrica}

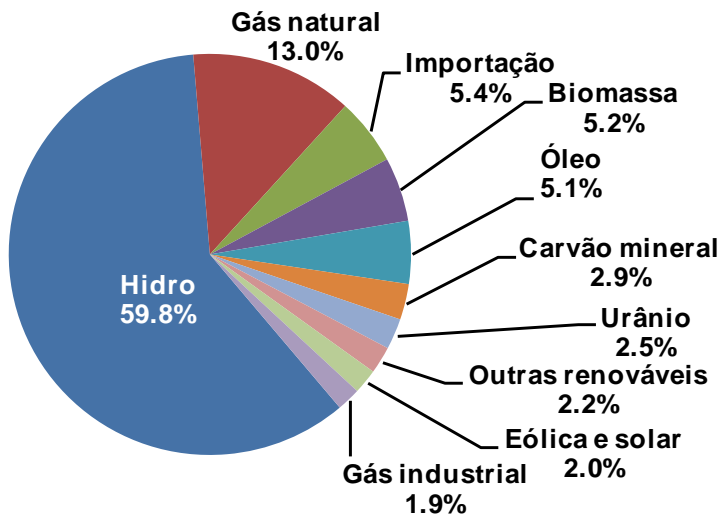

Figura 1.2 - Características da matriz energética brasileira (MINISTÉRIO DE MINAS E ENERGIA, 2015). 
Atualmente, existem poucas políticas específicas para incentivar o comércio e uso de carros híbridos e elétricos no Brasil. Alguns estados, porém, possuem IPVA (Imposto Sobre a Propriedade de Veículos Automotores) diferenciado para a compra de veículos híbridos (ABVE, 2014). Em geral, na importação de veículos elétricos e híbridos incide o usual imposto de importação de 35\%. Já o valor da alíquota do IPI (Imposto sobre Produtos Industrializados) para os elétricos é de $25 \%$, ou seja, o mesmo para automóveis com motor maior que 2 litros e que representa o teto do imposto para veículos leves. Em 2014, foi sancionada a Lei $\mathrm{N}^{\circ}$ 15.997/14 na cidade de São Paulo que fornece isenção de 50\% do IPVA para veículos elétricos e híbridos e os exclui do rodízio municipal. Incentivos como esse são importantes para promover a comercialização dessa tecnologia no Brasil. No caso de EUA e também Europa, o consumidor recebe créditos que podem chegar até a €6500 no caso da aquisição de um veículo elétrico.

No contexto do novo programa do governo brasileiro de incentivo e reformulação da indústria automobilística, o InovarAuto, o desenvolvimento de veículos híbridos aparece como uma boa alternativa, devido às penalizações que o programa impõe quanto ao atingimento de metas de consumo de combustível.

De acordo com Valentine-Urbschat e Bernhart (2010), o custo atual de automóveis híbridos plug-in (aqueles que são recarregáveis através da linha de eletricidade) é $€ 12000$ maior que o de veículos convencionais. O mesmo estudo faz uma extrapolação para o custo do trem-de-força em 2020 e o resultado mostra que, mesmo com o barateamento da tecnologia, a diferença ainda será de $€ 4000$. Devido à esses fatos, é importante frisar que, sem a inserção de políticas públicas, a adoção de veículos híbridos e elétricos no mercado automotivo brasileiro é pouco provável no curto prazo. Similar aos modelos adotados por outros países, a participação do governo deve ser na direção de redução dos impostos para comercialização e importação de tais veículos, criação de subsídios para desenvolvimento da sua tecnologia e créditos para o consumidor final. 


\subsection{Arquiteturas de veículos híbridos elétricos}

Nesta dissertação, a denominação de sistema híbrido será aplicada àquele veículo que possui propulsão através de motor de combustão interna (MCI) e motor elétrico e que utiliza uma bateria para armazenamento de energia. No Brasil, no entanto, a ausência do desenvolvimento dessa tecnologia faz com que a padronização dos seus termos em português seja por vezes confusa. $\mathrm{O}$ autor então realiza traduções da nomenclatura quando possível e também inclui o termo original em inglês para esclarecimento.

Segundo United States Environmental Protection Agency (2014), VHEs podem atingir redução de 50\% no consumo de combustível e de $80 \%$ em emissões em relação a veículos convencionais. Esse potencial de redução é fortemente dependente do grau de hibridização, definido como a razão da potência máxima de propulsão elétrica pela potência máxima total do trem-de-força (SUNDSTRÖM, 2009), da arquitetura do sistema híbrido e do ciclo de condução.

Os VHEs são classificados nas topologias série, paralelo e série-paralelo. Dentre esses, existem diferentes configurações possíveis que utilizam embreagens, tipos diferentes de transmissão no sistema, entre outros componentes, e que modificam a arquitetura e complexidade do conjunto.

A topologia em série é mostrada na Figura 1.3. A propulsão nessa configuração é puramente elétrica e o MCI não está acoplado mecanicamente à transmissão, mas sim a um gerador que produz energia elétrica. A energia produzida pelo MCI pode ser direcionada a uma bateria ou ao motor elétrico de tração, que está acoplado mecanicamente à transmissão e é responsável por realizar a propulsão do veículo. Esse tipo de híbrido também recebe o nome de veículo elétrico de autonomia estendida, pois o MCI é responsável por aumentar a autonomia disponibilizada pela bateria. A principal desvantagem desse sistema está em ciclos rodoviários, onde o MCI opera em regiões de maior eficiência mas não pode propulsionar o veículo diretamente. 


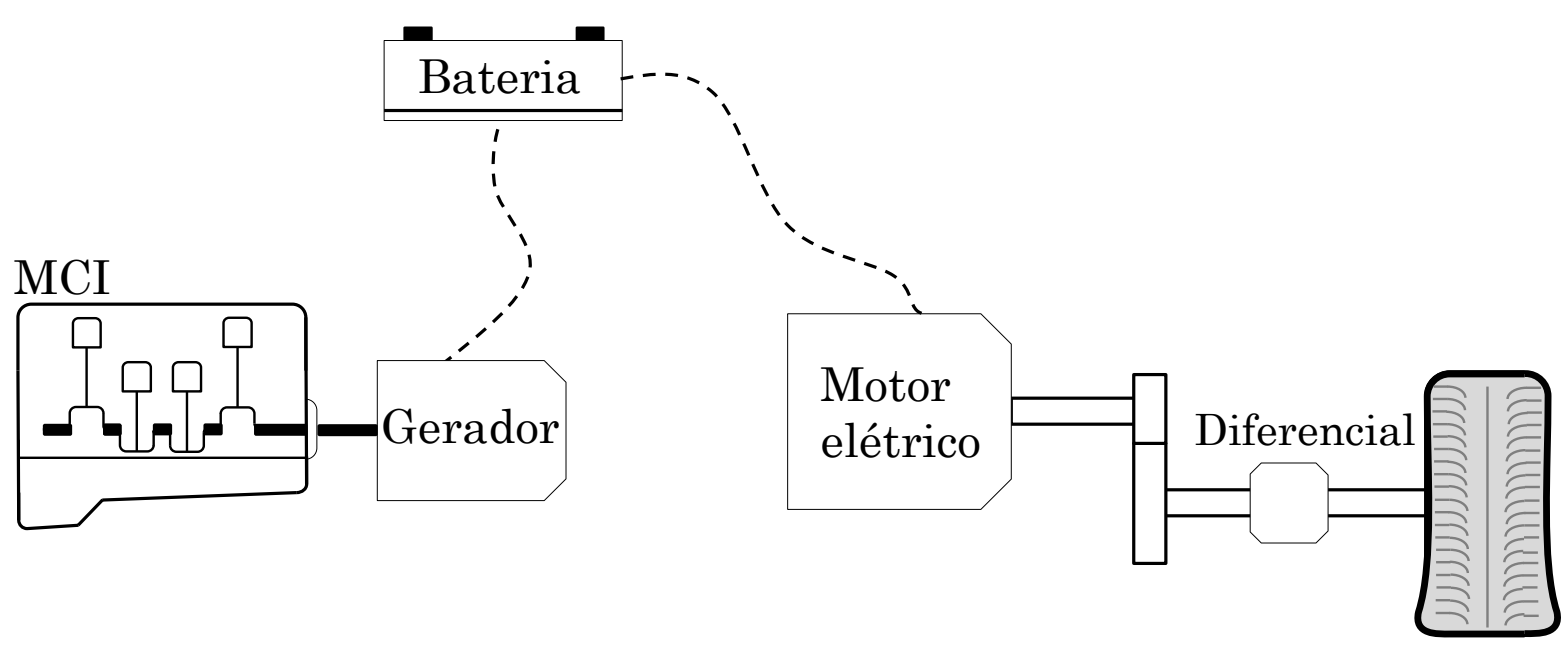

Figura 1.3 - Topologia série de um VHE.

$\mathrm{Na}$ topologia paralela mostrada na Figura 1.4, motor elétrico e MCI estão conectados mecanicamente às rodas e podem propulsionar o veículo de forma independente ou combinada. Caso uma embreagem seja introduzida entre o motor elétrico e o MCI, este último pode ser desligado durante a condução para diminuir as perdas no sistema. No caso de uma segunda embreagem entre o motor elétrico e a transmissão, o MCI pode gerar energia através do motor elétrico e recarregar a bateria. Usualmente esta configuração aplica motores elétricos menores se comparada com a configuração anterior devido ao fato da maior parte da demanda de potência ser suprida pelo MCI (WALTERS, 2001).

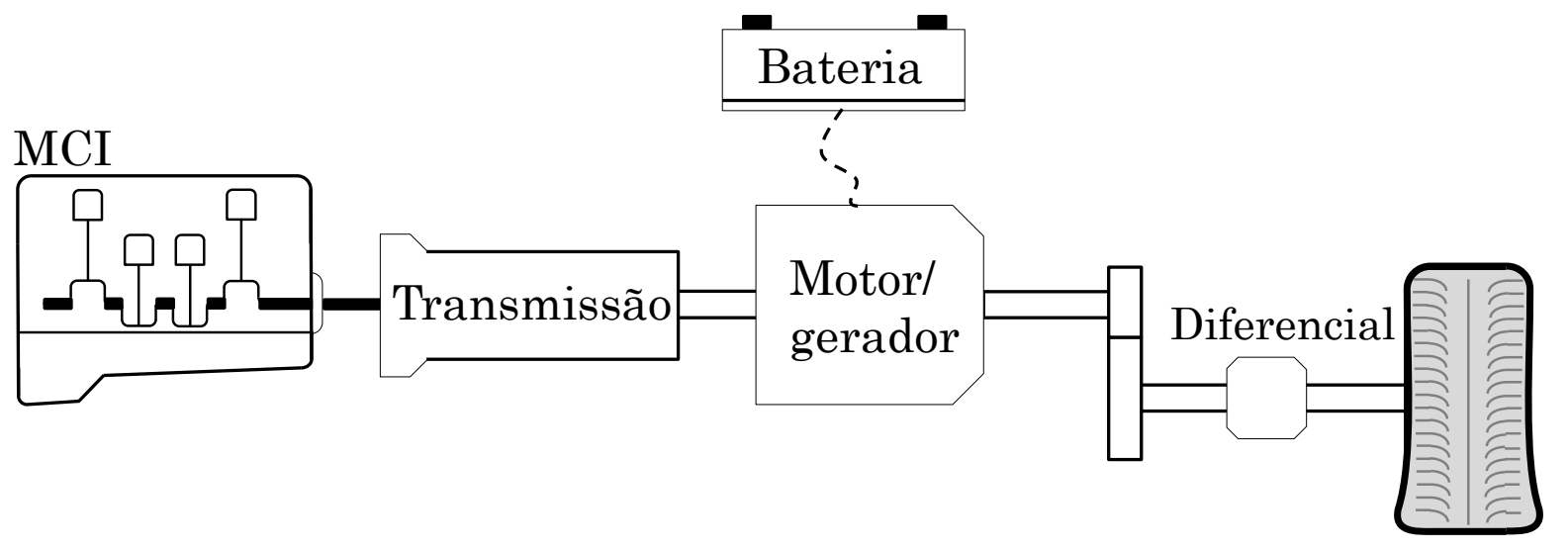

Figura 1.4 - Configuração do tipo paralelo.

A Figura 1.5 mostra a topologia série-paralelo, comumente conhecida como power-split. Essa topologia emprega um MCI e dois motores elétricos, todos conectados mecanicamente às rodas. A transmissão do veículo nesse caso pode 
ser uma transmissão planetária, o que faz o sistema funcionar tanto como tipo série ou paralelo, dependendo da velocidade do veículo e outros parâmetros de operação. Um exemplo dessa aplicação é o veículo Toyota Prius.

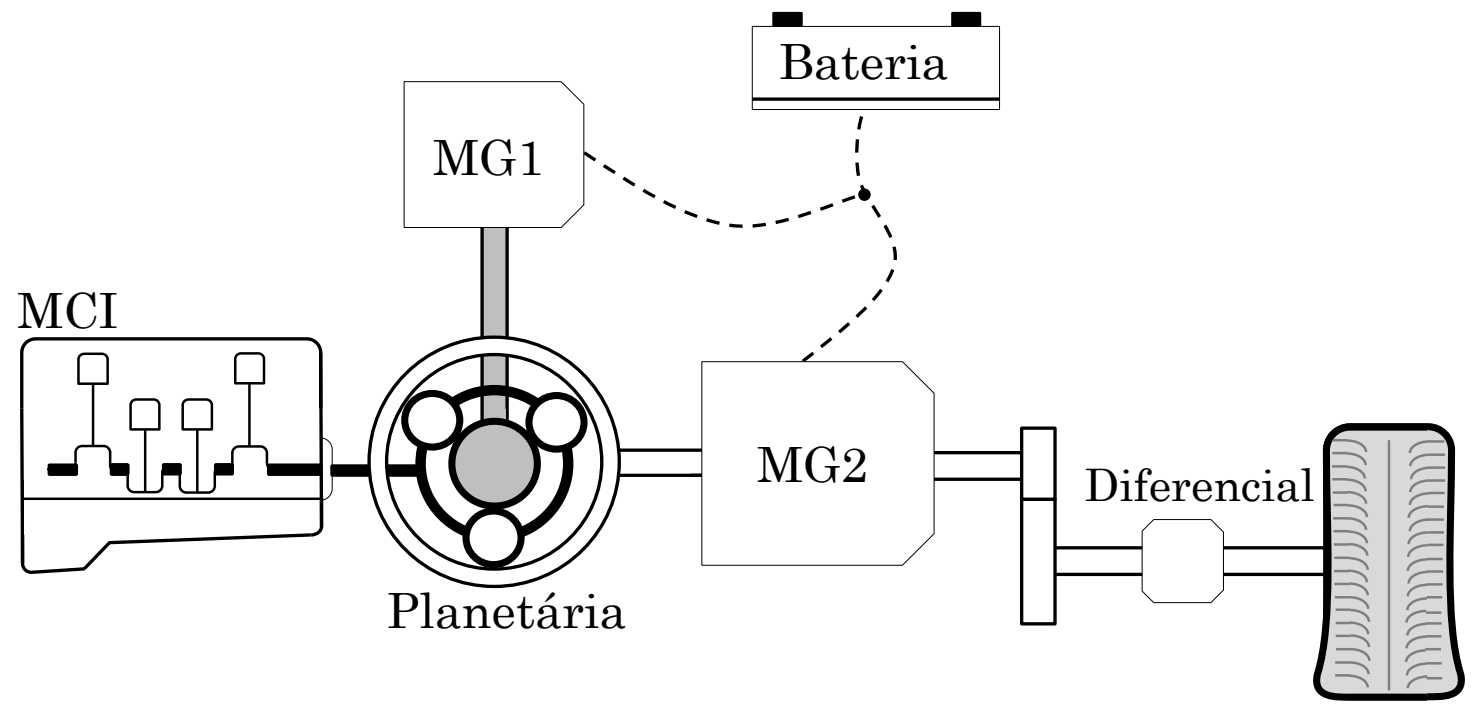

Figura 1.5 - Configuração do tipo série-paralelo ou power-split.

Apesar de diversas variações existirem na indústria, as configurações descritas acima constituem as principais topologias de VHEs. Existem vários fatores influentes no projeto da configuração que melhor se adeque a um certo veículo como, por exemplo, requerimentos de potência do sistema e tipo de aplicação.

Os principais modos de operação do trem-de-força de um VHE são:

- Tração puramente elétrica;

- Tração assistida elétrica e com MCI;

- Tração com MCI e geração de energia com motor elétrico;

- Regeneração de energia de frenagem.

Tais modos de operação são obtidos através da integração dos diferentes componentes do trem-de-força por meio de uma unidade de controle eletrônica. $\mathrm{O}$ sistema de controle supervisório do trem-de-forças é responsável não somente por determinar modos de operação mas também por coordenar o funcionamento do 
MCI, motor elétrico e bateria. Por sua vez, o consumo de combustível e emissão de poluentes é fortemente dependente do controle supervisório e de sua estratégia de distribuição de torque entre a propulsão elétrica e MCI.

Dentre os vários métodos para realizar o controle supervisório do sistema de trem-de-força de veículos híbridos, pode-se destacar 2 principais tipos: o controle baseado em regras, com funções de controle que classificam as variáveis em níveis discretos para criar as saídas do sistema e o controle ótimo, que soluciona as variáveis que otimizam uma ou mais funções custo. $\mathrm{O}$ primeiro método é mais simples de ser implementado, no entanto, não garante que o resultado ótimo seja atingido. Todavia, a implementação de um sistema de controle pode ser obtida com resultados provenientes dos dois métodos. As vantagens e desvantagens de cada tipo de controle serão apresentadas em mais detalhes no Capítulo 2.

\subsection{Objetivos gerais e específicos}

Tendo em vista que o principal objetivo de VHEs é o aumento da eficiência energética do sistema e a diminuição da emissão de poluentes, esta dissertação tem como objetivo principal estudar e aplicar métodos de controle para um tremde-força híbrido com foco na diminuição do consumo de combustível, colaborando para o conhecimento científico nessa área. $\mathrm{O}$ aspecto da emissão de poluentes não será estudado nesta dissertação, no entanto, é importante notar que a diminuição do consumo de combustível acarreta uma diminuição proporcional do nível de emissão de $\mathrm{CO}_{2}$. Partindo desse objetivo geral, tem-se os seguintes objetivos específicos:

- Modelagem computacional da dinâmica de um sistema de trem-de-força híbrido elétrico do tipo série-paralelo;

- Projeto de um sistema de controle para o trem-de-forças em questão;

- Validação do modelo de veículo e controle integrados comparando-os com resultados experimentais; 
- Aplicação de um controlador ótimo global para otimização do consumo de combustível com auxílio de programação dinâmica.

\subsection{Contribuição da dissertação}

Esta dissertação disponibiliza um modelo computacional da planta do VHE estudado e do seu sistema de controle. Este modelo poderá ser utilizado como plataforma para projeto de sistemas de trem-de-força híbrido e avaliação das estratégias de controle e dos fatores do sistema que influenciam na sua dinâmica, no consumo de combustível e na emissão de poluentes.

A otimização do consumo de combustível investiga dois cenários: um que objetiva a operação do motor de combustão nas suas regiões de maior eficiência e outro em que a região de operação do motor de combustão também é determinada através da otimização da função custo. Tais resultados poderão ser utilizados para uma eventual aplicação em motores flex onde parâmetros do sistema mudam de acordo com o combustível utilizado. 


\section{REVISÃO DA LITERATURA}

A primeira etapa da pesquisa bibliográfica foi o estudo do sistema híbrido escolhido para a modelagem matemática. Esse estudo será mostrado no Capítulojuntamente com a modelagem do sistema. A segunda parte é o foco deste capítulo e foi o estudo das estratégias de controle para trem-de-forças híbrido e de sua influência no sistema.

As saídas de uma estratégia de controle são decisões para modificar o funcionamento dos componentes do sistema através de comandos enviados aos seus atuadores e satisfazendo a demanda de potência do usuário e restrições do sistema. O problema central do controle de veículos híbridos é a distribuição de torque entre MCI, motores elétricos e bateria, o que terá impacto direto no consumo de combustível. Essa tarefa deve ser realizada visando um compromisso entre maximização da eficiência do trem-de-forças, conforto do condutor, redução de emissões, entre outros, ainda obedecendo as restrições impostas por variáveis do sistema.

O estudo da tecnologia de veículos híbridos e elétricos foi retomado a partir de 1990 e, desde então, houve grande aumento do número de publicações relacionadas ao tema (ROSARIO, 2007). No Brasil, a quantidade de trabalhos publicados na área é limitada, sendo que muitos estudos se restringem a pesquisas conceituais sobre a tecnologia e modelagem ou simulação aplicando pouco foco na análise das estratégias de controle (SOUZA, 2010; FERRAZ, 2004). Outros autores nacionais avaliam o impacto da introdução de veículos híbridos no Brasil. Como exemplo, Baran (2010) avalia implicações no consumo de energia da rede elétrica devido aos veículos híbridos elétricos e Queiroz (2006) estuda os benefícios para o meio ambiente e políticas sociais necessárias para introdução da tecnologia. 
O desenvolvimento de sistemas de controle se engloba no conceito de projeto baseado em modelo (model-based design). Na primeira etapa desse desenvolvimento, é realizada a simulação computacional do sistema de controle e da planta do veículo em malha fechada. Após o sistema de controle ser validado através de simulação, o código de controle e o modelo da planta são integrados e testados em sistemas HIL (Hardware-In-the-Loop), que realizam processamento em tempo real (KOOT, 2006; WALDNER, 2011). Na última etapa, o sistema de controle é então testado e calibrado em veículo. Nesse processo, o sistema é estudado e testado ao máximo em ambiente virtual de simulação, o que permite que certos erros sejam antecipados ao teste no veículo real e custos demasiados com protótipos sejam evitados.

Desai (2010), Salmasi (2007) e Zhu et al. (2004) propõe um sistema de classificação das estratégias de controle para VHEs e esta dissertação se baseia nessas classificações para expor as informações adiante. As estratégias de controle se distinguem, então, em controle ótimo e controle baseado em regras, como mostrado na Figura 2.1. Os métodos de controle ótimo são separados entre ótimo global e ótimo local. Já o controle baseado em regras se divide em regras determinísticas, lógica difusa (fuzzy) e controle preditivo.

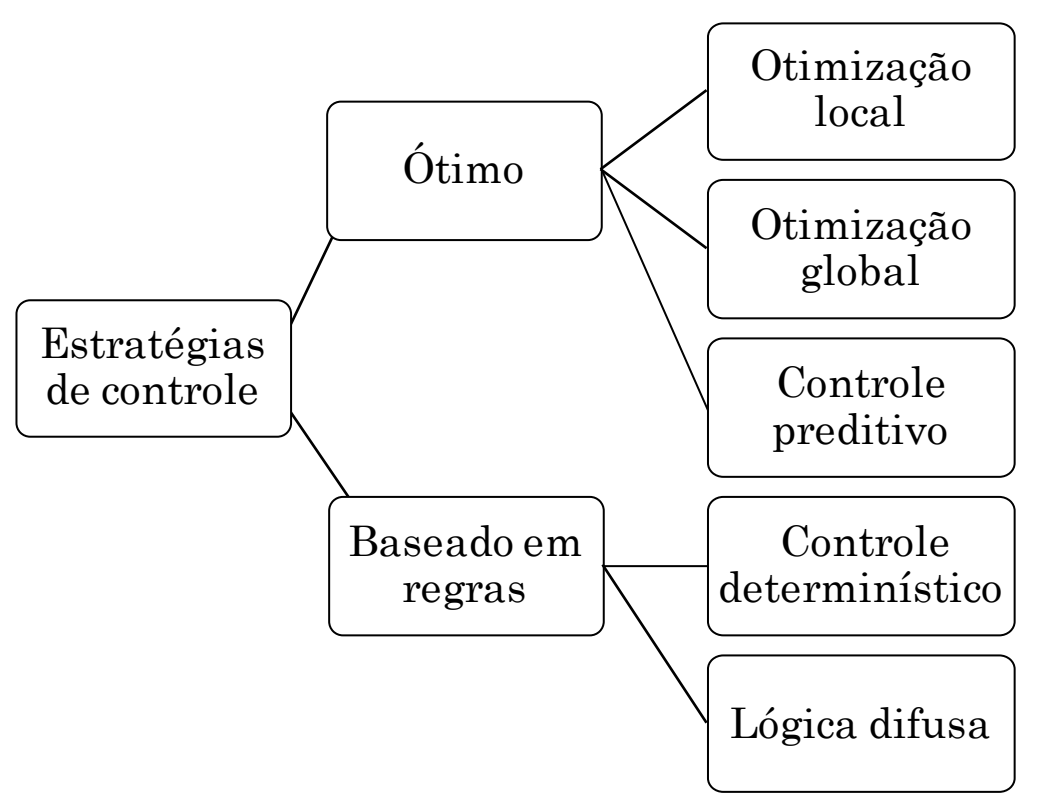

Figura 2.1 - Classificação das estratégias de controle para veículos híbridos elétricos. Adaptado de Salmasi (2007). 


\subsection{Controle baseado em regras}

O primeiro exemplo de controle baseado em regras é o controle determinístico, que utiliza sinais lógicos (0 ou 1) calculados com base no valor das variáveis do sistema usando estruturas de seleção (if-else). Uma aplicação do controle determinístico é na determinação do instante em que o motor de combustão deve ser ligado. Em um veículo híbrido, isso deve occorer se a demanda de potência exceder que um determinado nível.

O controle determinístico pode usar heurística ou cálculos pré-estabelecidos para definir as saídas de controle e sua vantagem é a implementação relativamente simples em tempo real. No entanto, a complexidade aumenta se o sistema for não linear, tornando sua efetividade baixa nesse caso (SALMASI, 2007).

O controle usando lógica difusa é semelhante ao controle determinístico, porém, não fica limitado à restrição imposta pela variável apresentar apenas valores lógicos. Ao invés disso, as variáveis são discretizadas em espaços finitos para caracterizar seus diferentes estados. Como exemplo, o estado de carga da bateria (SOC, do inglês State Of Charge) pode ser dividido nos espaços amostrais alto, médio e baixo. A lógica difusa então determina as saídas baseada no resultado lógico da combinação desta e outras variáveis. Esse tipo de controle é considerado como o método não-ótimo mais usado para VHE (RAJAGOPALAN et al., 2003; SALMASI, 2007; SCHOUTEN; SALMAN; KHEIR, 2003).

A maior parte da literatura encontrada sobre lógica difusa tem como entrada a demanda de torque trativa e o estado de carga da bateria para resultar na demanda de potência do MCI e do motor elétrico. No exemplo da Tabela 2.1, o controle do motor elétrico e do MCI é determinado com base na demanda de torque do veículo e no SOC da bateria. Para cada combinação dos estados das variáveis, uma certa decisão é tomada. As saídas são tais que, para demanda de torque menor que a ótima e baixo SOC, o MCI irá fornecer potência para propulsionar o veículo e também carregar a bateria. Caso a demanda de potência 
continue baixa, mas o SOC é alto, o MCI não será ligado e o motor elétrico fornecerá a demanda de potência do veículo.

\begin{tabular}{cccc}
\hline Entradas & SOC baixo & SOC ótimo & SOC alto \\
\hline \hline $\begin{array}{c}\text { Demanda de torque } \\
\text { menor que ótimo do } \\
\text { MCI }\end{array}$ & $\begin{array}{c}\text { Torque MCI } \\
\text { ótimo } \\
\text { Motor como } \\
\text { gerador }\end{array}$ & $\begin{array}{c}\text { Torque MCI ótimo } \\
\text { Motor como gerador } \\
\text { (baixo torque) }\end{array}$ & $\begin{array}{c}\text { MCI desligado } \\
\text { Motor em tração }\end{array}$ \\
\hline $\begin{array}{c}\text { Demanda de torque } \\
\text { igual ao ótimo do } \\
\text { MCI }\end{array}$ & $\begin{array}{c}\text { Torque MCI } \\
\text { ótimo } \\
\text { Motor como } \\
\text { gerador }\end{array}$ & $\begin{array}{c}\text { Torque MCI ótimo } \\
\text { Motor desligado }\end{array}$ & $\begin{array}{c}\text { Torque MCI } \\
\text { menor que ótimo } \\
\text { Motor em tração }\end{array}$ \\
\hline $\begin{array}{c}\text { Demanda de torque } \\
\text { maior que o ótimo do } \\
\text { MCI }\end{array}$ & $\begin{array}{c}\text { Torque MCI } \\
\text { maior que ótimo } \\
\text { Motor como } \\
\text { gerador }\end{array}$ & $\begin{array}{c}\text { Torque MCI menor } \\
\text { que ótimo } \\
\text { Motor em tração }\end{array}$ & $\begin{array}{c}\text { Torque MCI } \\
\text { menor que ótimo } \\
\text { Motor em tração }\end{array}$ \\
\hline
\end{tabular}

Tabela 2.1 - Exemplo de lógica difusa para um veículo híbrido paralelo. Adaptado de Rajagopalan et al. (2003).

Schouten; Salman e Kheir (2003) mostram uma implementação de lógica difusa para uma topologia paralela atrelada à uma rotina de otimização com redes neurais. $\mathrm{O}$ autor compara os resultados em relação a uma estratégia de controle base, a qual não é descrita no trabalho, sendo possível uma redução total das perdas de energia em torno de $7,7 \%$.

Yi; Heping e Huabin (2011) aplicaram um controlador baseado em lógica difusa para um veículo híbrido paralelo usando 5 espaços discretos das variáveis de entrada - SOC e demanda de torque trativa. Os autores comparam o resultado de simulação obtido com lógica difusa com resultados de simulação utilizando um controlador lógico, o qual não é descrito em detalhes na publicação. Os resultados foram de aumento de $23 \%$ para a eficiência média do MCI e de $10 \%$ para a eficiência total do trem-de-forças quando usando lógica difusa.

\subsection{Controle ótimo}

Os métodos de controle ótimo para veículos híbridos determinam as saídas do sistema que minimizam uma função custo relacionada ao consumo de 
combustível e/ou às emissões do MCI. O método de controle ótimo global soluciona as variáveis de controle que minimizam uma função custo acumulada no tempo, garantindo assim que o mínimo global do sistema seja encontrado. Dessa forma, quando aplicado ao problema de um veículo híbrido, é necessário o conhecimento prévio do ciclo de condução para o cálculo da função custo e para a determinação da solução de controle. Isso faz com que esse método não seja aplicável em algoritmos de tempo real. No entanto, os resultados obtidos a partir do controle ótimo global podem ser aplicados usando lógica difusa (ZHU et al., 2004), controle baseado em regras (LIN et al., 2003) ou mesmo controle ótimo local (LIU e PENG, 2006).

O método de solução do controle ótimo global mais usado para o problema de veículos híbridos é o de programação dinâmica, porém, outros métodos, como programação linear, também são mencionados na literatura (SALMASI, 2007).

Karbowski et al. (2009) aplicaram controle ótimo em veículos híbridos plugin de topologias série, paralelo e série-paralelo para comparar os resultados do consumo de combustível entre cada topologia. Nesse estudo, o trem-de-força de cada topologia foi dimensionado para possuir a mesma capacidade de tração e autonomia elétrica. Através do controle ótimo, os autores argumentam que garantem uma comparação justa entre as topologias operando em um determinado ciclo de condução. Os resultados mostram que, na configuração em paralelo, o motor de combustão propulsiona as rodas com frequência devido ao fato de a potência máxima do motor elétrico ser baixa, fazendo com que a eficiência média do MCI também seja baixa. Já na configuração série, o MCI opera próximo a sua eficiência máxima, pois a sua potência de operação não depende diretamente da demanda de potência de tração nas rodas. $\mathrm{O}$ autor ainda menciona que a configuração série-paralelo apresenta consumo de combustível comparável ao da configuração série para ciclos de condução com distância similar à autonomia elétrica do veículo. 
Nas estratégias de controle ótimo local, o controlador minimiza a função custo em cada instante de cálculo e não necessita de informações em avançado sobre a rota. Quando aplicado ao problema de otimização em veículos híbridos, o controle ótimo local minimiza o consumo de combustível em cada passo de tempo ao invés de minimizar a sua integral no domínio de tempo total, como efetuado pelo controle ótimo global. Para se aproximar da solução mínima global, o controle ótimo local introduz à função custo um termo de penalização referente à utilização de energia elétrica. Dessa forma, esse método leva em consideração que a energia descarregada da bateria deverá ser suprida pela energia proveniente do motor de combustão.

Alguns estudos da literatura com as estratégias de controle ótimo local investigam quão próximos do ótimo global são os seus resultados. Kim; Cha e Peng (2011) mostram que é possível obter resultados ótimos com controle ótimo local para sistemas lineares. Os autores mencionam que, no caso de veículos híbridos, o sistema é considerado linear na faixa em que a tensão na bateria varia linearmente com o seu estado de carga.

Para alcançar resultados similares ao ótimo global, alguns autores criam funções para o termo de penalização que variam de acordo com o SOC da bateria a cada passo de tempo. Tais funções levam em consideração a topologia do sistema, a extensão permitida de variação do SOC durante um ciclo, se existe recarga externa, entre outros fatores (LIU e PENG, 2006).

Musardo, Rizzoni e Staccia (2005), estudaram a aplicação de um controlador ótimo local em um veículo híbrido paralelo de $135 \mathrm{~kW}$ de potência total. Os autores criaram um método que adapta o termo de penalização ao decorrer do ciclo de condução. Os resultados são de redução em relação ao consumo de combustível quando comparado a um veículo convencional, porém ainda 10\% maiores em relação ao resultado da otimização global.

Outros métodos para encontrar soluções próximas do ótimo global utilizam informações sobre a rota futura a ser seguida pelo veículo. Como exemplo, se 
existir informação de tráfego congestionado a frente, o controlador pode decidir por carregar a bateria, aumentando o estado de carga e permitindo que o modo puramente elétrico seja utilizado mais adiante.

Na década de 2000 iniciaram-se estudos utilizando informações a priori da rota através de GPS (Global Position System) embarcado através de lógica difusa preditiva (LIN et al., 2004; GONDER, 2008; RAJAGOPALAN et al., 2003). Nesse caso, Rajagopalan et al. (2003) descreve um controlador de navegação que é responsável por estimar a elevação da pista e velocidade baseada nas condições de tráfego. Essas informações são utilizadas no conceito de lógica difusa, subdivididas em tráfego urbano, expresso, rodovia, etc. As saídas do controlador de navegação são enviadas ao controlador supervisório e usadas como fatores que modificam o torque final necessário dos componentes.

O conceito de controle preditivo é explicado em Lin et al. (2004) e mostrado na Figura 2.2. Condições em avançado sobre a rota são determinadas para uma certa janela finita no futuro $f_{i} T$. Os dados dessa janela são discretizados no tempo e a média dos seus parametros futuros é calculada. Os estados atuais do sistema também são levados em consideração para definição do controle preditivo. Como exemplo, não seria possível carregar a bateria para que o motor elétrico assista o veículo numa subida de rampa se o veículo já está na rampa e com bateria carregada. Dessa forma, uma janela finita $p T$ é usada para armazenar a média dos estados passados do sistema. Por último, uma janela finita $N T$ é determinada onde os resultados do controle preditivo serão aplicados. 


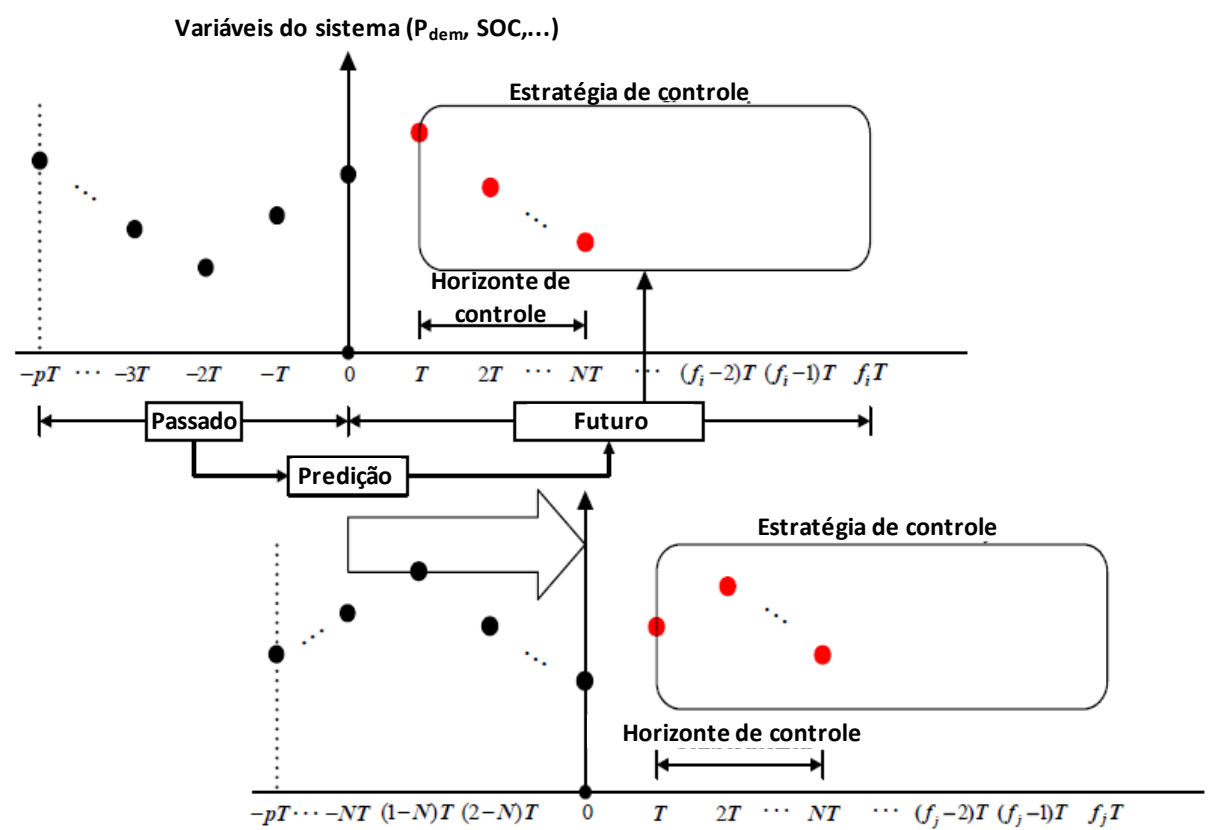

Figura 2.2 - Conceito de controle preditivo baseado em reconhecimento do padrão de condução.

Adaptado de Lin et al., (2004).

Resultados com lógica difusa preditiva são de $2,6 \%$ de redução de consumo de combustível em um ciclo rodoviário para Rajagopalan (2003) e de até 5,2\% para Lin et al. (2004) quando comparado com estratégias utilizando controle nãoótimo. Lin et al. (2004) mostra também que o melhor resultado obtido por lógica difusa preditiva está ainda 8,4\% acima do obtido através de controle ótimo global. Esta dissertação não encontrou medições experimentais de lógica difusa preditiva aplicada em unidades de controle em tempo-real.

\subsection{Conclusões da revisão da literatura}

Na seção anterior, foram apresentados diversos métodos de controle para veículos híbridos. Quando se objetiva a implementação da estratégia em uma unidade de controle eletrônica em tempo real, a lógica determinística se apresenta como o método mais simples e o que, possivelmente, requer o mínimo de capacidade de processamento eletrônico. No entanto, caso o sistema de controle deva levar em consideração muitas variáveis de controle e condições de operação, esse método não se mostra tão efetivo. Já a lógica difusa é o método mais usado para controle de sistemas híbridos, pois não requer alta capacidade de processamento e possui 
alta efetividade quando implementada utilizando resultados provenientes de métodos de otimização

O estudo de controle de veículos híbridos é relativamente recente e a maior parte da literatura disponível se baseia em simulação, existindo poucos resultados experimentais de uma implementação em tempo real. Além disso, há também escassez de estudos comparando os resultados de controle para quando o veículo opera em diferentes ciclos de condução ou em um ciclo real diferente do estudado para a construção da estratégia de controle.

Numa operação no mundo real, a efetividade do controle e o desempenho do veículo dependem também em grande parte do condutor. Estilos de direção diferentes em um veículo podem resultar em grandes variações de consumo de combustível e emissões para uma mesma rota. Esse é um assunto que carece de investigações mais profundas quanto aos métodos para sua caracterização e aplicação em um sistema de controle. 


\section{MODELAGEM DO VEÍCULO HÍBRIDO ELÉTRICO}

Esse capítulo descreve a modelagem da dinâmica do trem-de-força do veículo híbrido. Devido ao fato de o sistema em estudo se tratar de um produto em comercialização, existe certa escassez de dados disponíveis pelo fabricante em função da confidencialidade das suas informações. A maior parte dos dados encontrados foi obtida principalmente por experimentos realizados por institutos de pesquisa com o veículo em estudo.

No processo de modelagem, o equacionamento matemático foi primeiro derivado para então criar-se um modelo computacional do sistema usando o programa Matlab/Simulink. O pacote de simulação ADVISOR (WIPKE e CUDDY, 1998) também foi considerado, porém, foi constatado que o programa Matlab/Simulink possui maior gama de opções para a modelagem computacional como também poder ser usado para geração de código de controle para unidades de processamento eletrônico.

O sistema dinâmico em estudo nesta dissertação é baseado no veículo Toyota Prius Geração 2, que se caracteriza por ser um veículo de passeio, híbrido elétrico do tipo série-paralelo e não-plugin. Nesse sistema, os motores elétricos são do tipo sem escovas com ímã permanente no rotor e utilizam inversores de frequência para conversão de corrente contínua para corrente alternada. O sistema de alta tensão possui armazenamento de energia feito por uma bateria de níquel-hidreto metálico $(\mathrm{NiMH})$ e um conversor $\mathrm{CC} / \mathrm{CC}$ ainda é usado para conversão de tensão entre a bateria e os inversores de frequência.

Os dados de entrada do modelo do veículo correspondentes aos diferentes subsistemas são mostrados no ANEXO A. 


\subsection{Descrição do sistema}

O conceito do trem-de-força do veículo adotado é descrito por Muta; Yamazaki e Tokieda (2004) e mostrado na Figura 3.1. Os principais componentes ilustrados na figura são: transmissão planetária, motor de combustão interna (MCI), motorgerador com função principal de geração de energia (MG1), motor-gerador com função principal de tração (MG2) e bateria de alta tensão. O sistema de transmissão possui ainda uma redução de velocidades, um diferencial e o semieixo conectado as rodas. Os inversores de frequência de cada motor e o conversor CC/CC não são ilustrados na figura, porém, a modelagem contempla as perdas que eles introduzem no sistema.

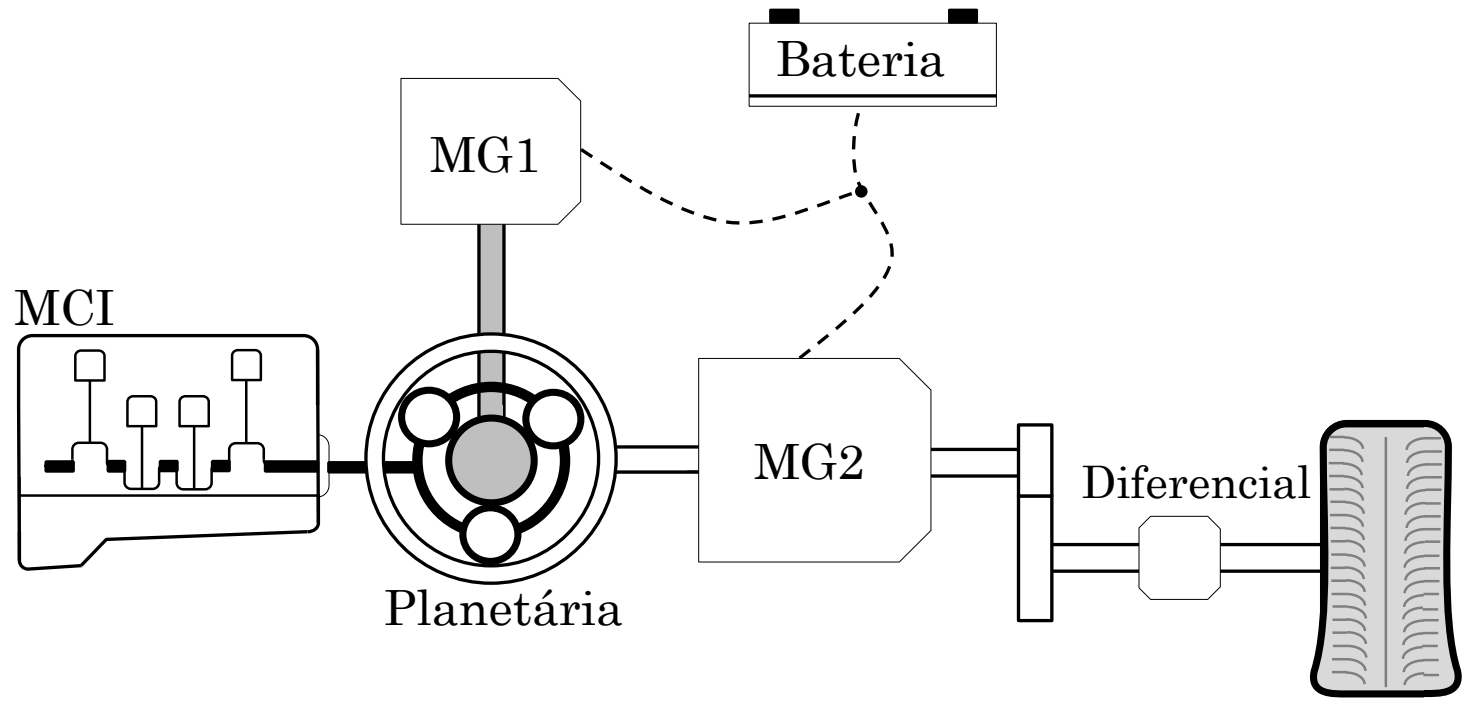

Figura 3.1 - Ilustração do trem-de-força do veículo adotado.

Nesse sistema, MCI, MG1 e MG2 estão conectados à engrenagem planetária através do braço planetário, engrenagem solar e engrenagem anular, respectivamente. A engrenagem anular está conectada as rodas através da redução final, portanto, a rotação do MG2 é diretamente proporcional à rotação das rodas.

A transmissão planetária é o componente da transmissão responsável pela arquitetura série-paralelo. Ela possibilita que uma parcela fixa do torque do motor de combustão seja transferida para o MG1 através da engrenagem solar e 
outra parcela fixa para as rodas através da engrenagem anular. Uma vez que a distribuição de torque é definida pelo número de dentes das engrenagens, a distribuição de torque do MCI através da transmissão planetária varia com a velocidade do sistema. Por esse motivo, essa topologia é usualmente conhecida pelo nome de power-split.

Durante a operação, o MG2 atua como motor de tração e regenera energia em eventos de frenagem. Já o MG1 tem a função de controlar a rotação de operação do MCI e pode funcionar em regime de tração ou de geração de energia, dependendo da velocidade desejada para o MCI. Dessa forma, o MG1 não propulsiona o veículo ou recupera energia de frenagem diretamente.

A Figura 3.2 ilustra um diagrama de alavancas que exemplifica a operação dos componentes para diferentes condições. Os eixos verticais correspondem à rotação de cada componente. O termo $i_{p}$ é a relação de transmissão característica da engrenagem planetária e será descrito mais adiante. A partir da figura, tem-se que em a) o veículo está em repouso e todos os componentes apresentam rotação nula, em b) o veículo acelera, MG2 possui rotação positiva e MG1 possui rotação negativa para manter o MCI parado e em c), a rotação do MG1 sobe e isso faz com que o MCI seja ligado e opere em baixa rotação. Se o MCI necessitar de maior velocidade ou fornecer mais potência às rodas, a velocidade do MG1 sobe novamente, como em d). Isso exemplifica a dependência do MG1 para controlar a velocidade desejada do MCI. Uma vez que a velocidade desejada é atingida, o torque do MCI é calculado para que se atinja a potência desejada. 


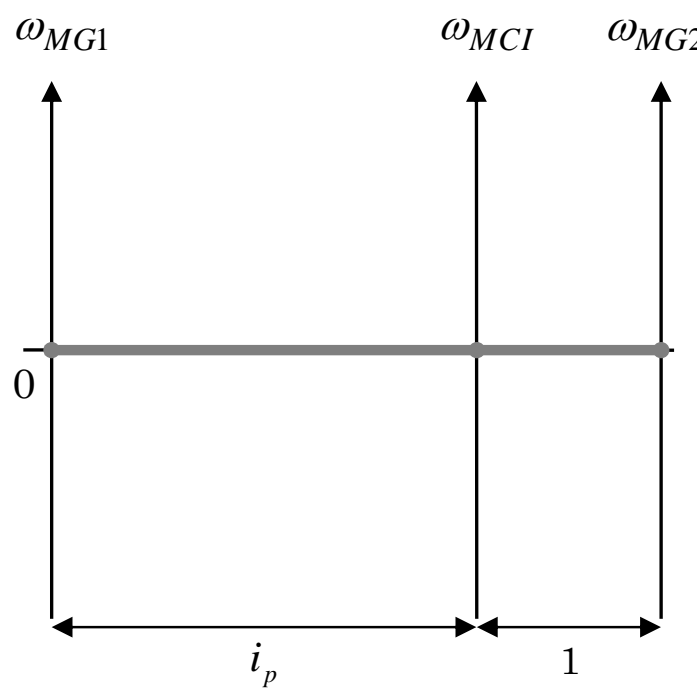

a) Veículo em repouso

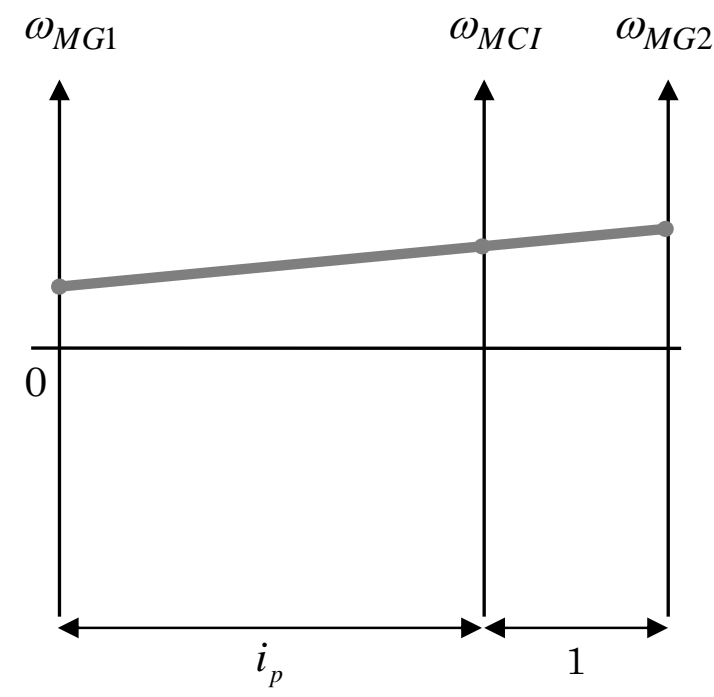

c) Propulsão com MG2 e MCI

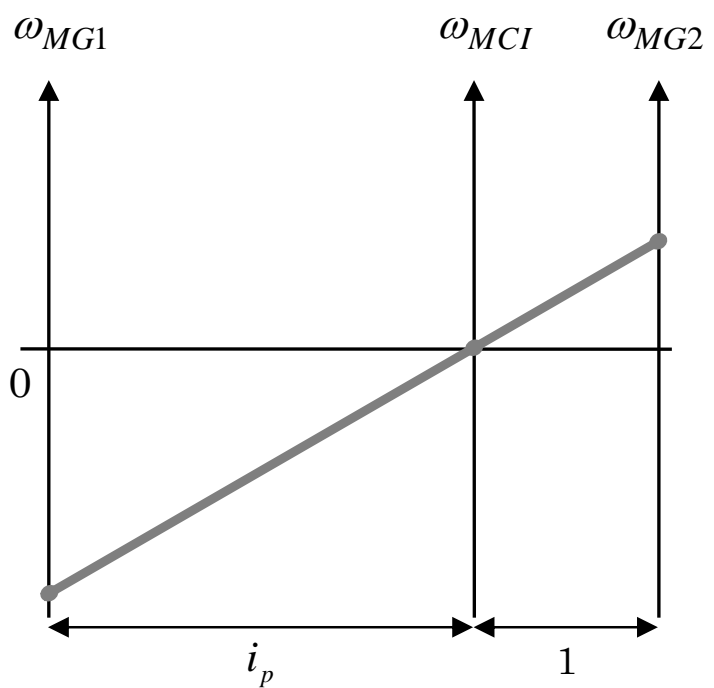

b) Aceleração somente com MG2

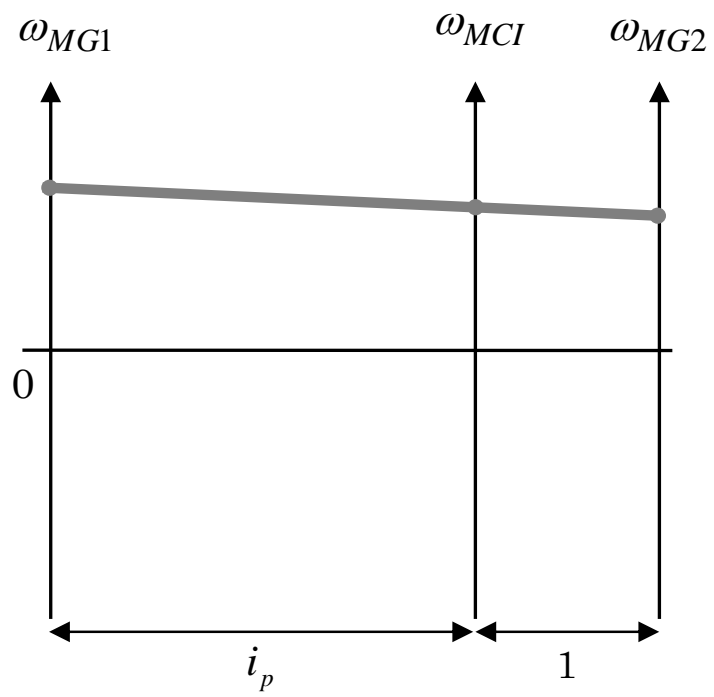

d) Idem c), mas com maior rotação do MCI

Figura 3.2 - Diagrama de alavancas da engrenagem planetária.

A relação de velocidades na engrenagem planetária correspondente ao diagrama acima é mostrada na equação abaixo.

$$
\omega_{M G 1}+i_{p} \cdot \omega_{M G 2}=\left(i_{p}+1\right) \cdot \omega_{M C I}
$$


Onde $\omega_{M G 1}, \omega_{M G 2}$ e $\omega_{M C I}$ correspondem à velocidade angular da engrenagem solar, anular e do braço planetário, respectivamente, e compõem as variáveis cinemáticas do sistema. A partir da Eq. (1), tem־se então um sistema mecânico com 2 graus de liberdade.

A relação de transmissão $i_{p}$ é calculada como:

$i_{p}=\frac{N_{A}}{N_{S}}$

Onde $N_{A}$ e $N_{S}$ correspondem ao número de dentes na engrenagem anular e solar, respectivamente.

Existem diferentes modos de operação na topologia série-paralelo relacionados com o fluxo de energia ao longo do trem-de-força híbrido. Os principais modos são mostrados na Figura 3.3, onde as setas ilustram o fluxo de energia no sistema. Os possíveis modos de operação são:

- Propulsão elétrica (Figura 3.3 a)): ocorre em baixas velocidades ou eventos em que a demanda de potência é baixa e não necessita da operação do MCI. Nesse modo, a bateria fornece energia para o MG2, que é o único responsável por propulsionar o veículo.

- Propulsão híbrida com recirculação de energia (Figura 3.3 b)): nesse modo o MCI fornece toda a energia necessária para propulsionar o veículo e não existe descarga ou recarga da bateria. Uma parcela do torque do MCI é transmitida às rodas mecanicamente e outra parcela é direcionada ao MG1, que funciona como gerador para controlar a rotação do MCI. A energia produzida pelo MG1 é então usada pelo MG2 para tração. Dessa forma, existe recirculação de energia no sistema, o que faz essa configuração não ser muito eficiente em ciclos de condução em rodovia ou quando o MCI é o único responsável pela propulsão. 
- Propulsão híbrida com recarga da bateria (Figura $3.3 \mathrm{c}$ )): semelhante ao caso anterior mas parte da potência gerada pelo MG1 é usada para recarregar a bateria. Pode ocorrer quando o SOC da bateria está abaixo do mínimo determinado pela estratégia de controle.

- Propulsão híbrida com descarga da bateria (Figura 3.3 d)): também semelhante ao caso anterior, com a diferença de que o MCI e a bateria fornecem energia para a propulsão. O MCI transmite parte do torque às rodas e o MG2 utiliza a energia proveniente do MG1 e da bateria para tração. Ocorre quando a demanda de potência nas rodas é superior à potência máxima ou ótima do MCI.

- Recuperação de energia de frenagem (Figura 3.3 e)): ocorre quando o MG2 absorve toda a energia de frenagem ou parte dela em conjunto com o freio mecânico. Nesse caso, o torque do MG2 é negativo para rotações positivas ou positivo para rotações negativas.

- Recarga da bateria em repouso (Figura 3.3 f)): o MG1 pode ligar o motor de combustão mesmo com o veículo em repouso, para que haja recarga da bateria. Isso pode ocorrer quando a bateria é lentamente descarregada devido à corrente elétrica parasita. 


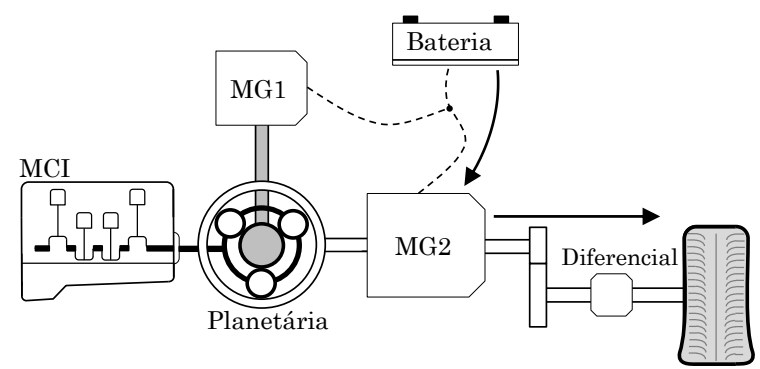

a)

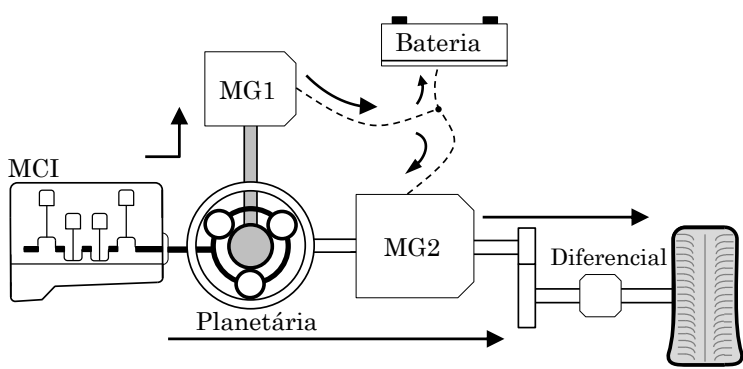

c)

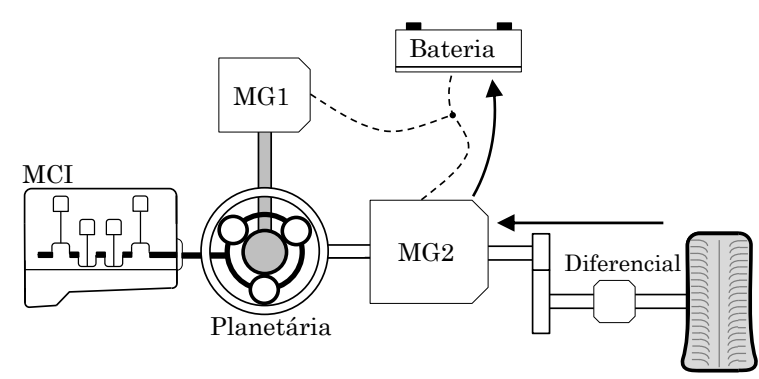

e)

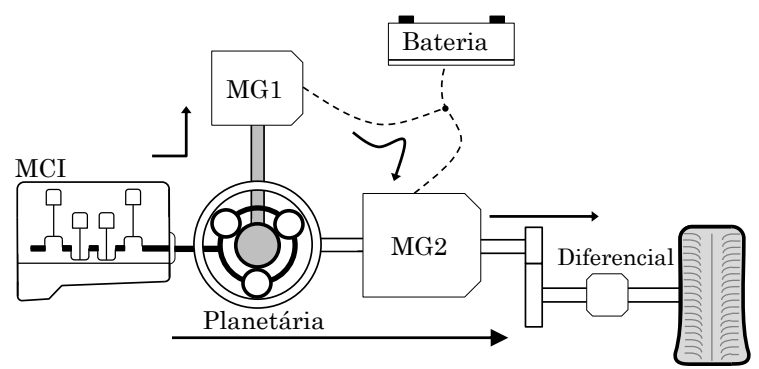

b)

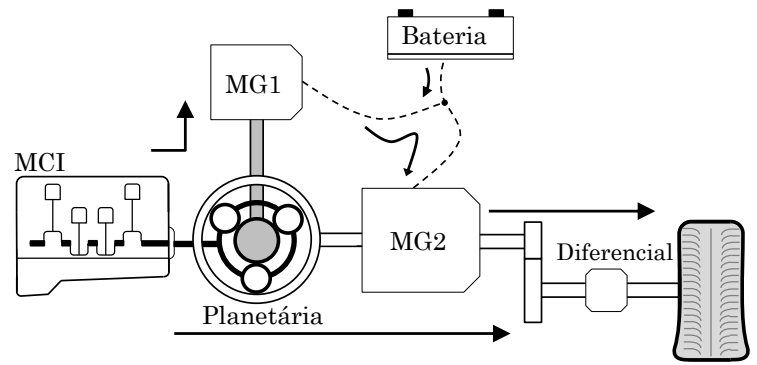

d)

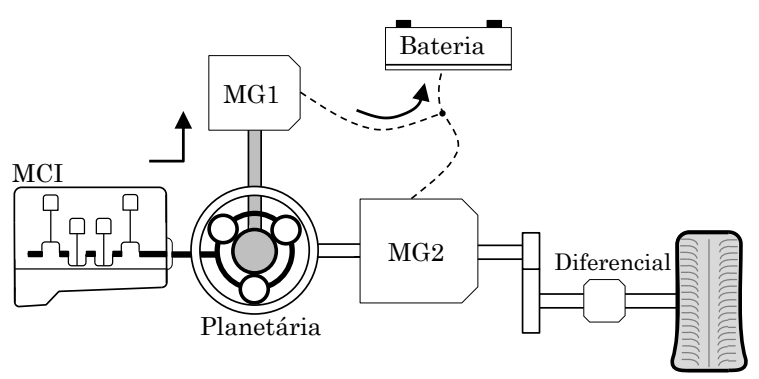

f)

Figura 3.3 - Modos de operação do sistema série-paralelo.

A partir do equacionamento da dinâmcia veicular longitudinal apresentado em Zhang et al. (2012) e Gillespie (1992), é derivado a equação abaixo para as forças trativas e resistivas ao movimento na roda no veículo.

$$
\begin{aligned}
& T_{\text {dem }} \cdot i_{D}=\left(M \cdot r_{p}^{2}+I_{T R}\right) \cdot \dot{\omega}_{p}+\left(0.5 \cdot C_{d} \cdot \rho_{a r} \cdot A \cdot V^{2}\right) \cdot r_{p}+\left(c_{R} \cdot M \cdot g\right) \cdot r_{p} \\
& +T_{\text {freio }}
\end{aligned}
$$

Onde $T_{d e m}$ é a demanda de torque nas rodas e $i_{D}$ é a relação de redução do diferencial. O primeiro termo do lado direito da equação refere-se à inercia, onde $M$ é a massa total do veículo, $I_{T R}$ é inércia equivalente de todos os componente 
rotacionais convertida no eixo das rodas e $\dot{\omega}_{p}$ é a aceleração angular das rodas. $\mathrm{O}$ segundo termo corresponde à resistência aerodinâmica, onde $C_{d}$ é o coeficiente de resistência aerodinâmica, $\rho_{a r}$ é a densidade do ar, $A$ é a área frontal e $V$ é a velocidade do veículo. O terceiro termo corresponde à resistência ao rolamento, com $c_{R}$ o coeficiente de resistência ao rolamento e $r_{p}$ o raio dinâmico do pneu. $T_{\text {freio }}$ é o termo referente ao torque de atrito do freio mecânico.

A modelagem matemática do trem-de-força com transmissão planetária é extensa e foi inserida no APÊEDICE A. A equação resultante que representa a dinâmica no trem-de-força é:

$$
\begin{aligned}
& {\left[\begin{array}{cccc}
I_{S}+I_{M G 1} & 0 & 0 & -r_{S} \\
0 & I_{B P}+I_{M C I} & 0 & \left(r_{A}+r_{S}\right) \\
0 & 0 & I_{A}+I_{M G 2}+\frac{\left(M+m_{\text {rodas }}\right) \cdot r_{p}{ }^{2}}{i_{D}{ }^{2}} & -r_{A} \\
r_{S} & -\left(r_{A}+r_{S}\right) & r_{A} & 0
\end{array}\right]\left[\begin{array}{c}
\dot{\omega}_{M G 1} \\
\dot{\omega}_{M C I} \\
\dot{\omega}_{M G 2} \\
F
\end{array}\right]=} \\
& {\left[\begin{array}{c}
-T_{M G 1} \\
T_{M G 2}-\frac{T_{\text {freio }}}{i_{D}}-\frac{0.5 \cdot C_{d} \cdot \rho_{a r} \cdot A \cdot V^{2}+c_{R} \cdot M \cdot g}{i_{D}} \cdot r_{P}
\end{array}\right]}
\end{aligned}
$$

Nota-se que a quarta equação do sistema corresponde à Eq. (1). A partir da equação acima, existem sete incógnitas: $\omega_{M C I}, \omega_{M G 1}, \omega_{M G 2}, T_{M C I}, T_{M G 1}, T_{M G 2}$ e $F$. O perfil de velocidade do ciclo de condunção, correspondente a $\omega_{M G 2}$, é conhecido, o que resulta em um sistema com 2 variáveis independentes.. 


\subsection{Modelagem dos componentes}

Este capítulo descreve a modelagem de cada componente do sistema. Quando necessário, o modelo unitário do componente foi validado frente a resultados experimentais, o que é apresentado adiante.

\subsubsection{Motor de combustão interna}

O motor de combustão usado no veículo em estudo possui 1,5 l, potência máxima de $57 \mathrm{~kW}$, torque máximo de $115 \mathrm{Nm}$ e opera com gasolina. O ciclo Atkinson é usado nesse motor, que caracteriza-se pelo curso de expansão ser maior que o de compressão, o que é obtido modificando o tempo de abertura e fechamento das válvulas de admissão e escape, contribuindo para o aumento da eficiência térmica.

O modelo do MCI desenvolvido nesta dissertação não incorpora fenômenos de combustão e, por isso, o seu comportamento durante aquecimento do sistema catalisador ou do fluido de arrefecimento não é considerado. A Figura 3.4 mostra o mapa de torque e potência máximos do MCI (MUTA; YAMAZAKI e TOKIEDA, 2004).

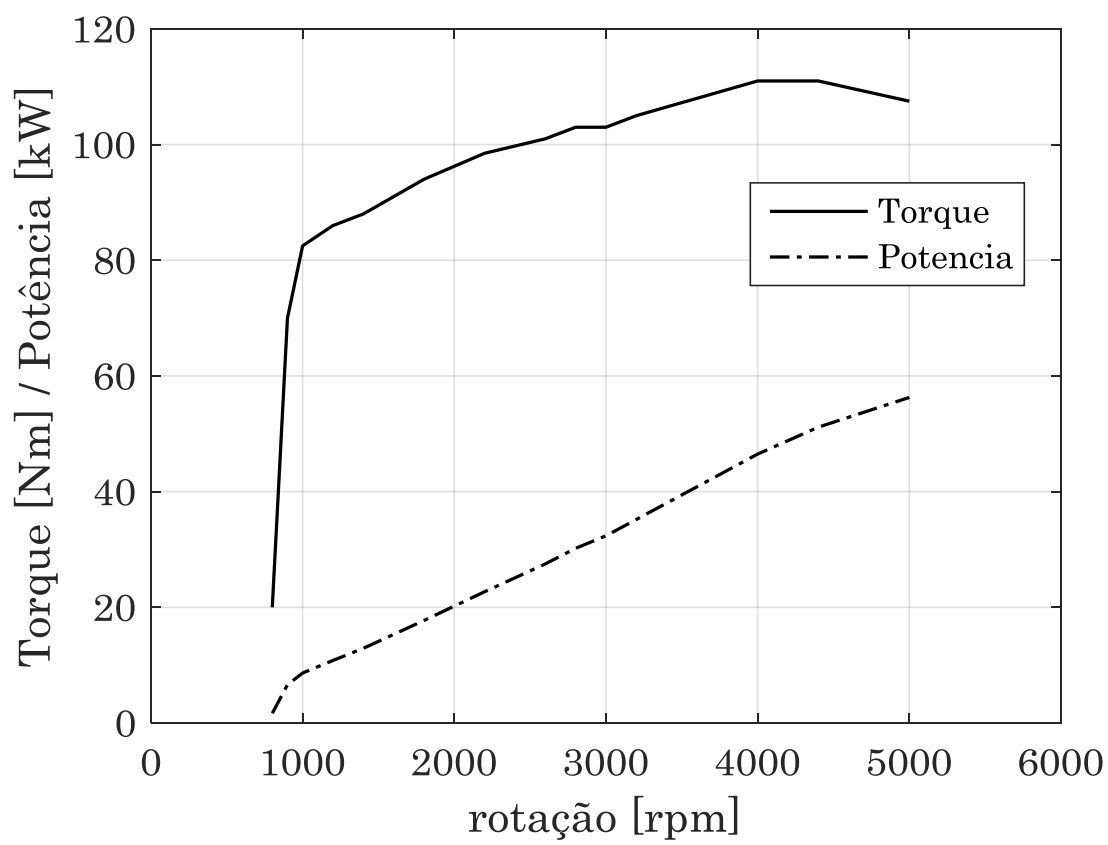

Figura 3.4 - Mapa de torque e potência máximos do MCI. 
Na Figura 3.5, é mostrado o mapa de consumo específico de combustível, que relaciona a massa de combustível necessária para geração de $1 \mathrm{kWh}$ de energia. Esse é um dado importante na modelagem para se obter boa correlação do consumo de combustível com dados experimentais durante a simulação do veículo. Kim; Rousseau e Rask (2012) usaram um sensor de torque na saída do volante do MCI e um sensor de vazão de combustível para medir o consumo de combustível. Para isso, o veículo foi operado em velocidades constantes, de modo a não capturar variações do consumo de combustível devido a transientes. Esta dissertação se baseou então nesses dados para construir o mapa de consumo específico de combustível abaixo.

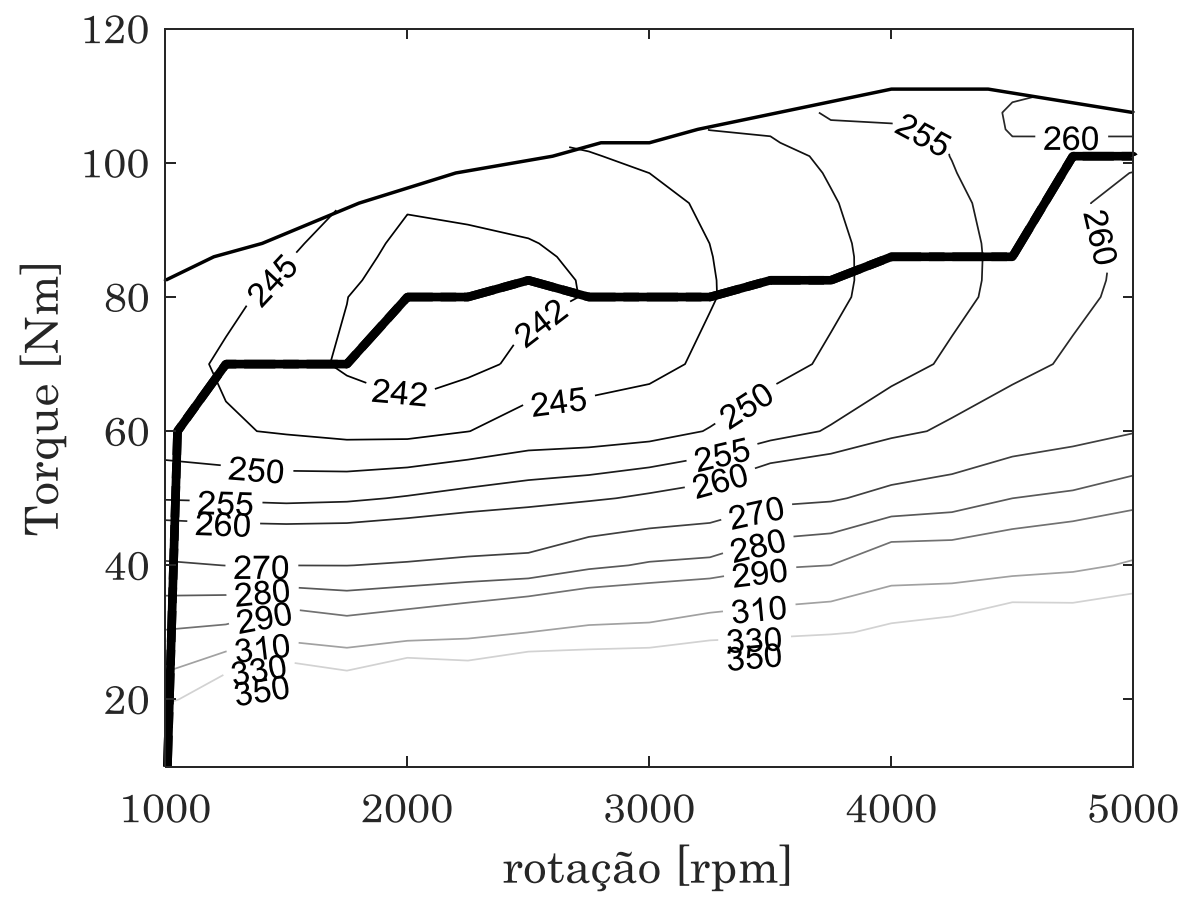

Figura 3.5 - Mapa de consumo específico do MCI em [g/kWh] e curva de operação ótima.

A eficiência térmica do motor de combustão é definida por Heywood (1988) como:

$$
\eta_{M C I}=\frac{3600}{b s f c \cdot Q_{P C I}}
$$


Onde $\eta_{M C I}$ é a eficiência do MCI, $Q_{P C I}$ é o poder calorífico inferior do combustível, equivalente a $42,5 \mathrm{MJ} / \mathrm{kg}$, e $b s f c$ é o consumo específico de combustível, definido pela vazão de combustível por unidade de potência.

Para cada rotação do MCI, pode-se calcular o valor de torque que corresponde à eficiência térmica máxima do MCI. Quando esse cálculo é efetuado para toda a faixa de rotação, obtém-se a curva de operação ótima (COO) do motor, também mostrada na Figura 3.5. Kim; Rousseau e Rask (2012) obtiveram a COO real a partir do experimento realizado e seu resultado é mostrado na Figura 3.6 juntamente com a COO calculada nesta dissertação, onde observa-se a boa aderência aos dados experimentais.

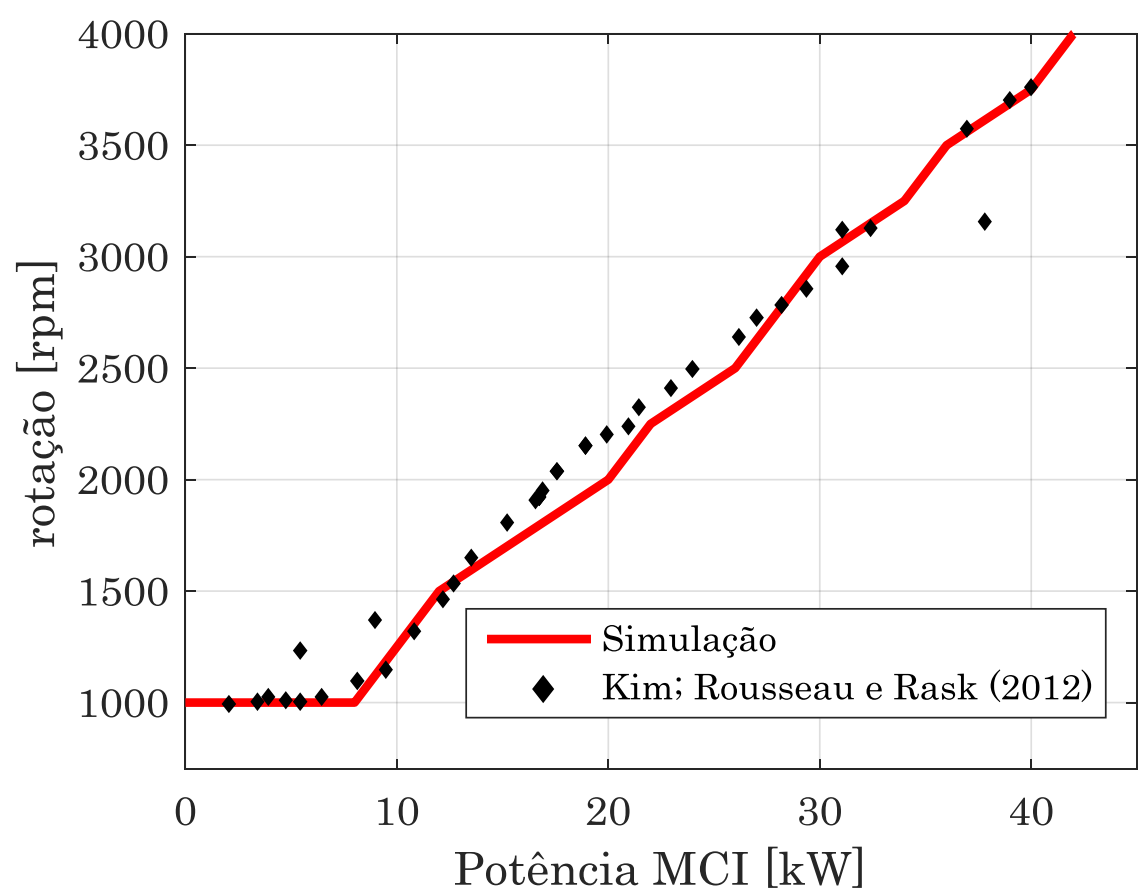

Figura 3.6 - Linha de operação ótima obtida da simulação e a partir de resultados experimentais de Kim; Rousseau e Rask (2012).

A curva de operação ótima relaciona cada valor de rotação a um valor único de potência do MCI, de modo que pode-se definir:

$T_{M C I}=f\left(\omega_{M C I}\right)$ 
A equação acima, juntamente com a Eq. (4), permite que o sistema possua apenas uma variável independente, que é a razão de distribuição de torque.

$\mathrm{O}$ atrito do motor foi modelado a partir da função proposta em Chen e Flynn (1965), que relaciona o torque de atrito do motor com a sua rotação e pressão de combustão no cilindro. A função correspondente ao modelo é:

$T_{M C I, \text { atrito }}=\left(C_{0}+C_{1} \cdot P_{c o m b}+C_{2} \cdot \omega_{M C I}+C_{3} \cdot \omega_{M C I}^{2}\right) \cdot l \cdot V_{M C I}$

Onde $T_{M C I, \text { atrito }}$ é o torque de atrito do MCI, $C_{0}, C_{1}, C_{2}$ e $C_{3}$ são coeficientes do modelo, $l$ é o curso de deslocamento do pistão, $V_{M C I}$ é o deslocamento volumétrico e $P_{\text {comb }}$ é a pressão de combustão no interior do cilindro. Os valores escolhidos para os coeficientes foram baseados em um motor $1,5 \mathrm{l}$ e equivalem a $C_{0}=0,6$, $C_{1}=0, C_{2}=0,10$ e $C_{3}=8 \cdot 10^{-4}$. O termo dependente da pressão de combustão, $C_{1}$, foi desconsiderado, pois seu efeito no atrito total é menor que 1\% (CHEN e FLYNN, 1965).

A Figura 3.7 mostra o diagrama do modelo computacional do MCI. O diagrama contém os módulos de cálculo para o torque de atrito, consumo de combustível e comando de torque, proveniente do controlador. 


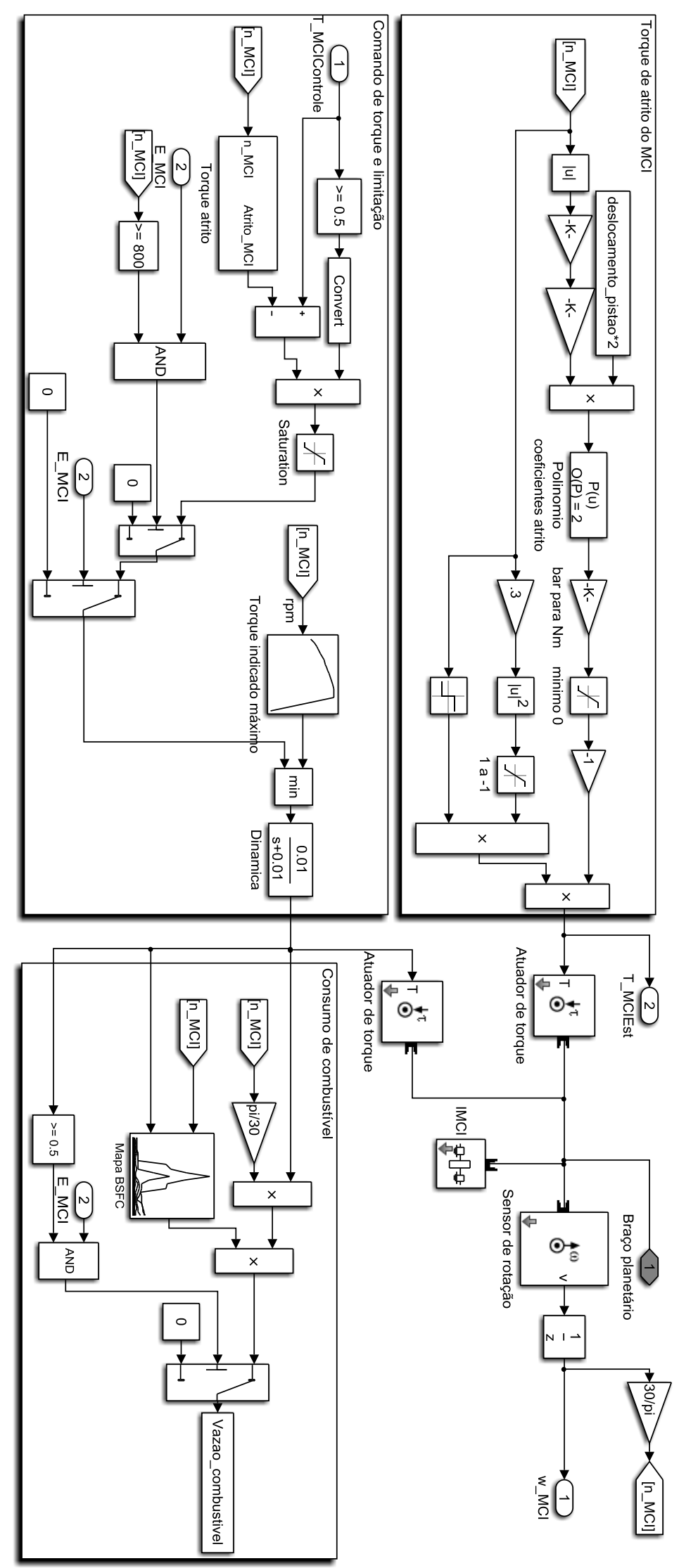

Figura 3.7 - Diagrama do modelo computacional do motor de combustão. 


\subsubsection{Bateria}

O modelo da bateria considera uma fonte de tensão operando com uma resistência interna, $R_{i}$, e uma resistência parasita, $R_{L}$. Esse modelo é apropriado para modelagem de veículos híbridos elétricos já que possibilita capturar a variação de tensão nos terminais durante carga e descarga. A tensão nos terminais da bateria é, então, definida por:

$V_{T}=V_{C A}-R_{i} \cdot I$

Onde $V_{T}$ é a tensão no terminal da bateria, $V_{C A}$ é a tensão em circuito aberto e $I$ é a corrente elétrica nos terminais da bateria. A corrente elétrica total corresponde à soma da corrente nos terminais e da corrente parasita e equivale a:

$$
I+I_{L}=-C \frac{d V_{C A}}{d t}
$$

Onde $C$ é a capacitância da bateria e a corrente parasita $I_{L}$ é definida por $I_{L}=V_{C A} / R_{L}$. Quando combinando as equações acima, obtém-se:

$$
\frac{d V_{C A}}{d t}=-\left(\frac{V_{C A}}{C R_{L}}+\frac{I}{C}\right)
$$

A corrente elétrica é, então, obtida a partir da potência de carga ou descarga da bateria e da tensão nos terminais por:

$$
I=\frac{P_{b a t}}{V_{T}}
$$

Gray e Shirk (2013) conduziram testes com a bateria realizando uma descarga constante de 6,5A durante 1 hora, o que resultou na descarga total da bateria já que sua capacidade de carga é $6,5 \mathrm{Ah}$. Foram realizados dois teste, um com a bateria nova e outro após a bateria operar em um veículo por $257000 \mathrm{~km}$. O modelo da bateria foi então simulado com a mesma corrente elétrica usada no 
teste. O resultado da simulação e dos testes obtidos na literatura acima são mostrados na Figura 3.8. Os testes realizados por Gray e Shirk (2013) ainda revelaram que a máxima potência de carga e descarga da bateria é $21 \mathrm{~kW}$.

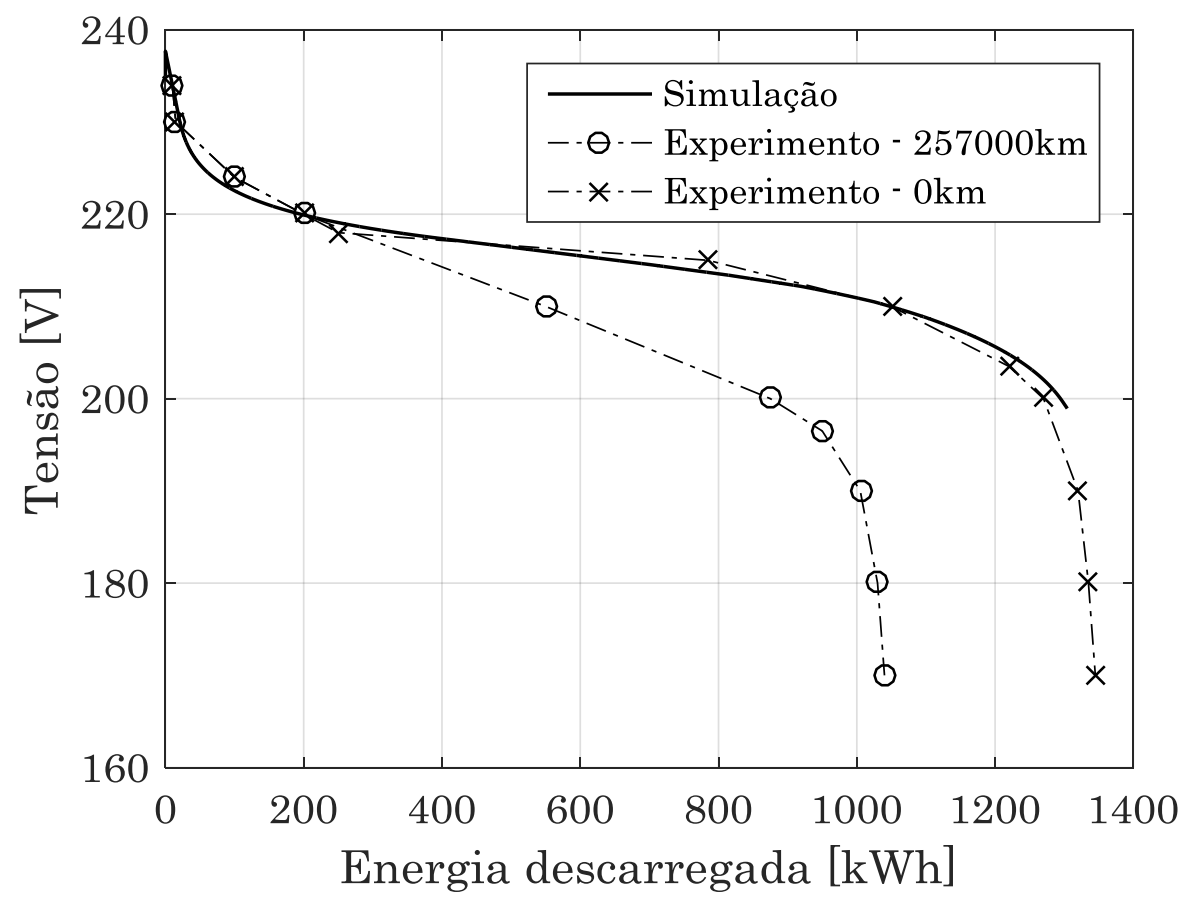

Figura 3.8 - Variação de tensão no terminal da bateria para a simulação. Dados experimentais são provenientes de Gray e Shirk (2013) e indicam o comportamento da bateria no início e fim da vida útil.

A Figura 3.9 mostra o diagrama do modelo computacional da bateria que contém os módulos de cálculo da tensão nos terminais e da energia da bateria. 


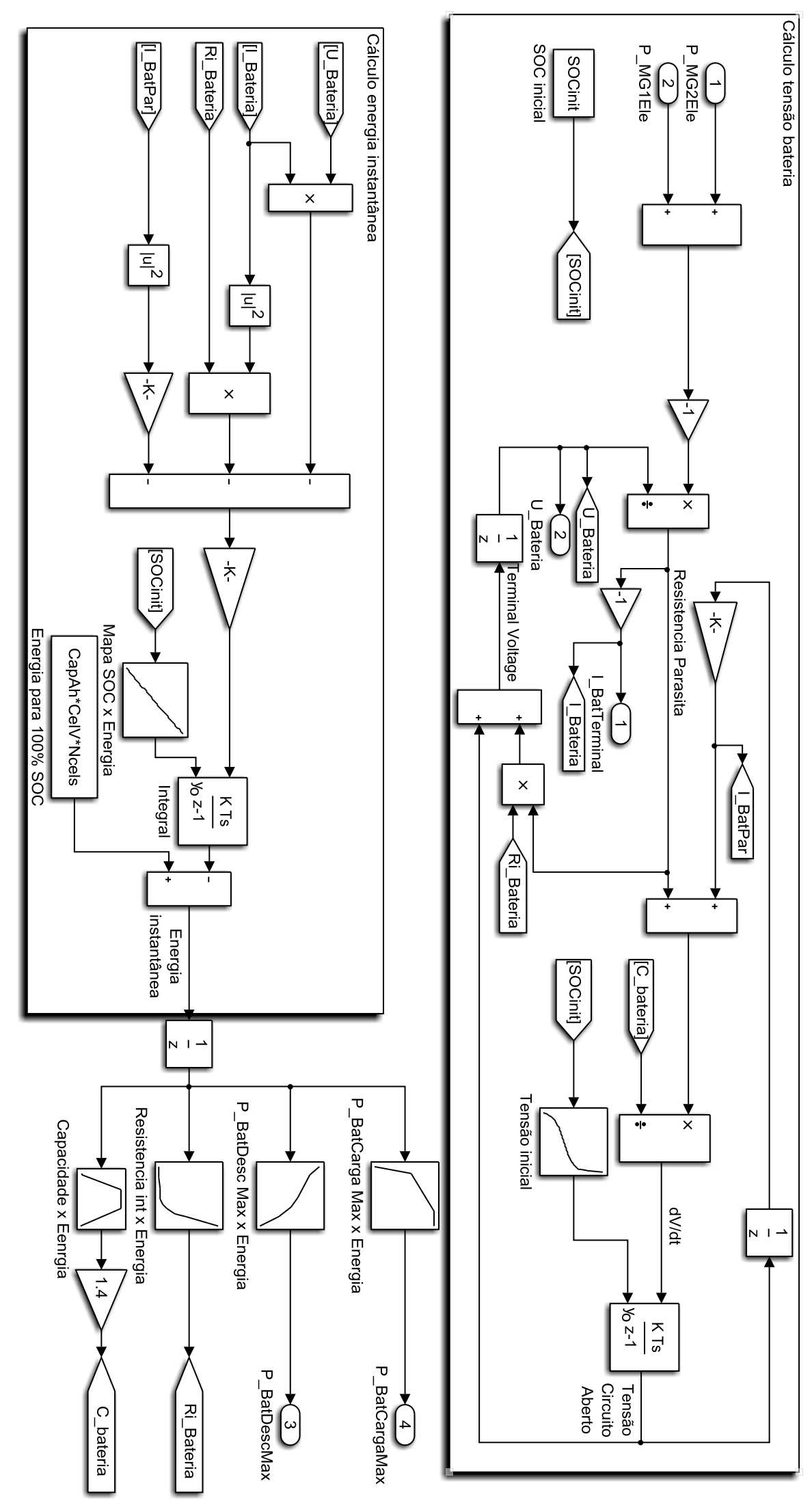

Figura 3.9 - Diagrama do modelo computacional da bateria. 


\subsubsection{Motores elétricos}

Para a modelagem do MG1 e MG2, foi construído um modelo baseado em mapas semelhante ao desenvolvido para o MCI. Muta; Yamazaki e Tokieda (2004) apresentam as características dos motores elétricos provenientes da etapa de desenvolvimento. O MG2 possui torque máximo de $400 \mathrm{Nm}$ e potência de $50 \mathrm{~kW}$. Para o MG1 existem apenas os dados de que sua potência e rotação máxima são $33 \mathrm{~kW}$ e $10000 \mathrm{rpm}$, respectivamente. Foi assumido adicionalmente que o torque máximo do MG1 é de 45Nm @ 6000rpm.

O mapa de eficiência para o MG2 foi obtido a partir de Staunton et al. (2006), que realizaram testes com o motor elétrico e disponibilizaram dados de eficiência para o conjunto motor e inversor. A eficiência dos motores elétricos incorpora as perdas ocorridas desde a potência elétrica na entrada do inversor até a conversão mecânica no eixo dos motores. O mapa de eficiência do MG2 para um dos quadrantes de operação é mostrado na Figura 3.10 e ele é replicado para os outros 3 quadrantes de operação. O mesmo mapa foi assumido para MG1, porém, escalando os limites de potência e torque respectivos para esse motor elétrico.

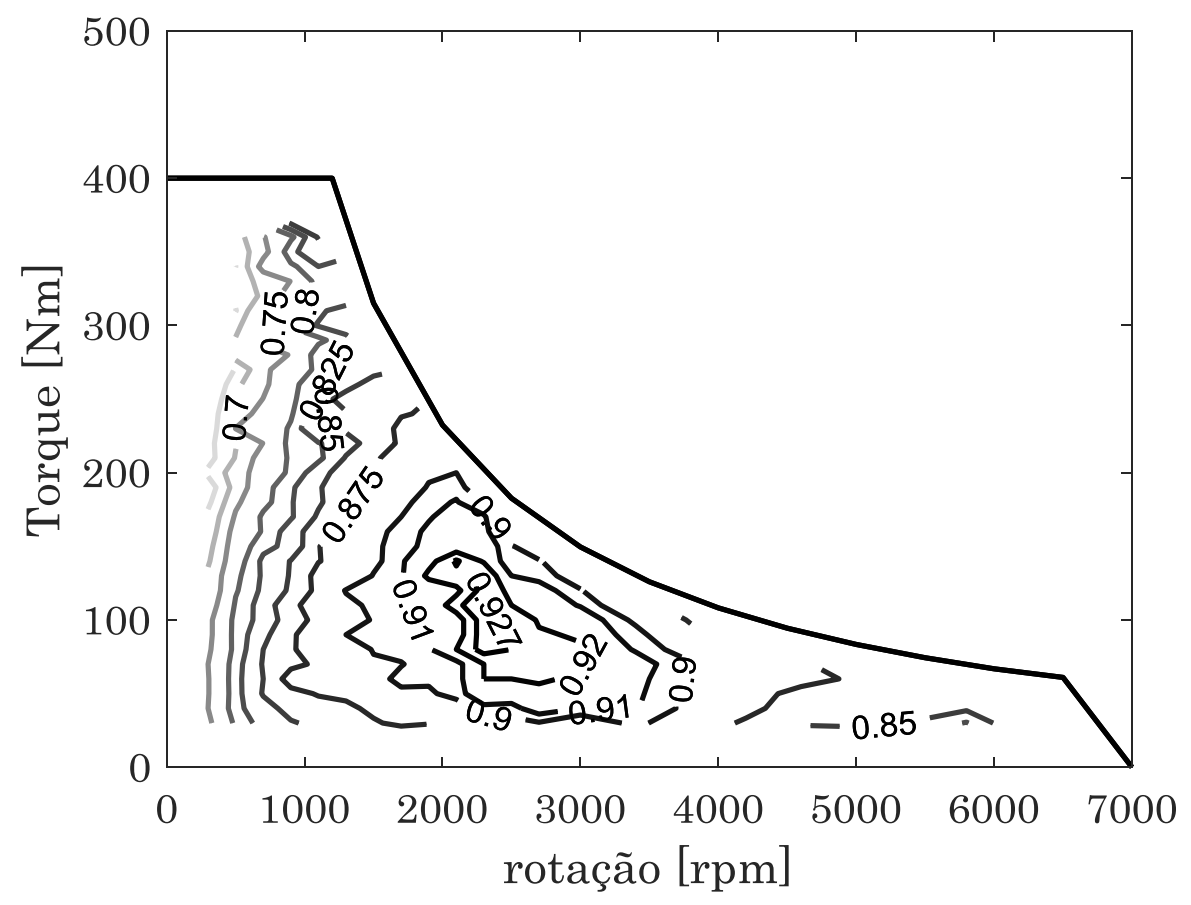

Figura 3.10 - Mapa de eficiência para o MG2. 
A Figura 3.11 mostra o modelo computacional do MG2 que incorpora o módulo de limitação de torque proveniente do controlador e cálculo da potência elétrica resultante. $\mathrm{O}$ conceito desse modelo foi o mesmo utilizado para o MG1.

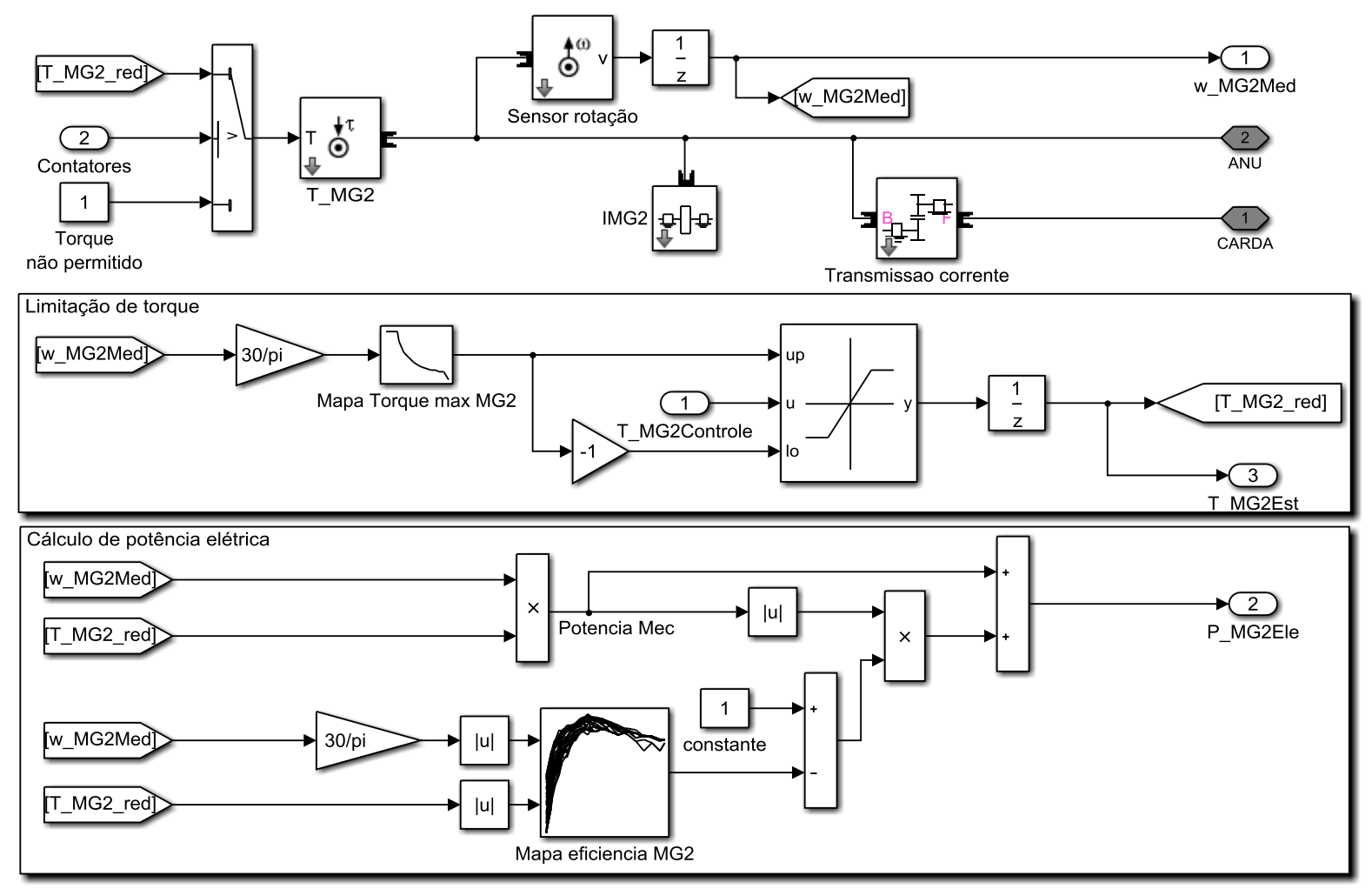

Figura 3.11 - Diagrama do modelo computacional do MG2.

\subsection{Modelo do piloto}

A simulação do sistema se baseia no veículo operando sob um determinado ciclo de condução. Tal ciclo se caracteriza por uma variação de velocidade em função do tempo que impõe certa demanda de tração ao veículo. Dentre os possíveis modos de simulação do problema, pode-se citar os seguintes:

- Modo implícito: a entrada do sistema é a velocidade do ciclo e a partir dela serão calculadas a aceleração do veículo e o torque requerido dos componentes;

- Modo explícito: a entrada do sistema é o torque fornecido pelos componentes e a aceleração e velocidade são resultados do cálculo. 
O modo explícito será usado nas simulações, pois condiz com a operação do sistema no mundo real. Devido ao modo de simulação ser explícito, é necessário um modelo de piloto que forneça o torque necessário para seguir o perfil de velocidade desejado do ciclo de condução. As entradas do modelo são a velocidade atual do veículo, $V(k)$, e a velocidade desejada, $V_{r e f}(k)$. A saída do modelo é a porcentagem do pedal de acelerador, a qual é convertida em demanda de torque de tração ou frenagem nas rodas através de um mapa. Um controlador proporcional-integral (PI) é então responsável por calcular a demanda de torque baseado no erro gerado pela velocidade atual em relação à velocidade desejada. A equação que representa o modelo do piloto é mostrada abaixo:

$T_{c, p}(k)=\left(V_{r e f}(k)-V(k)\right) \cdot K_{p, c}+K_{i, c} \cdot t_{s} \sum_{k=0}^{k}\left(V_{r e f}(k)-V(k)\right)+T_{a n t, p}(k)$

Onde $T_{c, p}$ é o torque de saída do controlador do piloto, $V_{\text {ref }}$ é a velocidade desejada, $K_{p}$ e $K_{i}$ são os ganhos proporcional e integral do controlador, respectivamente, $t_{s}$ é o passo de tempo da simulação, $k$ é o instante discreto atual e $N$ é o instante discreto final da simulação. O termo de antecipação do controlador, $T_{a n t}$, foi equacionado como a soma das resistências ao movimento, definida por:

$T_{a n t, p}(k)=\left(M \cdot r_{p}^{2}+I_{T R}\right) \cdot \dot{\omega}_{p}(k)+\left(0.5 \cdot C_{d} \cdot \rho_{a r} \cdot A \cdot V(k)^{2}+c_{R} \cdot M \cdot g\right) \cdot r_{p}$

Um algoritmo anti-windup também foi incorporado ao controlador PI tendo como objetivo limitar o termo integral caso o cálculo de $T_{a n t}$ ultrapasse a soma dos torques máximos provenientes do MCI e MG2.

A Figura 3.12 mostra o diagrama do modelo computacional do piloto composto pelos módulos de cálculo do controlador PI e da lógica de escolha de marchas. 


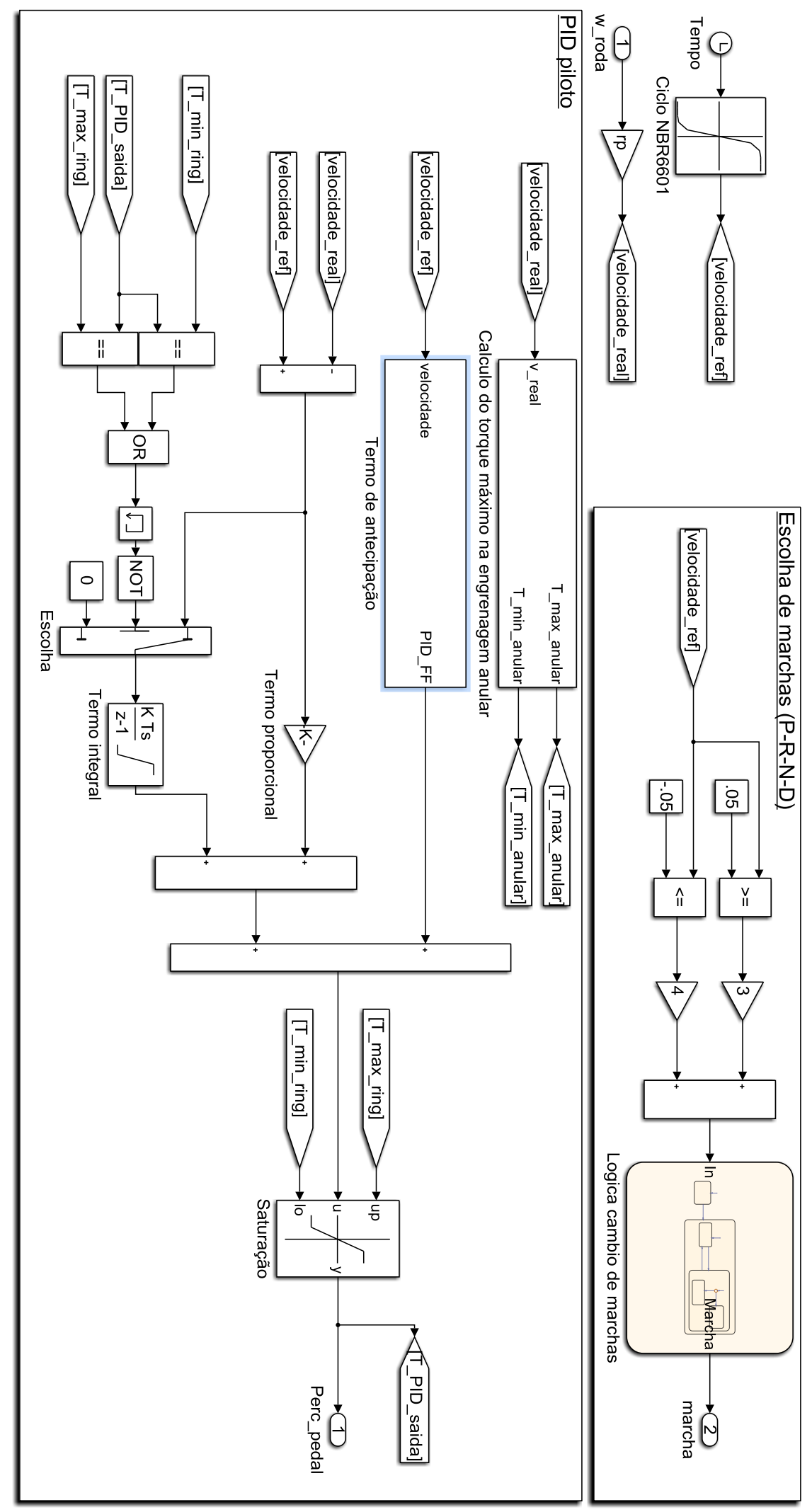

Figura 3.12 - Diagrama do modelo computacional do piloto. 


\subsection{Dinâmica veicular}

O modelo da dinâmica veicular implementado no modelo computacional é mostrado abaixo e corresponde à Eq. (3).

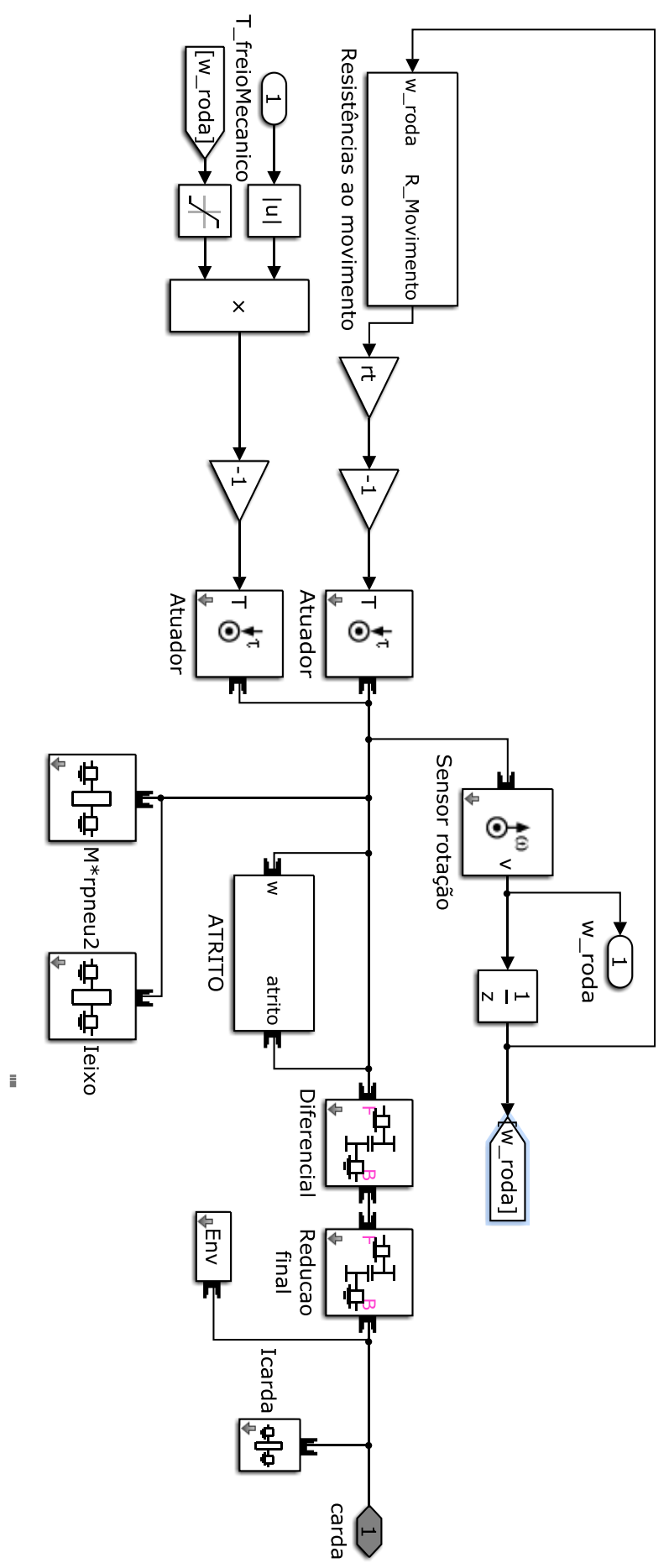

Figura 3.13 - Diagrama do modelo computacional da dinâmica veicular. 


\section{ESTRATÉGIA DE CONTROLE BASEADA EM REGRAS}

Este capítulo descreve o desenvolvimento da estratégia de controle que será usada para a simulação computacional com o modelo da planta do veículo em malha fechada. O objetivo deste capítulo foi elaborar estratégias que se aproximassem das usadas no veículo real em estudo e que possibilitassem a validação do modelo computacional frente a resultados experimentais.

A principal incógnita no sistema de controle do veículo híbrido é a razão de distribuição de torque no trem-de-força. Essa variável relaciona a fração da demanda de torque total que será fornecida pelo MCI com a fração que será fornecida pelo MG2. Considerando uma certa demanda de potência de tração nas rodas, $P_{d e m}$, esta deverá ser fornecida pelo MCI, MG1 e MG2 como mostrado na equação abaixo.

$$
P_{d e m}=P_{M G 2}+P_{M C I}+P_{M G 1}
$$

Onde $P_{M G 2}, P_{M C I}$ e $P_{M G 1}$ são as potências mecânica do MG2, MCI e MG1, respectivamente. A potência da bateria é calculada a partir da potência elétrica requerida por MG1 e MG2:

$$
P_{b a t}=P_{M G 2} \cdot \eta_{M G 2}{ }^{m}+P_{M G 1} \cdot \eta_{M G 1}{ }^{m}
$$

Onde $\eta_{M G 1}$ e $\eta_{M G 2}$ são as eficiências do MG1 e MG2, respectivamente, que incorporam também as eficiências dos seus inversores de frequência. $\mathrm{O}$ termo $\mathrm{m}$ é tal que $m=1$ equivale à descarga e $m=-1$ equivale à recarga da bateria. Combinando-se as equações (14) e (15) e, sendo a demanda de potência conhecida através do ciclo de condução, a potência da bateria torna-se uma função da potência do MCI. Como demonstrado anteriormente, a partir da COO do MCI, relaciona-se um valor único de torque ou potência do MCI para cada valor de sua 
rotação, portanto, pode-se escrever a potência da bateria como função do torque do MCI:

$$
P_{b a t}=f\left(T_{M C I}\right)
$$

Para uma determinada velocidade angular desejada do MCI, $\omega_{M C I, r e f}(k)$ e, consequentemente uma velocidade angular desejada para o MG1, $\omega_{M G 1, r e f}(k)$, o sistema de controle terá como saída o torque de atuação do MG1, $T_{M G 1}(k+1)$. O modelo matemático desenvolvido para atingir esse requerimento foi um controlador do tipo PI como descrito abaixo.

$$
\begin{aligned}
& T_{M G 1}(k+1)=\frac{T_{M C I}(k)}{i_{p}+1}+\frac{\left(\omega_{M G 1, r e f}(k)-\omega_{M G 1}(k)\right)}{\tau_{M G 1}} \cdot\left(I_{B P}+I_{S}+I_{M G 1}\right)+ \\
& +\left(\omega_{M G 1, r e f}(k)-\omega_{M G 1}(k)\right) \cdot K_{p, M G 1}+K_{i, M G 1} \cdot \sum_{k=0}^{k}\left(\omega_{M G 1, r e f}(k)-\omega_{M G 1}(k)\right)
\end{aligned}
$$

Onde as restrições do sistema correspondem a:

$$
\begin{aligned}
& \frac{\omega_{M G 1, r e f}-\omega_{M G 1}}{\tau_{M G 1}} \in[-1000,1000] \\
& T_{M G 1} \in\left[-\mathrm{T}_{M G 1, \max }, \mathrm{T}_{\mathrm{MGl}, \max }\right]
\end{aligned}
$$

Onde $I_{B P}, I_{S}$ e $I_{M G 1}$ são o momento de inércia do braço planetário, engrenagem solar e MG1, respectivamente, $K_{p, M G 1}$ e $K_{i, M G 1}$ são, respectivamente, os ganhos proporcional e integral e $\tau_{M G 1}$ é uma constante de tempo. Os primeiros dois termos do lado direito da Eq. (17) correspondem ao termo de antecipação do controlador e equivalem-se ao torque do MCI transferido através da engrenagem solar e ao torque resistivo gerado pelas inércias no sistema. As equações (18) e (19) representam as limitações do controlador, sendo que $T_{M G I \text {,max }}$ é o torque máximo do MG1. Esse controlador também possui limitação anti-windup assim como no modelo do piloto. 
Kim et al. (2012) realizaram testes com o veículo em estudo para caracterizar o comportamento da demanda de potência da bateria em função do seu estado-decarga (SOC). O resultado é mostrado na Figura 4.1, onde, por volta de 60\% SOC, a potência desejada da bateria é zero, ou seja, o controlador não objetiva descarga ou recarga da bateria. Caso a bateria esteja mais carregada do que $60 \%$ SOC, a sua demanda de potência é positiva, ou seja, ela objetiva ser descarregada para retornar ao valor de SOC em 60\%. O mesmo raciocínio é válido se a bateria estiver com menos de 60\% SOC. Tal comportamento foi incluído no sistema de controle através de um mapa.

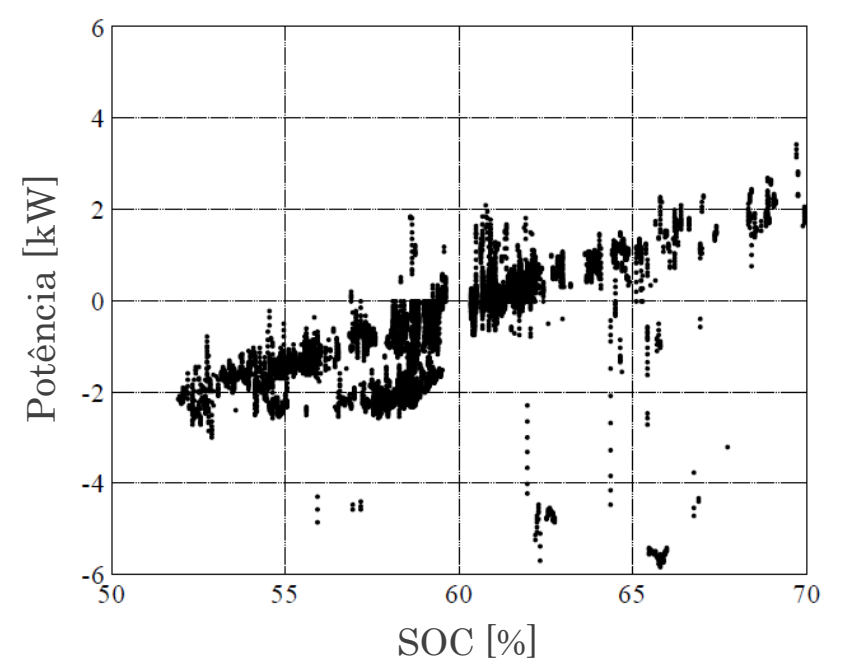

Figura 4.1 - Potência da bateria em função do seu estado de carga (KIM; ROUSSEAU e RASK, 2012).

Durante a operação no ciclo, a propulsão do veículo será puramente elétrica até que a demanda de potência nas rodas atinja um certo limiar, momento em que o MCI será ligado. Dados experimentais apresentados na Figura 4.2 a) obtidos por Argonne National Laboratory (2013) com o veículo adotado, mostram a demanda de potência nas rodas no instante em que o MCI é ligado. A Figura 4.2 b) corresponde à curva de distribuição normal dos pontos da Figura 4.2 a), onde é possível inferir que a maior probabilidade do MCI ser ligado é entre $8 \mathrm{~kW}$ e $9 \mathrm{~kW}$. 


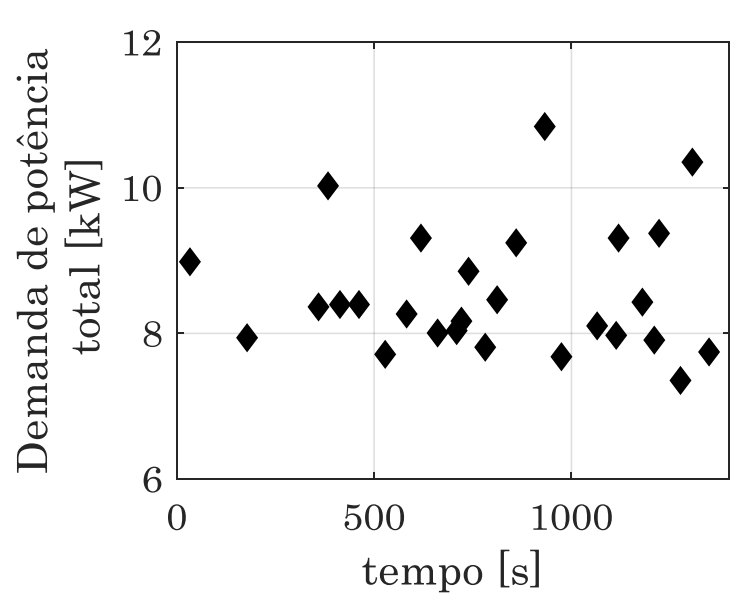

a) Demanda de potência acima da qual o MCI é ligado.

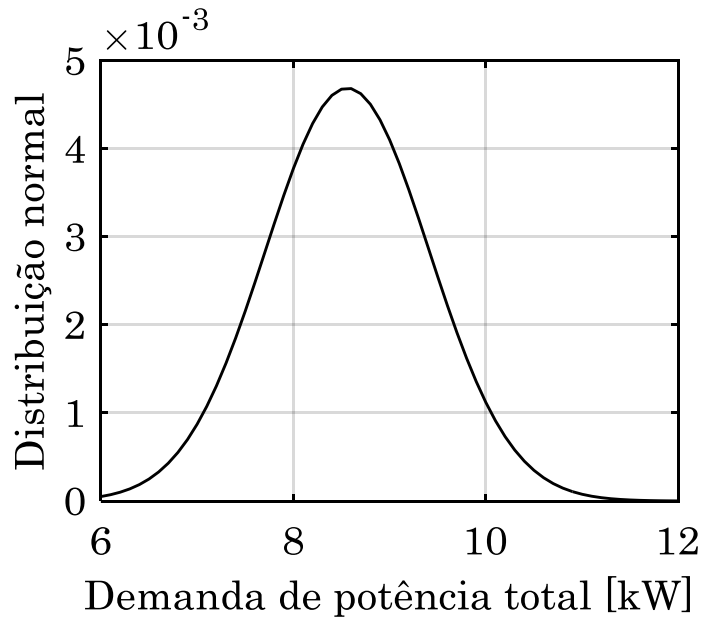

b) Probabilidade da potência nas rodas para quando o MCI é ligado.

Figura 4.2 - Resultados experimentais obtidos por Argonne National Laboratory (2013) para a potência trativa acima da qual o MCI é ligado.

O modelo computacional desenvolvido no programa Matlab/Simulink a partir da modelagem acima é mostrado na Figura 4.3. Do lado esquerdo do diagrama são mostrados os subsistemas de controle e do lado direito os subsistemas dos componentes. Os diagramas dos sub-módulos do sistema de controle são mostrados no APÊNDICE B. 


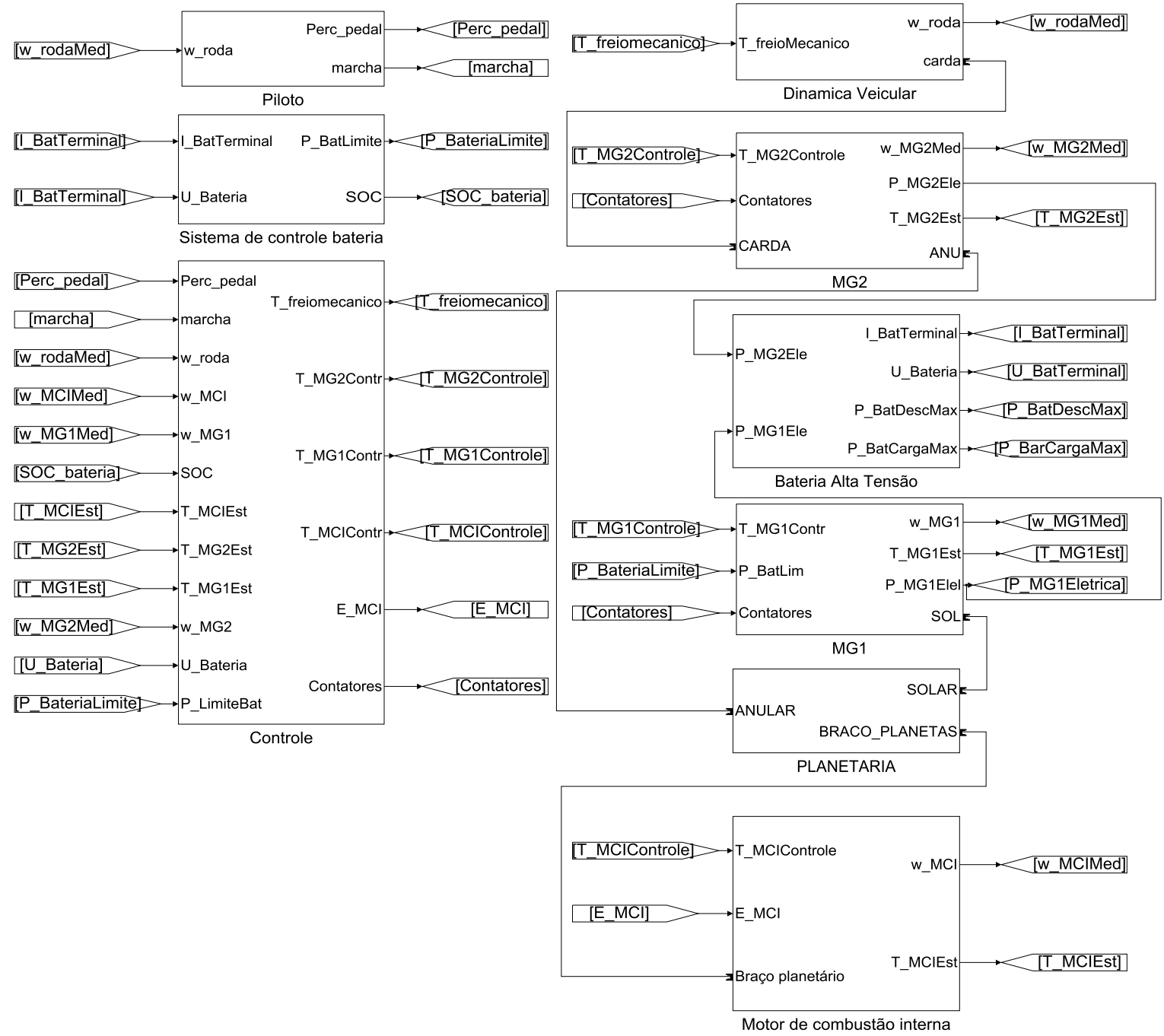

Figura 4.3 - Nível superior do modelo computacional do veículo em Matlab/Simulink. 


\section{VALIDAÇÃO DO MODELO}

Este capítulo apresenta a validação da simulação em malha fechada do modelo de controle e planta do veículo. O objetivo final da validação foi conseguir um modelo computacional em que a estimativa de consumo de combustível apresentasse um desvio de $\pm 5 \%$ em comparação com os dados de testes.

Os dados usados para validação são provenientes de Argonne National Laboratory (2013), que conduziu testes com o veículo Toyota Prius em dinamômetro de chassis. O experimento foi conduzido sob o ciclo de condução urbano especificado na norma brasileira NBR 6601, que regulamenta a medição de emissões em veículos automotores leves. Detalhes desse ciclo são mostrados no APÊNDICE C. Os dados medidos foram sinais provenientes da rede CAN do veículo e do sistema de controle do dinamômetro.

A simulação foi conduzida usando o programa Matlab/Simulink. O passo de tempo usado foi $0,01 \mathrm{~s}$ e o método de solução de equações diferenciais ordinárias foi Dormand-Prince (RK5).

A demanda de torque proveniente do ciclo de condução é o parâmetro de entrada da simulação e deve estar correta antes da validação do modelo. Por isso, o primeiro módulo a ser validado foi o modelo do piloto. A Figura 5.1 mostra os gráficos da velocidade real e desejada do veículo, juntamente com o erro do controlador PID. A norma NBR 6601 define que o erro da velocidade a ser seguida deve ser de no máximo $1 \mathrm{~km} / \mathrm{h}$. O erro máximo do controlador PI do modelo do piloto resultante está no intervalo $(-0,4,0,4)$. 

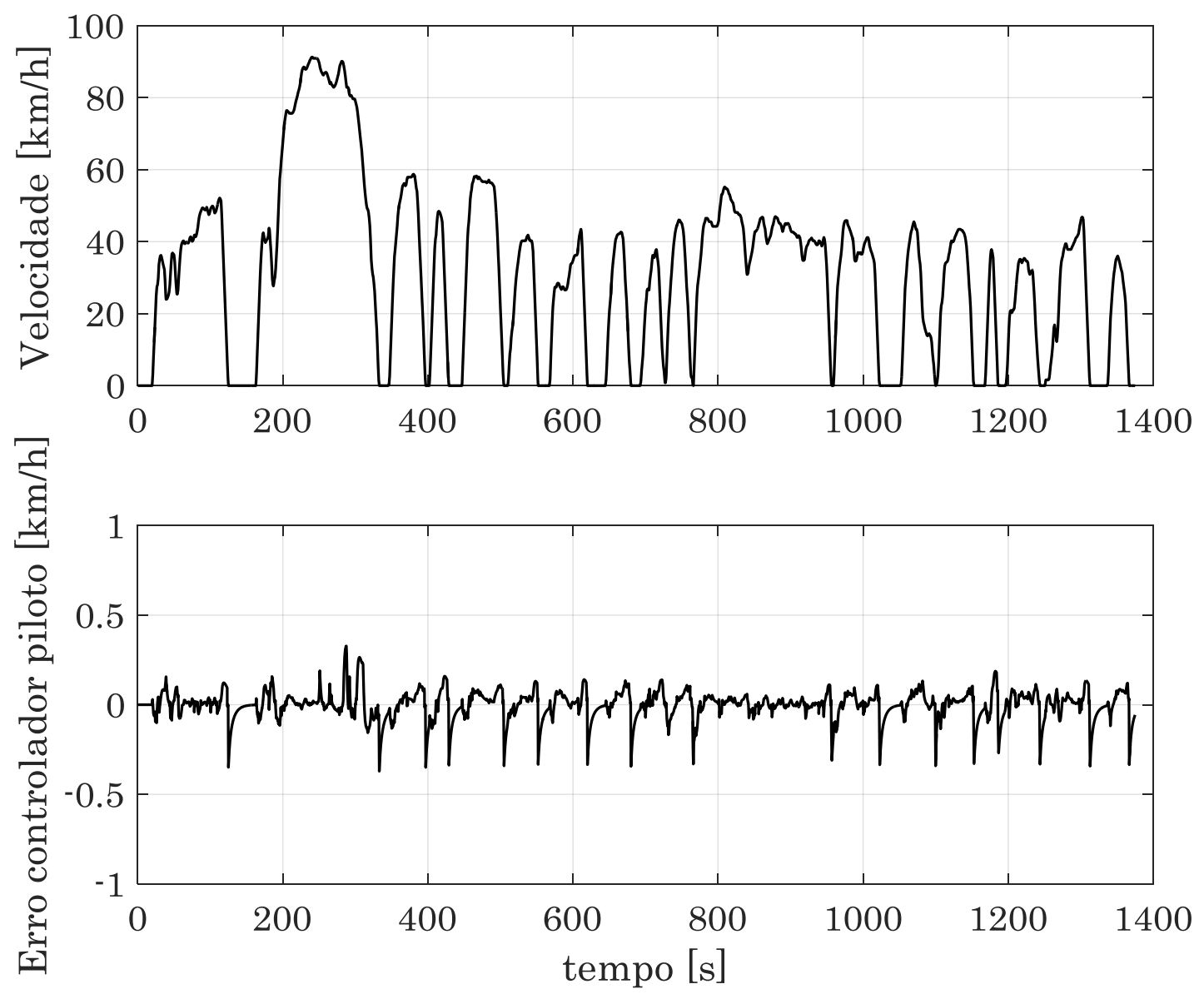

Figura 5.1 - Velocidade do veículo (acima) e erro do controlador do piloto (abaixo) para a simulação do modelo não-ótimo.

Na Figura 5.2, é mostrado o resultado da simulação e dos testes para a rotação do MCI. Enquanto que na simulação o MCI apresenta estratégia liga-desliga no início do ciclo ( 0 a 180s), os dados de teste mostram que ele permanece ligado nesse período. O MCI no veículo real possui estratégia para aquecimento do sistema de escape no início do teste como parte da estratégia de emissões, fenômeno que não está presente no modelo do MCI. O segundo gráfico da Figura 5.2 foca em uma determinada seção do ciclo de condução. Embora existam pontos onde há um desvio entre a rotação do MCI medida e simulada de 500rpm, é possível observar que, em geral, a simulação atinge uma boa reprodução da dinâmica do MCI. 


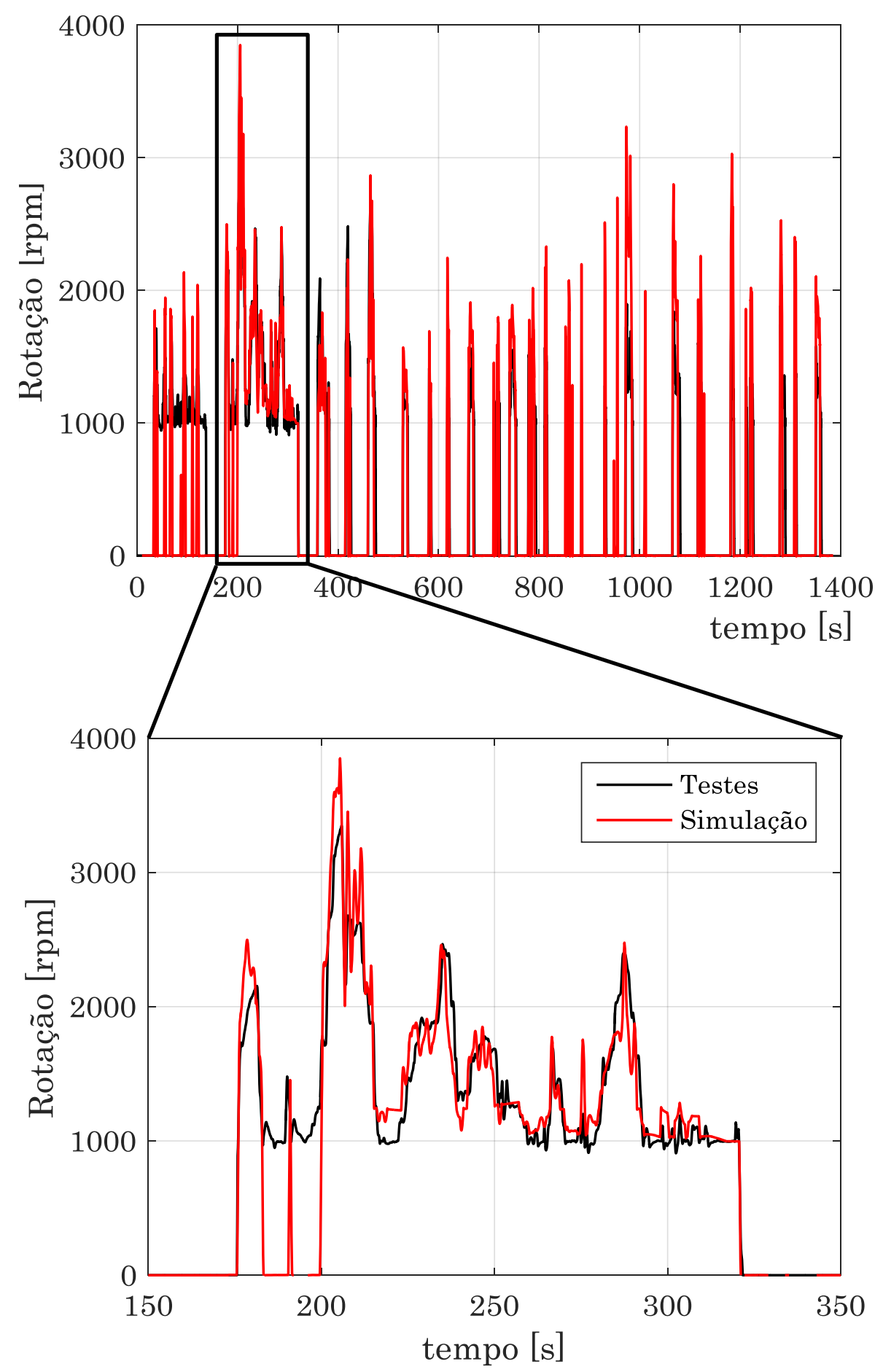

Figura 5.2 - Comparação da rotação do MCI para simulação do modelo não-ótimo com a rotação obtida nos testes efetuados por Argonne National Laboratory (2013).

A Figura 5.3 mostra o resultado para a corrente elétrica na bateria para o mesmo espaço de visualização da figura acima. Novamente, pode-se observar boa aderência geral da simulação com os dados de testes. A corrente elétrica na 
bateria é diretamente proporcional à potência da bateria e, por isso, o gráfico abaixo é uma boa representação da aderência da razão de distribuição de torque da simulação com o veículo real.

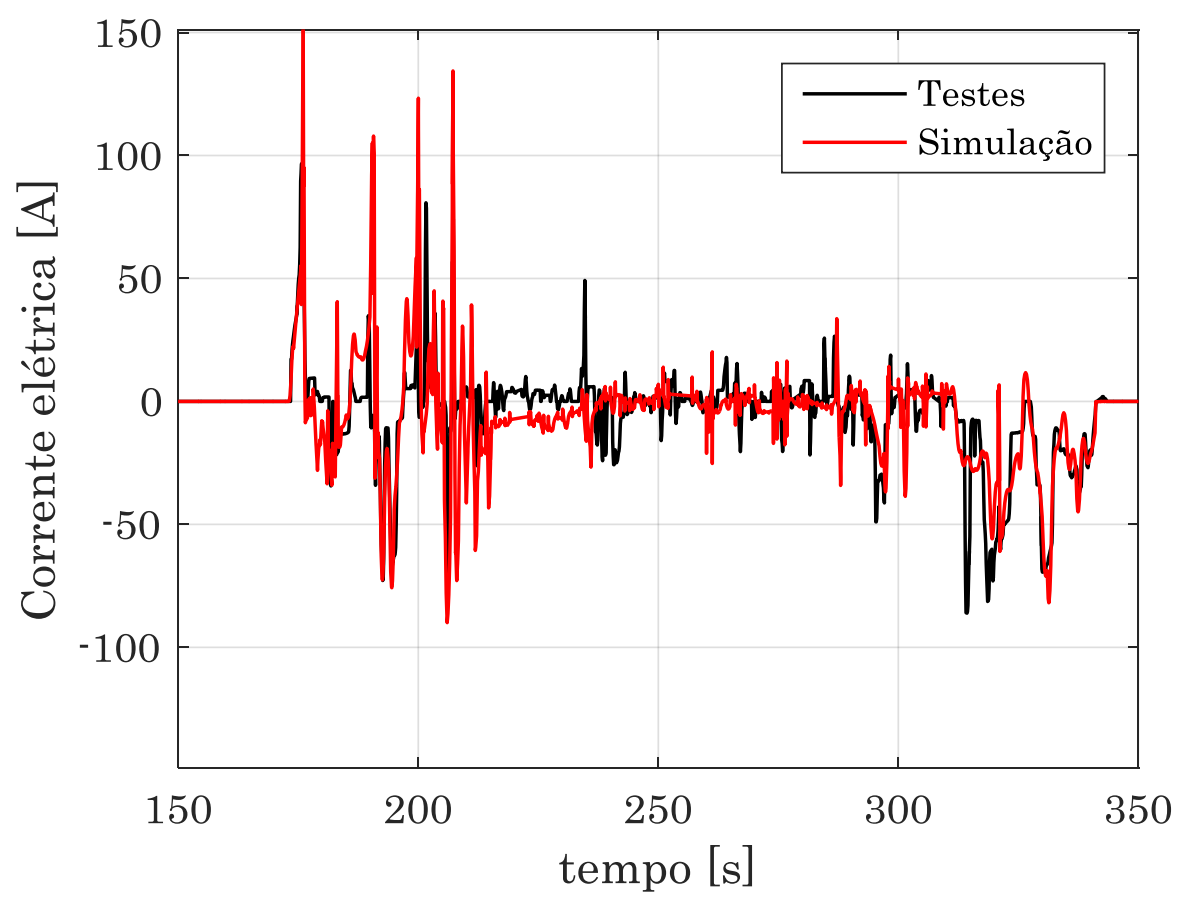

Figura 5.3 - Comparação da corrente elétrica da bateria para simulação do modelo não-ótimo com a corrente elétrica obtida nos testes efetuados por Argonne National Laboratory (2013).

A Figura 5.4 mostra o gráfico do SOC da bateria em função do tempo. O SOC inicial nos testes foi de 59.2\% enquanto que na simulação foi de 60\%. O SOC da bateria no fim do ciclo não deve apresentar grande variação em relação ao SOC no início do ciclo para que o consumo de combustível não seja influenciado pela energia elétrica consumida. A variação do SOC nos dados experimentais e na simulação foi de $-1,5 \%$ e $-2,3 \%$, respectivamente. Essa diferença foi considerada pequena e não foi efetuada nenhuma correção posterior no valor do consumo de combustível. 

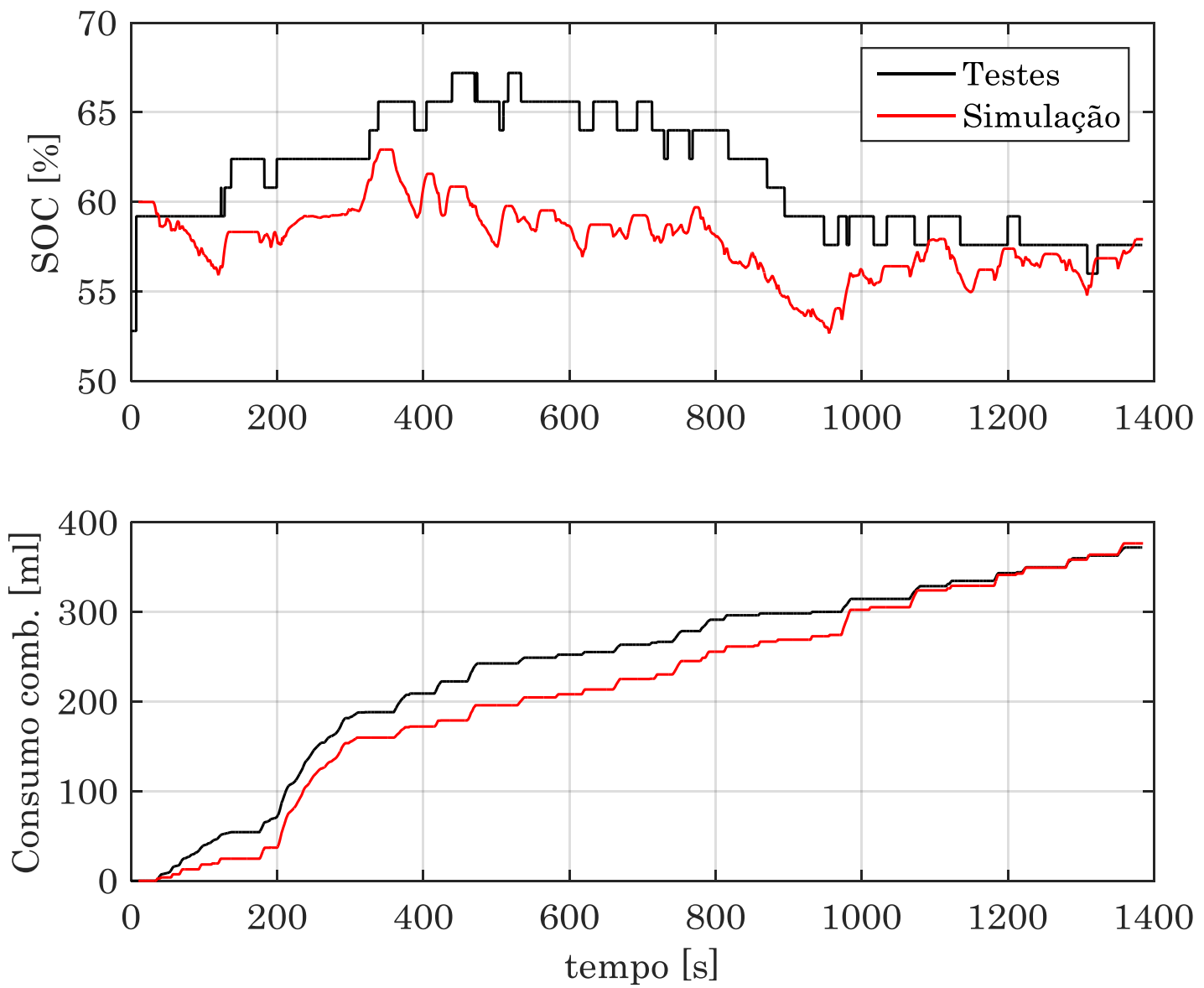

Figura 5.4 - Comparação do estado de carga (SOC) da bateria (acima) e do consumo de combustível (abaixo) para simulação do modelo não-ótimo com os resultados de testes efetuados por Argonne National Laboratory (2013).

O consumo de combustível resultante da simulação foi de 0,377 l, valor esse 1,2\% maior que o consumo de combustível nos testes, que foi de $0,373 \mathrm{l}$, como mostrado naTabela 5.1, juntamente com a variação do SOC da bateria.

Tabela 5.1 - Resultados comparativos da simulação de validação.

\begin{tabular}{lcc}
\hline Parametros & Testes & Simulação \\
\hline \hline Variação SOC [\%] & $-1,50$ & $-2,30$ \\
Consumo de combustível [1] & 0,372 & 0,377 \\
Consumo por quilometro [1/100km] & 3,13 & 3,14 \\
Desvio do consumo de combustível [\%] & - & 1,2 \\
\hline
\end{tabular}

A partir das comparações obtidas acima, pode-se inferir que o modelo do veículo e de controle foram adequados para modelar a dinâmica do sistema e o consumo de 
combustível. Demais resultados para a simulação do modelo computacional descrita neste capítulo são mostrados no APÊNDICE D. Os resultados da validação do modelo criam uma base para efetuar a modelagem da estratégia de controle ótimo global, como será mostrado no capítulo seguinte. 


\section{OTIMIZAÇÃO GLOBAL DO CONSUMO DE COMBUSTÍVEL USANDO PROGRAMAÇÃO DINÂMICA}

Partindo dos resultados do Capítulo 5, foi possível obter boa correlação para o consumo de combustível em comparação com resultados de testes. O controlador implementado utilizou lógicas determinísticas, o que resulta em um consumo de combustível acima do mínimo global possível para o sistema. O objetivo deste capítulo é aplicar um controlador ótimo que encontre o mínimo global do consumo de combustível. Para isso será usada uma rotina de programação dinâmica (PD) como descrito adiante.

Para definir a formulação do problema da otimização global, tem-se um sistema dinâmico contínuo no tempo descrito pelas seguintes equações:

$$
\begin{aligned}
& \dot{x}(t)=f(x(t), u(t), t) \\
& x(0)=x_{0} \\
& x(T) \in \mathrm{X}_{t} \\
& u(t) \in U_{t} \\
& 0 \leq t \leq T
\end{aligned}
$$

Onde $x(t)$ é a variável de estado e carrega informações do passado do sistema para serem usada nos instantes futuros de otimização, $u(t)$ é a variável de controle e representa a decisão a ser tomada no instante $t$ e $T$ é o tempo final do problema.

De acordo com Bertsekas (2005) e Neto (2012), o problema da otimização global consiste em encontrar uma trajetória ótima , $u *(t)$, da variável de controle e a correspondente trajetória, $x^{*}(t)$, da variável de estado. Tais soluções deverão otimizar uma função custo, $J$, definida pela seguinte equação: 
$J=G(x(T))+\int_{0}^{T} H(x(t), u(t), t) d t$

Onde $H$ representa o custo instantâneo no intervalo $t \in[0, T]$ e $G$, o custo final, ou seja, um termo que penaliza a função custo no tempo final $t=T$.

Supondo que o problema de otimização tenha início nos pontos $t=t_{0}$ e $x=x\left(t_{0}\right)$, o princípio de otimalidade estabelece que, se $x^{*}(t)$ é a solução ótima obtida usando o controle $u^{*}(t)$ a partir de $\left(t_{0}, x\left(t_{0}\right)\right)$, o mesmo problema usando um ponto de partida diferente, digamos $t_{i}, x\left(t_{i}\right)$ com $i \in[0, T]$, terá como solução a mesma trajetória $x^{*}(t)$ associado a $u^{*}(t)$. Em outras palavras, os estados antecedentes a $t_{i}$ não influenciam na solução ótima na sua frente. O principio de otimalidade é construído em intervalos de tempo, sendo que a combinação da solução ótima de cada intervalo resulta na solução ótima em todo o espaço de tempo. Dessa forma, Neto (2012) mostra que a trajetória $x^{*}(t)$ correspondente a $u^{*}(t)$ que otimiza $J$ equivale a:

$$
\begin{aligned}
& \vee(x(0), 0)=G(x *(T))+\int_{0}^{T} H(x *(t), u *(t), t) d t \\
& x *(0)=x(0)
\end{aligned}
$$

A função $\vee(x(0), 0)$ é chamada de função retorno e representa o custo acumulado a frente do tempo $t=0$.

Para a resolução do problema de otimização, será usada uma rotina de programação dinâmica. Essa rotina foi desenvolvida por Sundström (2009) e é disponibilizada publicamente pela universidade ETH Zurique. Como mencionado anteriormente, a programação dinâmica necessita do conhecimento da rota em avançado e, por isso, opera no modo implícito, recebendo como entrada a velocidade e aceleração no ciclo de condução. A Eq. (26) é então resolvida recuando no tempo, começando pelo instante $k=N$ e retrocedendo em direção ao instante $k=0$. 
Para solução do problema, as variáveis de estado, $x$, e controle, $u$, são subdivididas em espaços discretos. Sejam $N_{x}$ o número de estados discretos, $N_{u}$ o número de decisões de controle para cada estado e $N_{k}$ o número de passos de tempo discretos no problema, para o cálculo da solução que minimiza a função custo, a programação dinâmica calcula uma matriz $N_{x} \times N_{u} \times N_{k}$ com as trajetórias possíveis resultantes da combinação de $x_{k} \in\left\{x_{1}, x_{2}, \ldots, x_{N x}\right\}$ e $u_{k} \in\left\{u_{1}, u_{2}, \ldots, u_{N u}\right\}$ ao longo do espaço de tempo discreto $k \in\left\{k_{1}, k_{2}, \ldots, u_{N k}\right\}$. A trajetória que minimiza a função custo é então a solução da rotina de programação dinâmica.

A Figura 6.1 é um exemplo de resultado do cálculo efetuado pela rotina de programação dinâmica. A figura mostra o custo ótimo total associado à um estado $x_{k}$ para se alcançar o instante final $N$. Dessa forma, movendo na direção de $k=0$, o custo aumentará gradativamente. Uma decisão de controle em um instante $k$ resultará em um novo estado no instante seguinte, $k+1$, e o custo instantâneo para se mover a partir desse estado é então subtraído do custo ótimo total. Como exemplo, partindo-se do instante $k=4$, o custo mínimo associado ao presente estado é 1,69 . O custo instantâneo para mover até o estado seguinte é então $1,69-1,15=0,54$, de forma que o novo custo mínimo para se mover até o final do ciclo a partir de $k=5$ é 1,15. Esse exemplo expressa o princípio de otimalidade, onde o custo mínimo para o caminho $\mathrm{A}$ até $\mathrm{C}$ é a soma dos custos mínimos de $\mathrm{A}$ até $\mathrm{B}$ e $\mathrm{B}$ até $\mathrm{C}$. 


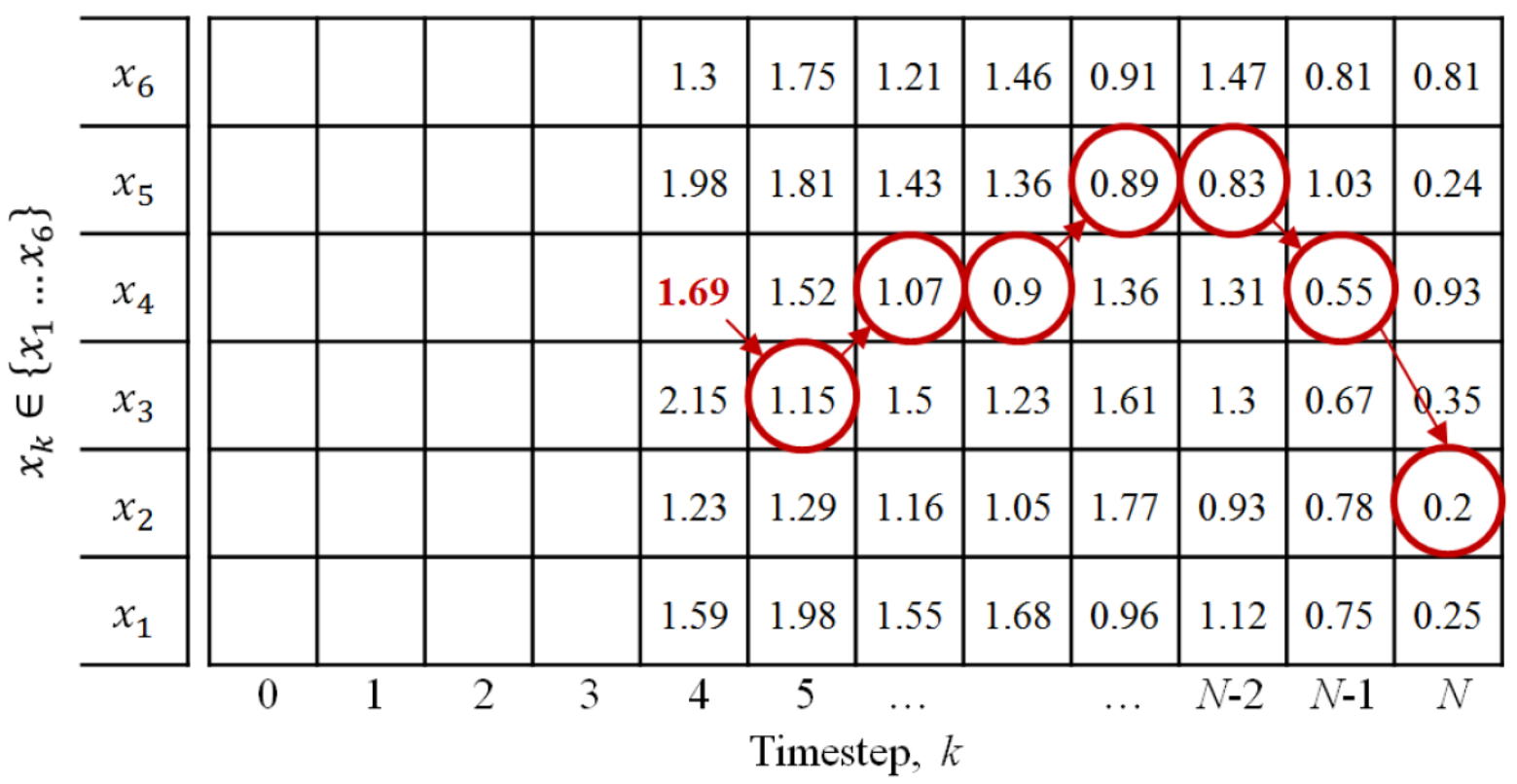

Figura 6.1 - Exemplo de tabela contendo valores ótimos da função custo da programação dinâmica para cada valor da variável de estado e instante de tempo. (VAGG, 2014).

\subsection{Programação dinâmica aplicada ao sistema híbrido}

O objetivo do controle ótimo é determinar a distribuição de torque proveniente do motor de combustão e dos motores elétricos que resulte no mínimo consumo de combustível respeitando as restrições do sistema. A função custo escolhida para o problema do sistema híbrido é o consumo de combustível, resultante do torque e rotação do MCI ao longo do ciclo. A otimização global aplicada ao sistema híbrido pode ser descrita pela seguinte equação:

$J^{*}=\min \sum_{k=0}^{N-1} \dot{m}_{c o m b}\left(P_{b a t}(k)\right)$

Deve-se considerar ainda as restrições das variáveis de estado e controle:

$$
\begin{aligned}
& \omega_{M C I, \text { min }}<\omega_{M C I}(k)<\omega_{M C I, \text { max }} \\
& S O C_{\min }<S O C(k)<S O C_{\max } \\
& S O C_{\text {final,min }}<S O C(N)<S O C_{\text {final,max }} \\
& T_{M C I, \text { min }}<T_{M C I}(k)<T_{M C I, \text { max }}
\end{aligned}
$$


No caso do sistema híbrido, a variável de controle é a razão de distribuição de torque, definida por $r_{\text {torque }}=\frac{T_{M G 2}}{T_{M G 2}+T_{M C I}}$. A aplicação de um determinado comando de torque nos motores elétricos e no MCI em um passo de tempo $k$ resultará em uma variação do SOC da bateria no instante seguinte $k+1$, dessa forma, o SOC representará então a variável de estado do sistema. Abaixo é mostrado como a razão de distribuição de torque se relaciona com o torque do MCI e MG2.

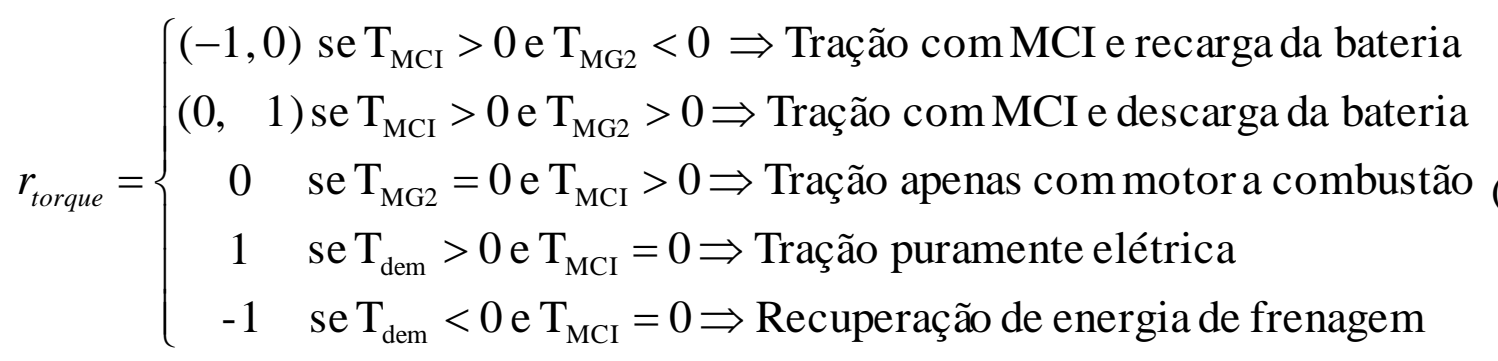

O SOC é descrito como a razão entre a carga instantânea da bateria e a sua carga máxima. A variação do SOC está relacionada com a corrente elétrica da bateria da seguinte forma:

$$
S O C=\frac{I}{C}
$$

Onde SOC é a derivada do estado de carga da bateria. A potência da bateria é definida por um termo dependente da tensão em circuito aberto e outro termo resultante das perdas na resistência interna:

$$
P_{b a t}=V_{C A} \cdot I-I^{2} R_{i}
$$

A convenção para a equação acima é que a potência é positiva quando a bateria é descarregada e negativa quando carregada. Substituindo o valor de $P_{b a t}$ da Eq. (15) na solução da Eq. (35) para I, resulta em:

$$
\dot{S O C}=-\frac{1}{C} \frac{V_{C A}-\sqrt{V_{C A}{ }^{2}-4 R_{i} \cdot\left(T_{M G 2} \cdot \omega_{M G 2} \cdot \eta_{M G 2}{ }^{m}+T_{M G 1} \cdot \omega_{M G 1} \cdot \eta_{M G 1}{ }^{m}\right)}}{2 R_{i}}
$$


A equação acima relaciona a variável de estado, SOC, com a demanda de potência da bateria e representa a dinâmica resultante do estado a partir de uma entrada de controle.

Ao usar a linha de operação ótima do MCI, o sistema possui apenas 1 variável independente. Dessa forma, sabendo-se que $P_{b a t}=f\left(T_{M C I}\right) \quad(\mathrm{Eq} . \quad 16) \quad$ e $\dot{m}_{c o m b}=h\left(\omega_{M C I}\right)$, pode-se relacionar a vazão de combustível em função da potência da bateria como na equação abaixo.

$\dot{m}_{\text {comb }}(k)=f\left(P_{b a t}(k)\right)$

A equação acima mostra que o custo do problema pode ser descrito como função da potência da bateria. Substituindo a equação acima na Eq. (28), a solução da otimização é função da variável de estado e da variável de controle $P_{b a t}$ :

$$
J^{*}=\min \sum_{k=0}^{N-1} \dot{m}_{c o m b}\left(\operatorname{SOC}(k), P_{b a t}(k)\right)
$$

\subsubsection{Considerações sobre a adaptação computacional}

A programação dinâmica exige alta capacidade computacional devido ao grande número de pontos calculados para resultar na matriz de solução. O modelo com controle baseado em regras apresentado no Capítulo 3 leva 80 s para simulação, o que acarretaria em um tempo demasiadamente alto de processamento se fosse usado para a programação dinâmica devido ao alto número de iterações. Por isso, foi necessário criar um novo modelo computacional simplificado do veículo e que pudesse ser simulado com baixo custo computacional. Esse modelo simplificado utiliza a mesma modelagem matemática apresentada no Caítulo 3, no entanto, a modelagem computacional foi implementada em forma de linhas de comando de modo a diminuir o tempo de processamento. Dessa forma, deve haver cuidado ao comparar os resultados obtidos pela programação dinâmica com resultados utilizando o modelo com controle baseado em regras. 
$\mathrm{Na}$ rotina de programação dinâmica, foram investigados dois casos para calcular o controle ótimo. No primeiro, a razão de distribuição de torque é a única variável de controle e será otimizada sempre que o MCI estiver ligado. O instante em que o MCI entra em operação é um dado de entrada da rotina e foi fixado em $8 \mathrm{~kW}$, como obtido a partir da Figura 4.2. Após a determinação da razão de distribuição de torque, o ponto de operação do MCI estará localizado na COO (Figura 3.5).

Já no segundo caso, além de determinar a razão de distribuição de torque, a programação dinâmica também otimizará o instante em que o MCI entra em operação. Um vez em funcionamento, o ponto de operação do MCI não estará mais na COO, mas será também determinado pela programação dinâmica. $\mathrm{O}$ objetivo dos 2 casos distintos é avaliar a influência da escolha do instante de operação do MCI e da sua região de operação no consumo de combustível final.

A Tabela 6.1 mostra a configuração dos parâmetros em cada caso.

Tabela 6.1 - Parâmetros dos dois casos da programação dinâmica.

\begin{tabular}{lcc}
\hline Variável & Caso 1 & Caso 2 \\
\hline \hline Razão de distribuição de torque & Otimizado & Otimizado \\
\hline Instante em que o MCI é ligado & $\begin{array}{c}\text { Fixo em 8kW } \\
\text { (Figura 4.2) }\end{array}$ & Otimizado \\
\hline Região de operação do MCI & $\begin{array}{c}\text { Contido na COO } \\
\text { (Figura 3.5) }\end{array}$ & Otimizado \\
\hline
\end{tabular}

\subsection{Resultados da programação dinâmica - Caso 1}

A Figura 6.2 mostra a trajetória da variável de estado, SOC, resultante da caso 1. O gráfico de contorno na mesma figura contém os valores da variável de controle $r_{\text {torque }}$ para cada valor de SOC, onde as cores e modos de operação na legenda são os mesmos especificados na Eq. (33). O valor da solução de controle encontrada pela programação dinâmica corresponde aos pontos onde o gráfico de contorno intercepta o gráfico do SOC. 


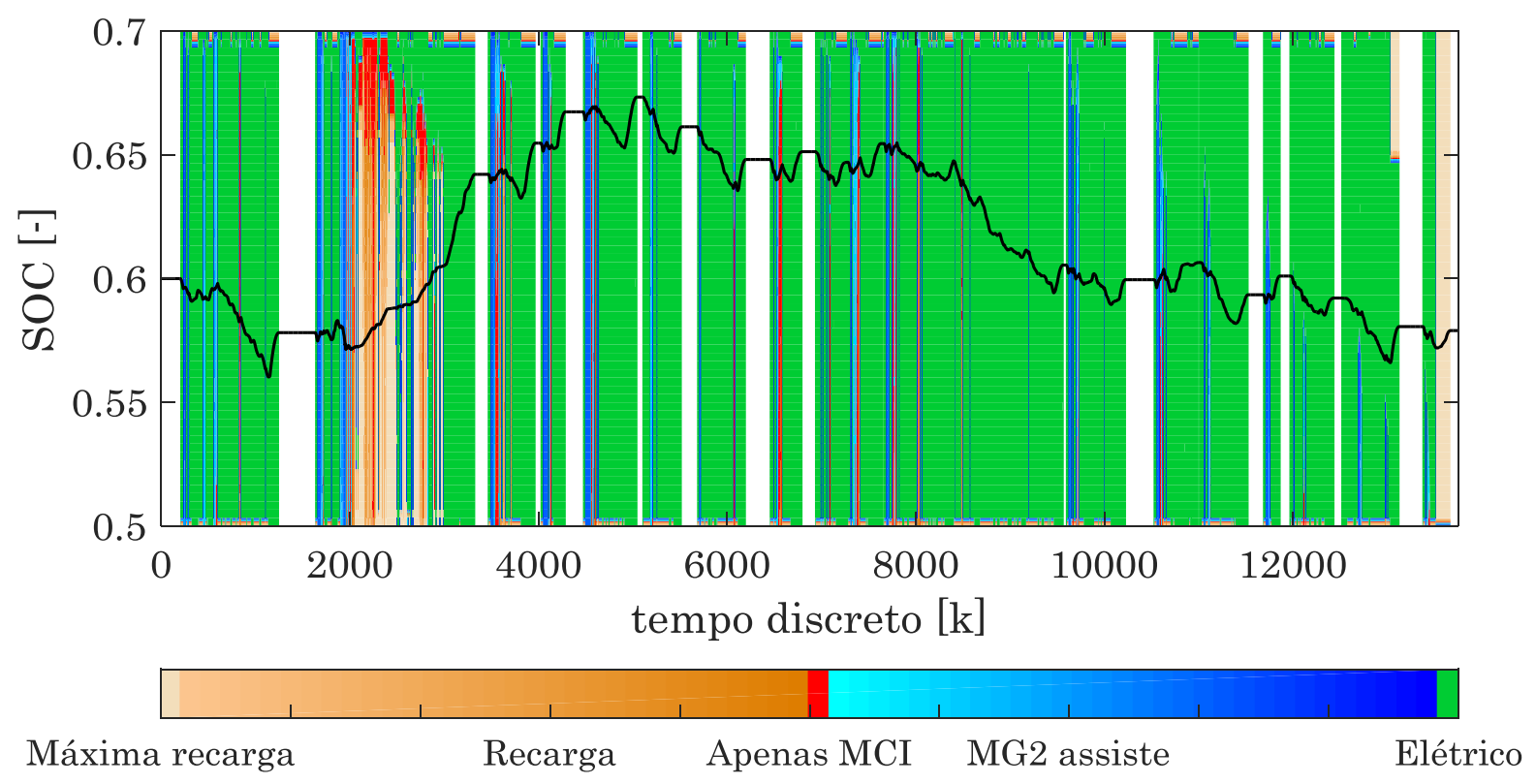

Figura 6.2 - Resultado do caso 1 para o SOC da bateria. O gráfico de contorno mostra todas as soluções de controle ótimo possíveis resultantes da otimização global.

A Figura 6.3 mostra o comportamento da variável de controle em função da velocidade do veículo e da demanda total de potência nas rodas. No primeiro gráfico, é possível identificar 3 modos de operação:

- Elétrico $\left(r_{\text {torque }}=1\right)$, correspondente à potências de $0 \mathrm{~kW}$ a $8 \mathrm{~kW}$;

- Recarga $\left(r_{\text {torque }}<0\right)$ : ocorre para valores baixos de potência entre $8 \mathrm{~kW}$ e 20kW. Nesses pontos, devido à demanda de potência total ser baixa, a programação dinâmica procura aumentar a potência fornecida pelo MCI para que este opere em regiões de melhor eficiência e possa carregar a bateria.

- Assistência com MG2 $\left(r_{\text {torque }} \in(0,1)\right)$ : para valores mais altos de potência, a programação dinâmica decide que o motor elétrico assista na propulsão, possibilitando com que o MCI não opere em altas rotações, onde sua eficiência diminui devido ao aumento do atrito e das perdas de bombeamento. 


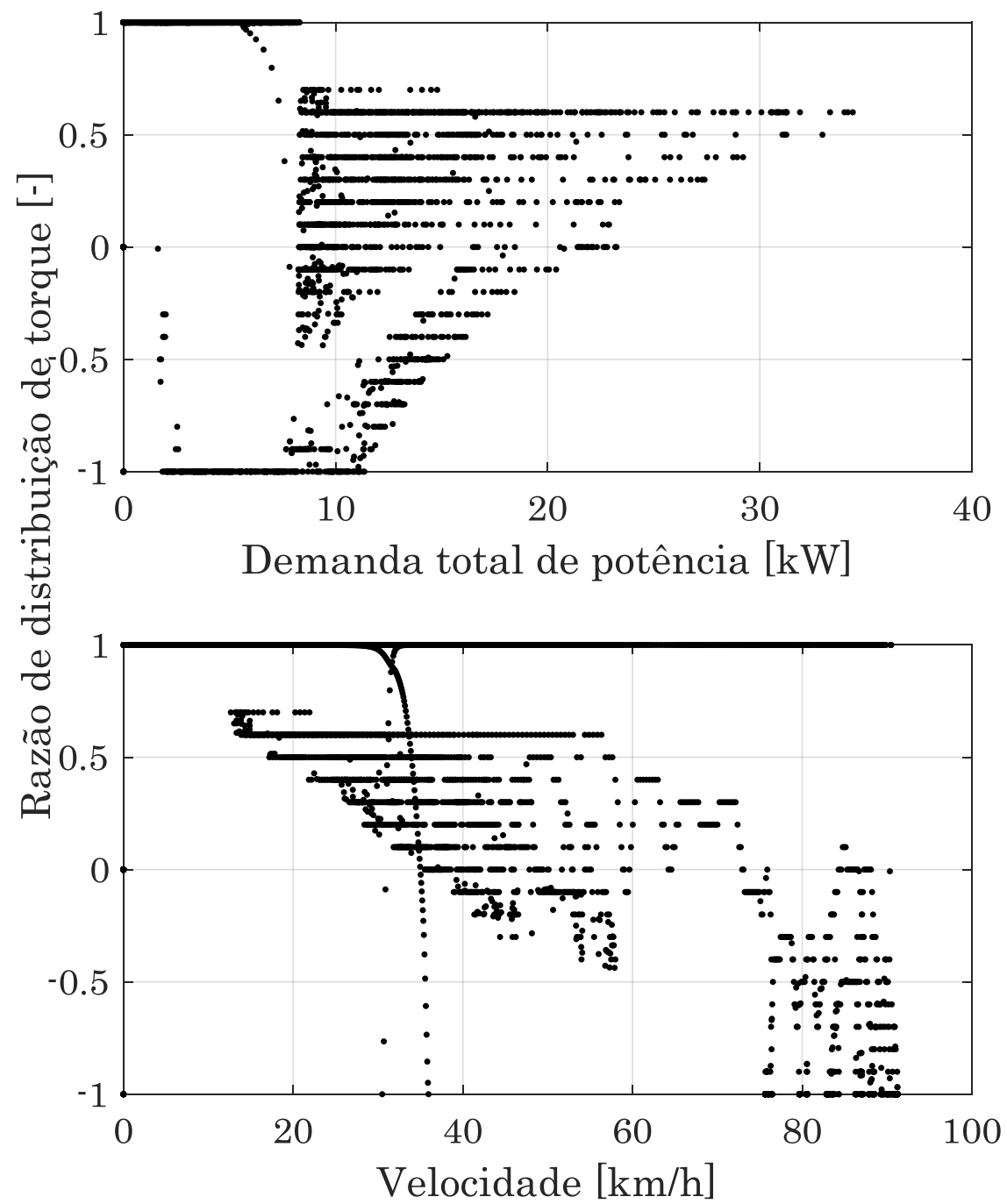

Figura 6.3 - Razão de distribuição de torque em função da demanda de potência (acima) e velocidade (abaixo) para a caso 1 da programação dinâmica.

A Figura 6.4 mostra o consumo de combustível acumulado durante o ciclo de condução. O consumo final foi de 0,3411 , o que mostra um potencial de redução do consumo de combustível do sistema de 9,5\% em relação ao modelo com controle não ótimo. 


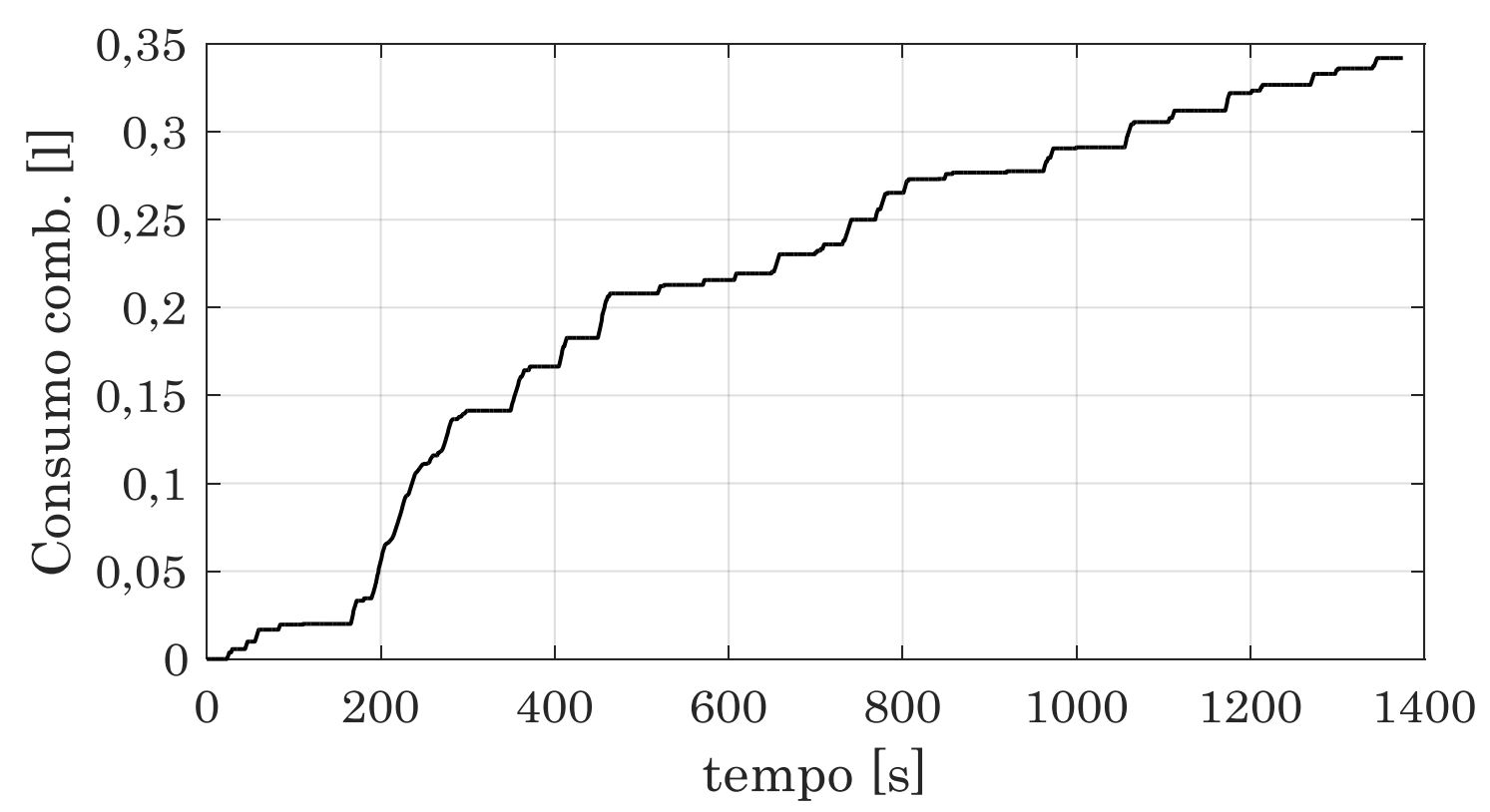

Figura 6.4 - Consumo de combustível acumulado resultante do caso 1 da programação dinâmica.

A Tabela 6.2 apresenta os resultados gerais do primeiro caso da programação dinâmica. Outros resultados são mostrados no APÊNDICE E.

Tabela 6.2 - Resultados do caso 1 da programação dinâmica.

\begin{tabular}{lc}
\hline Parâmetro & PD Caso 1 \\
\hline \hline Variável de estado & SOC \\
Variável de controle & $r_{\text {torque }}$ \\
Variação de SOC [\%] & $-1,5 \%$ \\
Consumo de combustível [1] & 0,341 \\
Consumo por quilometro [1/100km] & 2,84 \\
Tempo de processamento & $8 \min 47 \mathrm{~s}$ \\
Número de iterações total & 17613750 \\
\hline
\end{tabular}

\subsection{Resultados da programação dinâmica - Caso 2}

A Figura 6.5 mostra o resultado da variável de estado e controle para o caso 2 . Nesse caso, a programação dinâmica escolhe por utilizar a potência da bateria mais frequentemente para assistir a propulsão do veículo quando o MCI está ligado. Isso pode ser notado devido ao fato de o SOC não apresentar valores 
acima de $60 \%$, indicando que há pouca recarga efetuada para bateria fora de eventos de frenagem.

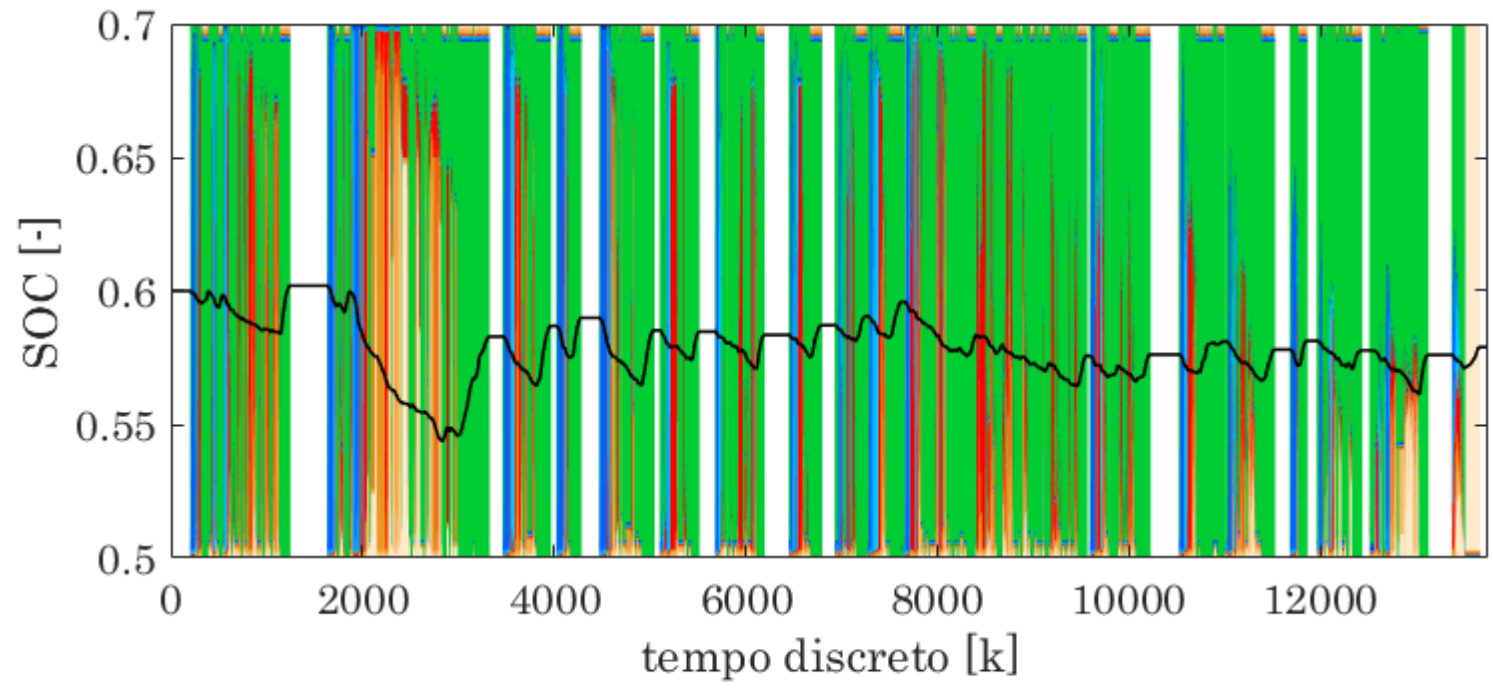

Máxima recarga

Recarga Apenas MCI MG2 assiste

Elétrico

Figura 6.5 -Resultado da caso 2 para o SOC da bateria. O gráfico de contorno mostra todas as soluções de controle ótimo possíveis resultantes da otimização global.

O resultado para a razão de distribuição de torque é mostrado na Figura 6.6. Observa-se que a rotina de PD decide por ligar o MCI a partir de $4 \mathrm{~kW}$ (regiões onde $\left.-1<r_{\text {torque }}<1\right)$. Como notado na Figura 6.5, existe também um menor número de pontos em máxima recarga $\left(r_{\text {torque }}=-1\right)$ quando comparado com o caso 1, principalmente para valores de potência menores que $6 \mathrm{~kW}$. 


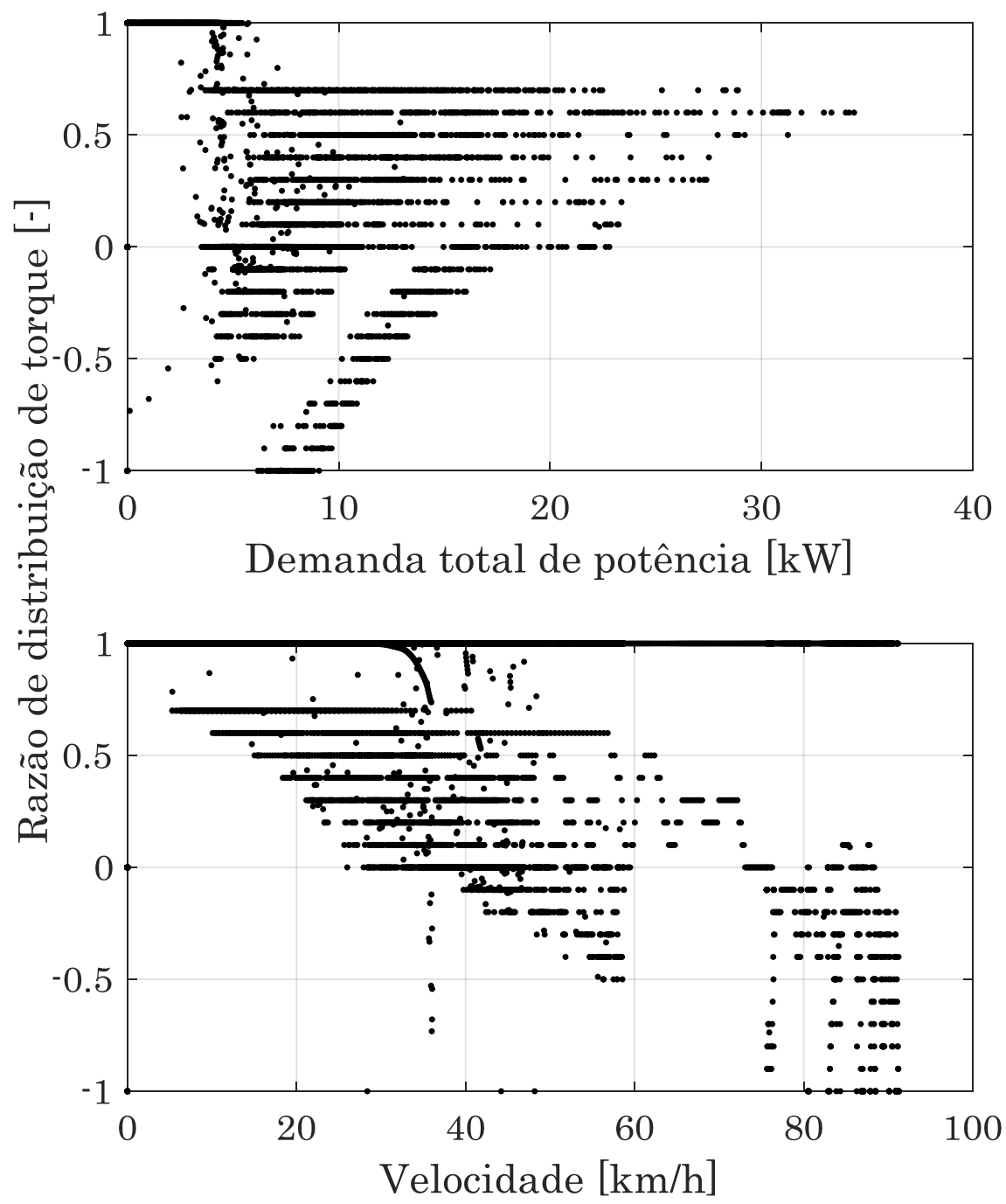

Figura 6.6 - Razão de distribuição de torque em função da demanda de potência (acima) e velocidade (abaixo) para o caso 2 da programação dinâmica.

As regiões de operação do motor de combustão são mostrados na Figura 6.7 para os dois casos. Observa-se que, no caso 1, os pontos de operação estão confinados na linha de operação ótima. Já no caso 2 , a rotina de $\mathrm{PD}$ decide por operar o motor de combustão em regiões diferentes. Nota-se que os pontos do caso 2 ainda seguem a tendência do caso 1 , que concentra a operação em região de torque elevado, onde a eficiência é mais alta do que em regiões de baixo torque. O fato de o MCI não operar na sua região ótima no caso 2 , mostra que o ótimo global do 
sistema leva em consideração a eficiência de todo o trem-de-força híbrido, composto pelo MCI, MG1 e MG2.

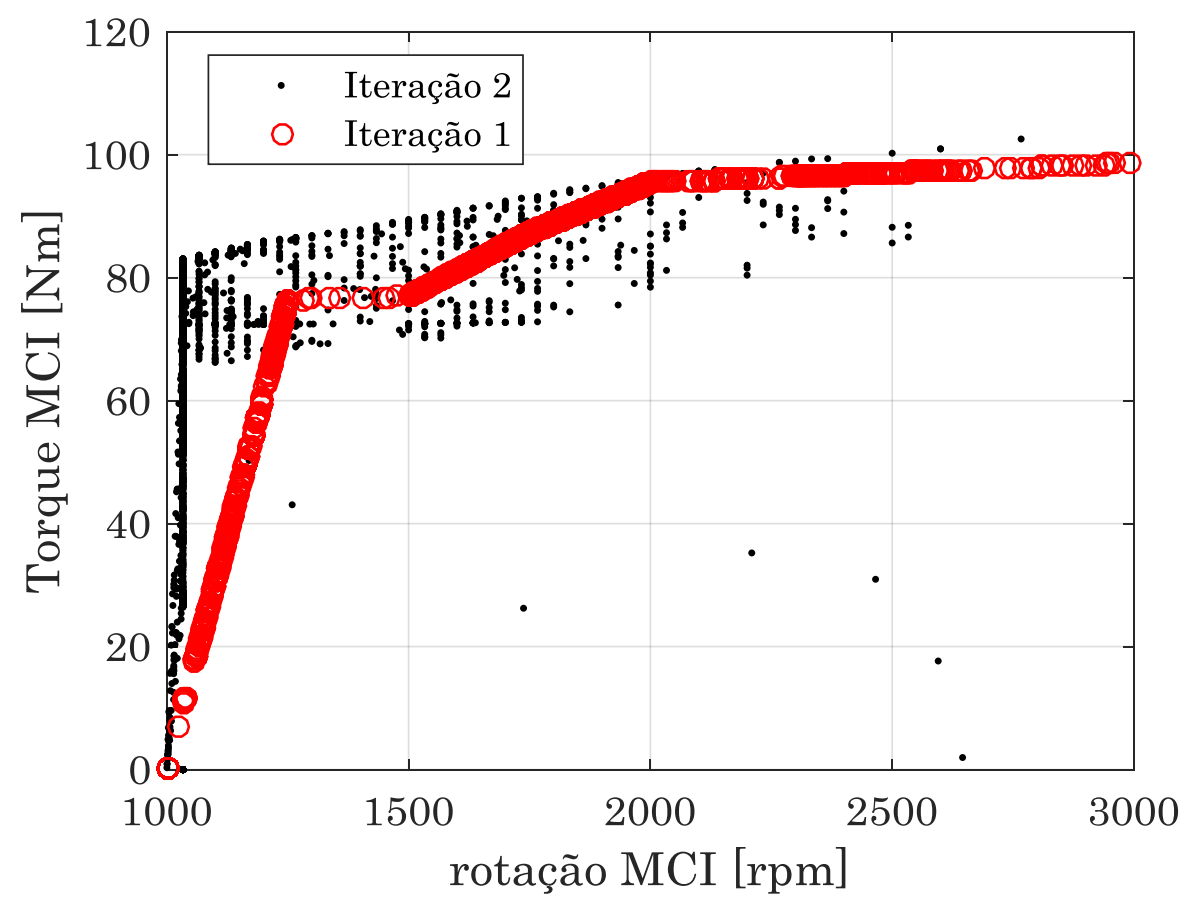

Figura 6.7 - Pontos de operação do MCI durante para os dois casos da programação dinâmica.

A partir da Figura 6.7 ainda é possível observar que a concentração de pontos do caso 1 em altas rotações é maior do que no caso 2. Como mencionado acima, no caso 2 o MCI é ligado em instantes correspondentes à menor demanda de potência e, portanto, antes no tempo em relação ao caso 1. Isso causa uma menor necessidade de recarga da bateria sendo que o MCI não deve fornecer uma parcela tão alta de potência como no caso 1 .

O consumo de combustível do caso 2 foi de 0,3061 (Figura 6.8), o que equivale a uma redução de $10 \%$ em relação ao caso 1 . Esse resultado mostra que a eficiência de todo o sistema em conjunto é de fato dominante para se atingir o mínimo consumo de combustível e que o confinamento dos pontos de operação do MCI na linha de operação ótima não corresponde ao mínimo global. 


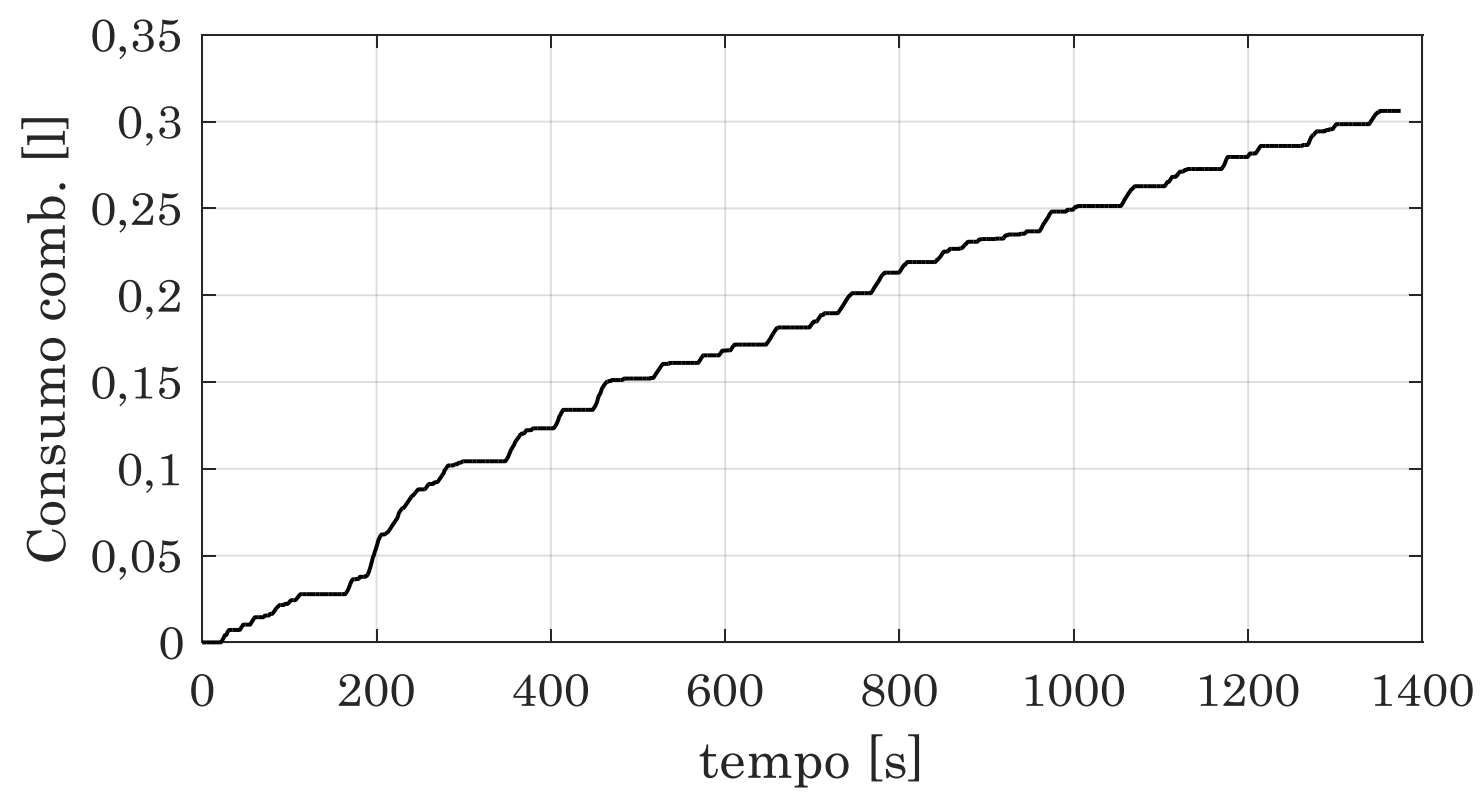

Figura 6.8 - Consumo de combustível resultante do caso 2 da programação dinâmica.

A Tabela 6.3 mostra os resultados do caso 2 da programação dinâmica. Demais resultados são mostrados no APÊNDICE E.

Tabela 6.3 - Resultados do caso 2 da programação dinâmica.

\begin{tabular}{lc}
\hline Parâmetro & PD caso 2 \\
\hline \hline Variável de estado & SOC \\
Variáveis de controle & $r_{\text {torque }}$ \\
Variação SOC [\%] & $-1,5 \%$ \\
Consumo de combustível [l] & 0,306 \\
Consumo por quilometro [l/100km] & 2,55 \\
Tempo de simulação & $3 \mathrm{~h} 45 \mathrm{~min}$ \\
Número de iterações total & 2131263750 \\
\hline
\end{tabular}




\section{CONCLUSÃO}

Este capítulo contêm as conclusões e propostas de trabalhos futuros relacionados com o estudo de trem-de-força híbrido e suas estratégias de controle. As conclusões são divididas em: modelo da planta do veículo com controle não-ótimo e aplicação de controle ótimo. A seguir, serão propostos tópicos para continuidade do trabalho.

\subsection{Modelo da planta do veículo e controle baseado em regras}

O presente trabalho apresenta a modelagem matemática do trem-de-forças do veículo híbrido elétrico. Os modelos computacionais do motor de combustão, piloto e da bateria foram validados frente à dados experimentais para que o modelo completo contendo estratégia de controle não-ótima pudesse ser construído.

A representatividade do modelo em malha fechada com controle não-ótimo foi verificada frente à resultados experimentais obtidos com o veículo estudado operando em um ciclo de condução urbano. A resposta do estado de carga da bateria (SOC) para a simulação apresentou baixa correlação com resultados experimentais. Isso mostra que a estratégia de gerenciamento de energia, baseada nos dados apresentados na literatura pesquisada, possui certo desvio em relação à estratégia de controle real implementada no veículo. No entanto, o controle baseado em regras aplicado ao modelo permitiu boa correlação da velocidade de operação do motor de combustão, da corrente elétrica na bateria e do consumo de combustível, o que criou uma base para se prosseguir com a aplicação da estratégia de controle ótimo global. 
O modelo computacional implementado em Malab/Simulink nesta dissertação é disponibilizado como ferramenta para o estudo de estratégias de controle e da dinâmica de trem-de-força de sistemas híbridos.

\subsection{Controle ótimo}

Esse trabalho utilizou uma rotina de programação dinâmica para aplicar estratégias de controle ótimo ao trem-de-forças em estudo. Foi então mostrado como é realizada a formulação do método de controle ótimo global para o caso de um veículo híbrido elétrico usando uma rotina de programação dinâmica disponível na literatura. Os resultados para o uso do controle ótimo foram de redução significativa do consumo de combustível em relação ao controle não ótimo.

A Figura 7.1 mostra o SOC da bateria para o caso 1 da programação dinâmica e para os testes realizados com o veículo estudado. Percebe-se uma alta correlação da programação dinâmica com os resultados experimentais em todo o ciclo, com exceção dos primeiros $350 \mathrm{~s}$, onde a temperatura de arrefecimento do MCI ainda é baixa e uma estratégia de controle específica para a diminuição de emissões é necessária, o que não foi levado em consideração na simulação. Esse resultado é interessante e evidencia a presença de uma estratégia de controle no veículo real também baseada em controle ótimo. Isso mostra também a qualidade do modelo e da rotina de programação dinâmica desenvolvido e a sua eficácia no desenvolvimento de estratégias de controle. 


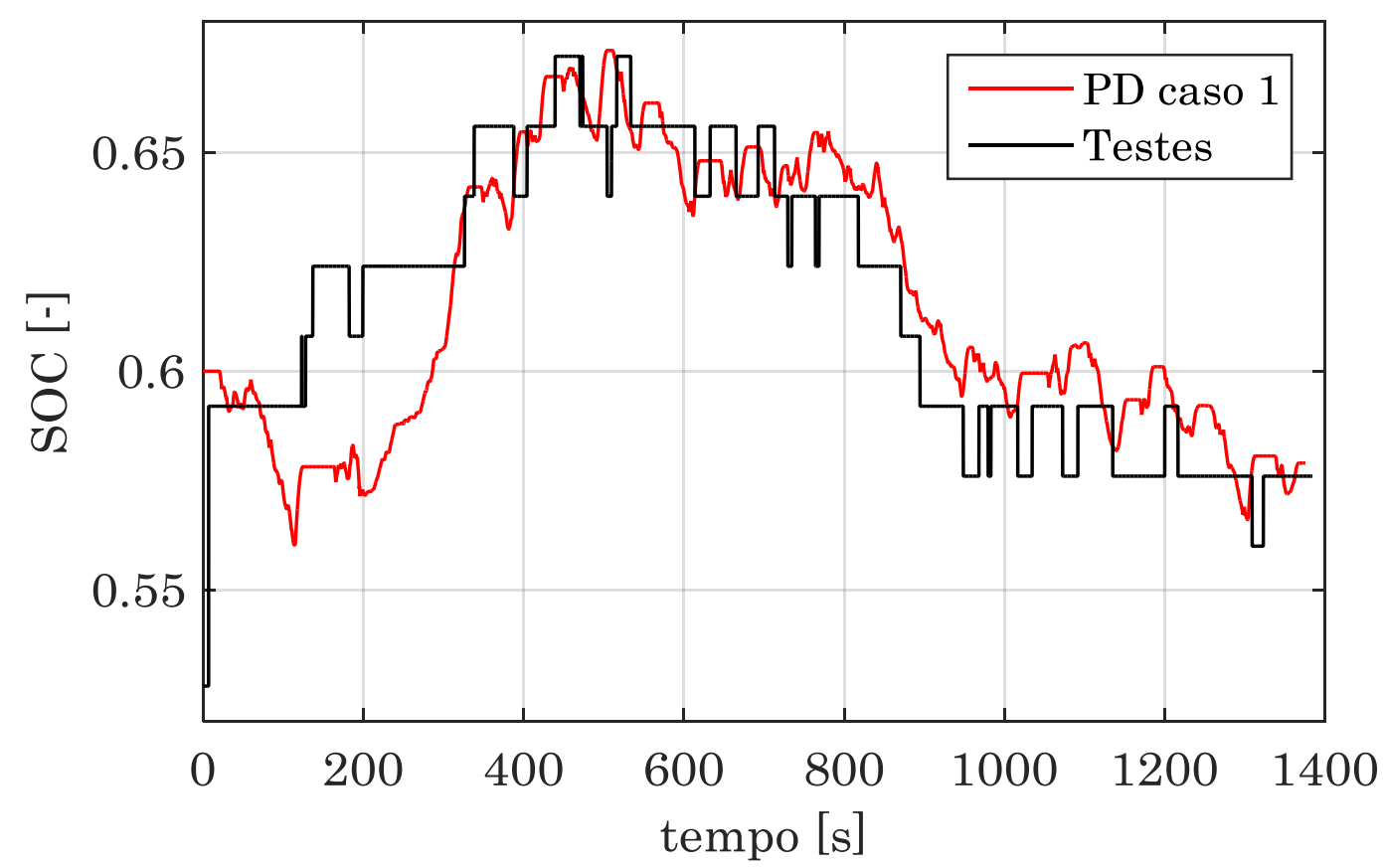

Figura 7.1 - Comparação do resultado para o SOC da bateria proveninente da programação dinâmica - caso 1 - com os resultados de testes com o veículo estudado.

Esse estudo mostra que pode-se obter diferentes graus de otimização baseados no número de variáveis a serem otimizadas. A grande maioria das estratégias de controle presentes na literatura utiliza a curva de operação ótima do motor de combustão para definir sua região de funcionamento. No entanto, foi mostrado que o controle ótimo visando otimizar os pontos de operação do motor de combustão apresenta resultados significativamente menores para consumo de combustível quando comparado com o controle ótimo utilizando a curva de operação ótima. Esse resultado é interessante para ser aplicado na hibridização de veículos que utilizam motores flex, onde a estratégia de controle poderia ser ajustada baseada na fração de etanol no combustível.

\subsection{Proposta para trabalhos futuros}

A seguir são descritas as propostas para dar continuidade à esse estudo. 


\subsubsection{Modelo de controle não ótimo}

O modelo de controle baseado em regras pode ser melhorado realizando-se uma investigação mais detalhada sobre a estratégia de distribuição de torque implementada no veículo real. Nesse contexto, pode-se construir uma estratégia utilizando lógica difusa onde a razão de distribuição de torque seria função da demanda de potência e do estado de carga da bateria.

\subsubsection{Otimização global aplicada a veículos flex}

No caso de veículos operando com motores flex, pode-se investigar a influência de diferentes mapas de consumo específico de combustível resultantes de frações distintas de etanol e gasolina na mistura. Os objetivos principais seriam utilizar diferentes estratégias de distribuição de torque, regiões de operação do motor de combustão e regras para o instante em que o MCI é ligado dependendo da fração de etanol no combustível. Novamente, a utilização de lógica difusa parece promissora para essa caso.

\subsubsection{Controle visando ciclos de condução reais}

Esse estudo investigou o controle ótimo global em um ciclo de condução urbano específico, o que é usualmente o foco da indústria pelo fato de a homologação de veículos ocorrer muitas vezes sob um único ciclo de condução. As estratégias de controle extraídas de tais estudos podem resultar em consumo de combustível bem diferentes do mínimo global quando aplicadas em um veículo real que opera em diversos ciclos de condução. Para isso, pode-se investigar os parâmetros em um ciclo real que diferem de um ciclo de homologação, como por exemplo: aceleração máxima e máxima média, eventos em que existem picos de aceleração e sua amplitude em relação às acelerações médias, ocorrência de eventos de frenagem, etc. A partir desse estudo conceitual pode-se avaliar os métodos de controle que possuam resultados compromissando diversos ciclos de condução. 


\subsubsection{Controle ótimo local}

O objetivo final do estudo de estratégias de controle é a sua aplicação em tempo real em uma unidade de controle eletrônica. O método de controle ótimo global necessita de conhecimento a priori do ciclo de condução, o que impossibilita que ele seja implementado em tempo real. No entanto, métodos de otimização local não necessitam de conhecimento prévio do ciclo por realizarem a minimização do consumo a cada instante e, por isso, podem ser implementados em unidades eletrônicas de controle em tempo real. Pode-se então estudar a influência dos parâmetros da otimização local, sua relação com o estado de carga da bateria e a sua efetividade em relação à otimização global. 


\section{REFERÊNCIAS}

ABVE. Apresenta dados sobre veículos elétricos no Brasil. Disponível em: <http://www.abve.org.br/>. Acesso em: 19 ago. 2014.

ANFAVEA. Anuário da Indústria Automobilística Brasileira. São Paulo: Associação Nacional dos Fabricantes de Veículos Automotores - ANFAVEA, 2015.

ARGONNE NATIONAL LABORATORY. Downloadable Dynamometer Database.

Disponível em: < $\quad$ http://www.anl.gov/energy-systems/group/downloadabledynamometer-database $>$. Acesso em: 12 jun. 2013.

BARAN, R. A Introdução de Veículos Elétricos no Brasil: Avaliação do Impacto no Consumo de Gasolina e Eletricidade. 139 p. Tese (Doutorado) - Universidade Federal do Rio de Janeiro, Rio de Janeiro, 2012.

BARAN, R.; LEGEY, L. F. L. Veículos elétricos: história e perspectivas no Brasil. In: XIII CONGRESSO BRASILEIRO DE ENERGIA, 2010, Rio de Janeiro. Trabalho completo. Rio de Janeiro: BNDES, 2010. <http://www.bndes.gov.br/SiteBNDES/bndes/bndes_pt/Institucional/Publicacoes/ Consulta_Expressa/Setor/Complexo_Automotivo/201103_06.html>. Acesso em: 25 ago. 2013.

BERTSEKAS, D. P. Dynamic Programming and Optimal Control. 3rd Edition Belmont: Athena Scientific, 2005. v. 1.

CHEN, S.; FLYNN, P. Development of a Single Cylinder Compression Ignition Research Engine. SAE Paper 650733, 1965. 
COMPANHIA AMBIENTAL DO ESTADO DE SÃO PAULO. $\mathbf{1}^{\circ}$ Inventário de emissões antrópicas de gases de efeito estufa diretos e indiretos do Estado de São Paulo. São Paulo: CETESB (São Paulo), 2011. (Relatório técnico, ISBN 978-8561405-23-6).

DESAI, C. Design and Optimization of Hybrid Electric Vehicle Drivetrain and Control Strategy Parameters using Evolutionary Algorithms. 117 p. Dissertação (Mestrado) - Concordia University, Montréal, 2010.

DOMINGUES, J. M.; PECORELLI-PERES, L. A. Electric Vehicle, taxes and public polices in Brazil. In: Kreiser, L. Green Taxation and Environmental Sustaintability. Cheltenham: Edward Elgar, 2012. cap. 8, p. 113 - 119.

EHSANI, M.; GAO, Y.; EMADI, A. Modern electric, hybrid electric and fuel cell vehicles. $2^{\mathrm{a}}$ ed. Boca Raton: CRC Press, 2010. 558 p.

FERRAZ, C. V. Sistemas Controladores de Propulsão de Veículos Automotores. 2004. Dissertação (Mestrado) - Escola Politécnica, Universidade de São Paulo, São Paulo, 2004.

GILLESPIE, T.D. Fundamentals of Vehicle Dynamics, 1.ed. Warrendale: Society of Automotive Engineers, Inc. 1992.

GONDER, J. N. Route-Based Control of Hybrid Electric Vehicles. In: SAE World Congress \& Exhibition, Detroit, 2008. SAE Paper 2008-01-1315, 2008.

GRAY, T.; SHIRK, M. 2010 Toyota Prius VIN 0462 Hybrid Electric Vehicle Battery Test Results. DOE Idaho Operations Office, 2013. (INL/EXT-13-28025).

GREENE, D. L.; HOPSON, J. L.; LI, J. Running Into and Out of Oil: Scenarios of Global Oil Use and Resource Depletion to 2050. Tennessee: Oak Ridge National Laboratory, July 2002. 
HEYWOOD, J. B. Internal Combustion Engine Fundamentals. New York: McGraw-Hill, Inc. 1988.

INTERGOVERNMENTAL PANEL ON CLIMATE CHANGE. IPCC Fourth Assessment report: Climate Change 2007. Disponível em: $<$ http://www.ipcc.ch/publications_and_data/ar4/syr/en/spm.html $>$. Acesso em: 03 mar. 2007.

KAMIYA, M. Development of traction drive motors for the toyota hybrid system. IEEJ Transactions on Industry Applications. v. 126. n. 4 473-479, 2006.

KARBOWSKI, D.; PAGERIT, S.; KWON, J.; ROUSSEAU, A. "Fair" Comparison of Powertrain Configurations for Plug-In Hybrid Operation Using Global Optimization. In: SAE World Congress \& Exhibition, Detroit, 2009. SAE Paper 2009-01-1334, 2009.

KIM, K.; CHA, S.; PENG, H. Optimal Control of Hybrid Electric Vehicles Based on Pontryagin's Minimum Principle. IEEE Transactions on Control System Technology, v. 19, n. 5, p. 1279 - 1287, 2011.

KIM, N.; ROUSSEAU, A.; RASK, E. Autonomie Model Validation with Test Data for 2010 Toyota Prius. In: SAE World Congress \& Exhibition, Detroit, 2012. SAE Paper 2012-01-1040, 2012.

KOOT, M. W. T. Energy Management for Vehicular Electric Power Systems. 130 p. Tese (Doutorado) - Technische Universiteit Eindhoven, Eindhoven, 2006.

LIN, C.-C.; JEON, S.; PENG, H.; LEE, J. M. Driving pattern recognition for control of hybrid electric trucks. Vehicle System Dynamics: International Journal of Vehicle Mechanics and Mobility, v.42, n. 1-2, p. 41-58, 2004. 
LIU, J.; PENG, H.; FILIP, Z. Modeling and Control Analysis of Toyota Hybrid System. Proceedings of the 2005 IEEE/ASME International Conference on Advanced Intelligent Mechatronics, Monterey, p.134-13, 2005.

LIU, J.; PENG, H. Control optimization for a power-split hybrid vehicle. American Control Conference, Minneapolis, p. 14-16, 2006.

MINISTÉRIO DA CIÊNCIA, TECNOLOGIA E INOVAÇÃO - MCTI. Estimativas anuais de emissões de gases de efeito estufa no Brasil. Brasília: Secretaria de Políticas e Programas de Pesquisa e Desenvolvimento - SEPED, 2013.

MINISTÉRIO DE MINAS E ENERGIA. Emissões Veiculares. Disponível em: $<$ http://www.mma.gov.br/mma-em-numeros/emissoes-veiculares $>$. Acesso em: 02 out. 2014.

MINISTÉRIO DE MINAS E ENERGIA. Resenha Energética Brasileira. Brasília, Junho 2015. 32 p.

MINISTÉRIO DO DESENVOLVIMENTO, INDÚSTRIA E COMÉRCIO EXTERIOR. Desenvolvimento da Produção. Disponível em :

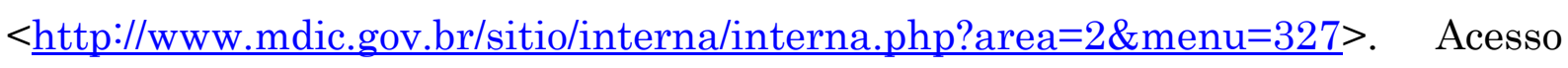
em: 04 mar. 2014.

MINISTÉRIO DO MEIO AMBIENTE. PROCONVE: Programa de controle da poluição do ar por veículos. Disponível em: $<$ http://www.mma.gov.br/estruturas/163/_arquivos/proconve_163.pdf $>$. Acesso: 15 fev. 2015.

MUSARDO, C.; RIZZONI, G.; STACCIA, B. A-ECMS: An Adaptive Algorithm for Hybrid Electric Vehicle Energy Management. Proceedings of the 44th IEEE Conference on Decision and Control, p. 1816 - 1823, 2005. 
MUTA, K.; YAMAZAKI, M.; TOKIEDA, J. Development of New-Generation Hybrid System THS II - Drastic Improvement of Power Perfomance and Fuel Economy. In: SAE World Congress \& Exposition, Detroit, 2004. SAE Paper 200401-0064, 2004.

NETO, A. R. Controle Ótimo de Sistemas Mecânicos: Notas de Aula e Exemplos de Aplicação, Anotações de aula, São José dos Campos, 2012.

NOBEN, P. A comparison study between power-split CVTs and a push-belt CVT. Dissertação (Mestrado) - Department Mechanical Engineering, Technische Universiteit Eindhoven, Eindhoven, 2007.

QUEIROZ, J. F. Introdução do veículo híbrido no Brasil: Evolução tecnológica aliada à qualidade de vida. Dissertação (Mestrado) - Escola Politécnica, Universidade de São Paulo, São Paulo, 2006.

RAJAGOPALAN, A.; WASHINGTON, G.; RIZZONI, G.; GUEZENNEC, Y. Development of Fuzzy Logic and Neural Network Control and Advanced Emissions Modeling for Parallel Hybrid Vehicles. Ohio: National Renewable Energy Laboratory, December 2003. (NREL/SR-540-32919).

ROSARIO, L. C., Power and Energy Management of Multiple Energy Storage Systems in Electric Vehicles. Tese (Doutorado) - Department of Aerospace Power \& Sensors, Cranfield University, Wiltshire, 2007.

SALMASI, F. R., Control Strategies for Hybrid Electric Vehicles: Evolution, Classification, Comparison, and Future Trends. IEEE Transactions on Vehicular Technology, v. 56, n. 5, p. 2393 - 2404, 2007.

SCHOUTEN, N. J.; SALMAN, M. A.; KHEIR, N. A. Energy management strategies for parallel hybrid vehicles using fuzzy logic. Control Engineering Practice, v. 11, n. 2, p. 171-177, Feb. 2003. Disponível em: 
<http://www.sciencedirect.com/science/article/pii/S0967066102000722> . Acesso em 05 jun. 2013.

SOUZA, R. B. Uma visão sobre o balanço de energia e desempenho em veículos híbridos. 2010. 124 p. Dissertação (Mestrado) - Faculdade de Engenharia Mecânica, Universidade Estadual de Campinas, Campinas, 2010.

STAUNTON, R. H.; AYERS, C. W.; MARLINO, L. D.; CHIASSON, J. N.; BURRESS, T.A. Evaluation of 2004 Toyota Prius hybrid electric drive system. Washington: Oak Ridge National Laboratory, May 2006. p. 95. (ORNL/TM2006/423).

SUNDSTÖM, O. Optimal Control and Design of Hybrid Electric Vehicles. 198 p. Tese (Doutorado) - Institute for Dynamic Systems and Control, Chalmers University of Technology, Zurich, 2009.

UNIÃO DA INDÚSTRIA DE CANA-DE-AÇÚCAR. Relatório de sustentabilidade 2008. 2008. Disponível em: < $\underline{w w w . u n i c a . c o m . b r / d o w n l o a d s / r e l a t o r i o ~}>$. Acesso em: 04 fev. de 2015 .

UNICA. UNICADATA - Consumo de combustíveis 2014. Disponível em: $<$ http://www.unicadata.com.br/historico-de-consumo-decombustiveis.php?idMn=11\&tipoHistorico $=10 \& a c a o=$ visualizar\&idTabela $=1576 \&$ produto=Gasolina\%2BC\&nivelAgregacao=1>. Acesso em: 28 mar. 2015.

UNITED STATES ENVIRONMENTAL PROTECTION AGENCY. Test Car List Data Files. 2014. Disponível em: <http://www.epa.gov/otaq/tcldata.htm $>$. Acesso em: maio 2014.

VAGG, C. Optimal Control of Hybrid Electric Vehicles for Real-World Driving Patterns. 201 p. Tese (Doutorado) - Department of Mechanical Engineering, University of Bath, Bath, 2014. 
VALENTINE-URBSCHAT, M.; BERNHART, W. Powertrain 2020 - The Future Drives Electric. Roland Berger Strategic Consultants. Disponível em: $<$ http://www.rolandberger.be/media/pdf/Roland_Berger_Powertrain_2020_201102 15.pdf> Acesso em: 03 mar. 2014.

WALDNER, J., WISE, J., CRAWFORD, C., DONG, Z. Development and Testing of an Advanced Extended Range Electric Vehicle. In: SAE World Congress \& Exhibition, Detroit, 2011. SAE Paper 2011-01-0913, 2011.

WALTERS, J.; HUSTED, H.; RAJASHEKARA, K. Comparative Study of Hybrid Powertrain Strategies. In: Future Transportation Technology Conference \& Exposition, Costa Mesa, CA, USA, 2001. SAE Paper 2001-01-2501, 2001.

WIPKE, K. B.; CUDDY, M. R. Using An Advanced Vehicle Simulator (ADVISOR) To Guide Hybrid Vehicle Propulsion System Development. Golden: National renewable Energy Laboratory (NREL), 1998.

WISHART, J. D. Modelling, Simulation, Testing, and Optimization of Advanced Hybrid Vehicle Powertrains. 308 p. Tese (Doutorado) - Department of Mechanical Engineering, University of Victoria. Victoria, 2008.

YI, Z.; HEPING, L.; HUABIN, W. Torque Control Strategy for Parallel Hybrid Electric Vehicles using Fuzzy Logic. WSEAS Transactions on Systems, Wisconsin, v. 10, n. 4, p. 116-125, April 2010.

ZHANG, X.; LI, C.-T.; KUM, D.; PENG, H. Prius+ and Volt-: Configuration Analysis of Power-Split Hybrid Vehicles With a Single Planetary Gear. IEEE Transactions on Vehicular Technology, Gainesville, v. 61, n. 8, p. 3544-3552, July 2012. 
ZHU, Y.; CHEN, Y.; TIAN, G.; WU, H.; CHEN, Q. A Four-Step Method to Design an Energy Management Strategy for Hybrid Vehicles. Proceeding of the 2004 American Control Conference, Boston, 2004. 


\section{ANEXO A - DADOS DO VEÍCULO}

Tabela A.1 - Especificações do sistema adotado.

\begin{tabular}{|c|c|}
\hline \multicolumn{2}{|r|}{ MCI } \\
\hline Deslocamento volumétrico & 1,51 \\
\hline Tipo & 4 cilindros, 16 válvulas DOHC, VVTi \\
\hline Torque máximo & 115 Nm @ 4200 rpm \\
\hline Potência máxima & 57 kW@ 5000 rpm \\
\hline \multicolumn{2}{|r|}{ MG2 } \\
\hline Tipo & Motor CA síncrono de ímã permanente \\
\hline Torque máximo & $400 \mathrm{Nm}$ \\
\hline Potência máxima & $50 \mathrm{~kW}$ \\
\hline Rotação máxima & $6500 \mathrm{rpm}$ \\
\hline \multicolumn{2}{|r|}{ MG1 } \\
\hline Tipo & Motor CA síncrono de ímã permanente \\
\hline Torque máximo & $20 \mathrm{Nm}$ \\
\hline Potência máxima & $30 \mathrm{~kW}$ \\
\hline Maximum speed & $10000 \mathrm{rpm}$ \\
\hline \multicolumn{2}{|r|}{ Bateria } \\
\hline Tipo & $\mathrm{Ni}-\mathrm{MH}$ \\
\hline Número de células & 168 \\
\hline Tensão da célula & $1,2 \mathrm{~V}$ \\
\hline Tensão nominal & $201,6 \mathrm{~V}$ \\
\hline Capacidade de carga & $6,5 \mathrm{Ah}$ \\
\hline \multicolumn{2}{|r|}{ Transmissão } \\
\hline Tipo & Automática controlada eletronicamente \\
\hline $\begin{array}{l}\text { Redução do diferencial } \\
\text { com engrenagem final }\end{array}$ & 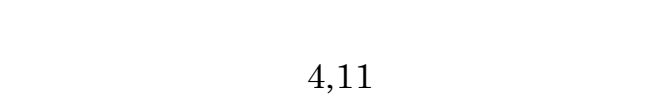 \\
\hline Redução da planetária & 2,6 \\
\hline
\end{tabular}




\section{APÊNDICE A - MODELAGEM DA DINÂMICA NA ENGRENAGEM PLANETARIA}

A Figura A.1 mostra o diagrama de corpo livre para as engrenagens da transmissão planetária. Enquanto alguns autores descrevem as equações na forma estática (EHSANI; GAO e EMADI, 2010; NOBEN, 2007), Liu, Peng e Filip (2005) e Wishart (2008) fazem o equacionamento dinâmico do sistema, como será mostrado abaixo.

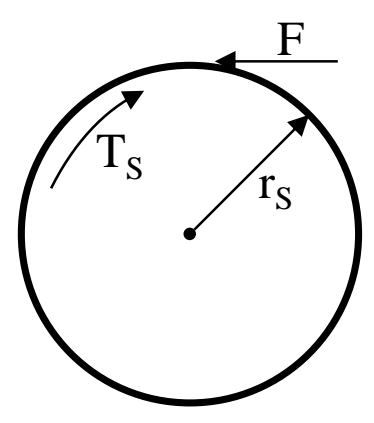

a)

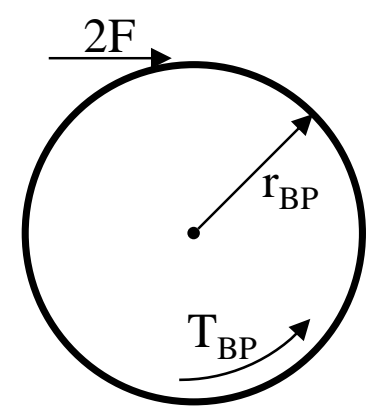

b)

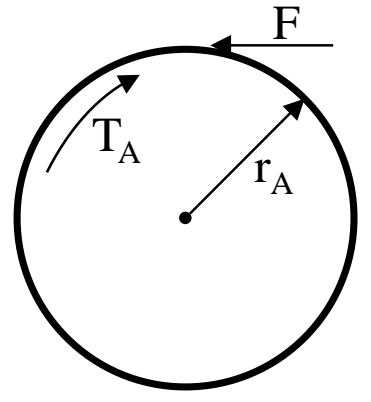

c)

Figura A.1 - Diagrama de corpo livre para componentes da engrenagem planetária: a) engrenagem solar, b) braço planetário e c) engrenagem anular.

O termo de atrito é deixado fora da modelagem a fim de simplificar os cálculos. A convenção usada é que torque positivo age no sentido anti-horário. A somatória dos momentos nos elementos da figura acima resulta em:

$$
\begin{aligned}
& F \cdot r_{S}-T_{S}=I_{S} \cdot \dot{\omega}_{M G 1} \\
& T_{B P}-2 F \cdot \frac{r_{A}+r_{S}}{2}=I_{B P} \cdot \dot{\omega}_{B P} \\
& F \cdot r_{A}-T_{A}=I_{A} \cdot \dot{\omega}_{A}
\end{aligned}
$$

Onde $I_{S}, \quad I_{A}$ e $I_{B P}$ representam o momento de inércia e $T_{S}, T_{A}$ e $T_{B P}$ o torque resistivo nas engrenagens solar, anular e do braço planetário, respectivamente. A 
força interna $F$ é resultante da reação da engrenagem solar com a engrenagem planeta. Os diagramas de corpo livre para o MG1, MCI e MG2 são mostrados abaixo.

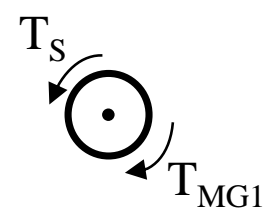

a)

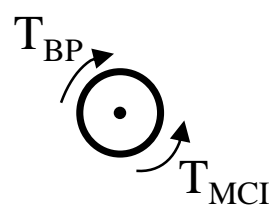

b)

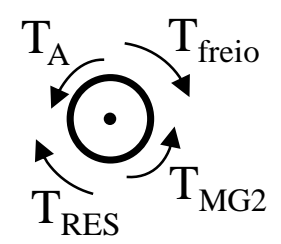

c)

Figura A.2 - Diagrama de corpo livre para a) MG1, b) MCI e c) MG2.

O balanço de forças no MG1 resulta em:

$T_{S}-T_{M G 1}=I_{M G 1} \cdot \dot{\omega}_{M G 1}$

Substituindo a equação acima em (39):

$F \cdot r_{S}-T_{M G 1}=\left(I_{M G 1}+I_{S}\right) \cdot \dot{\omega}_{M G 1}$

Da mesma forma para o MCI:

$$
T_{M C I}-T_{B P}=I_{M C I} \cdot \dot{\omega}_{M C I}
$$

Substituindo essa equação em (40):

$$
T_{M C I}-2 F \cdot \frac{r_{A}+r_{S}}{2}=\left(I_{B P}+I_{M C I}\right) \cdot \dot{\omega}_{B P}
$$

Da mesma forma para o MG2, mas sobre ele agem as forças advindas das resistências ao movimento e do freio mecânico.

$$
\begin{aligned}
& T_{A}+T_{M G 2}-\frac{T_{\text {freio }}}{i_{D}}-\left(\frac{0.5 \cdot C_{d} \cdot \rho_{a r} \cdot A \cdot V^{2}+c_{R} \cdot M \cdot g}{i_{D}}\right) \cdot r_{P}= \\
& \left(I_{M G 2}+\frac{\left(M+m_{\text {rodas }}\right) \cdot r_{p}{ }^{2}}{i_{D}{ }^{2}}\right) \cdot \dot{\omega}_{M G 2}
\end{aligned}
$$


Onde $\left(\frac{0.5 \cdot C_{d} \cdot \rho_{a r} \cdot A \cdot V^{2}+c_{R} \cdot M \cdot g}{i_{D}}\right) \cdot r_{P}=T_{R E S}$, corresponde ao torque nas rodas proveniente da resistência aerodinâmica e ao rolamento. $\mathrm{O}$ termo de inércia $m_{\text {rodas }}$ é a massa equivalente das inércias rotacionais do conjunto do eixo trativo do veículo. Substituindo a Eq. (46) na Eq. (41) resulta em:

$$
\begin{aligned}
& F \cdot r_{A}+T_{M G 2}-\frac{T_{\text {freio }}}{i_{D}}-\left(\frac{0.5 \cdot C_{d} \cdot \rho_{a r} \cdot A \cdot V^{2}+c_{R} \cdot M \cdot g}{i_{D}} \cdot\right) r_{P}= \\
& \left(I_{A}+I_{M G 2}+\frac{\left(M+m_{\text {rodas }}\right) \cdot r_{p}{ }^{2}}{i_{D}{ }^{2}}\right) \cdot \dot{\omega}_{M G 2}
\end{aligned}
$$




\section{APÊNDICE B - DIAGRAMAS DO MODELO COMPUTACIONAL PARA O SISTEMA DE CONTROLE}

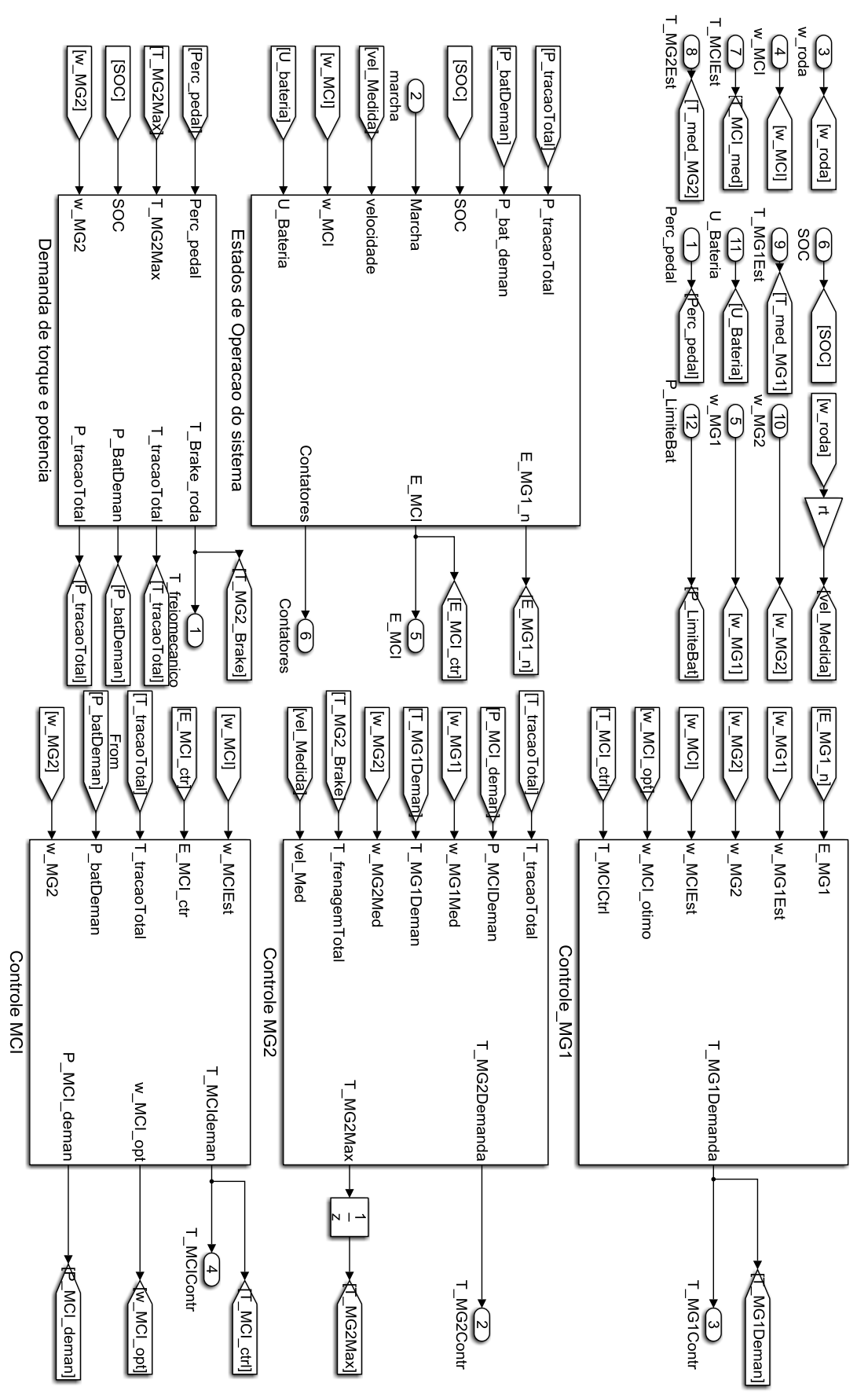

Figura B.1 - Diagrama do nível superior do sistema de controle. 


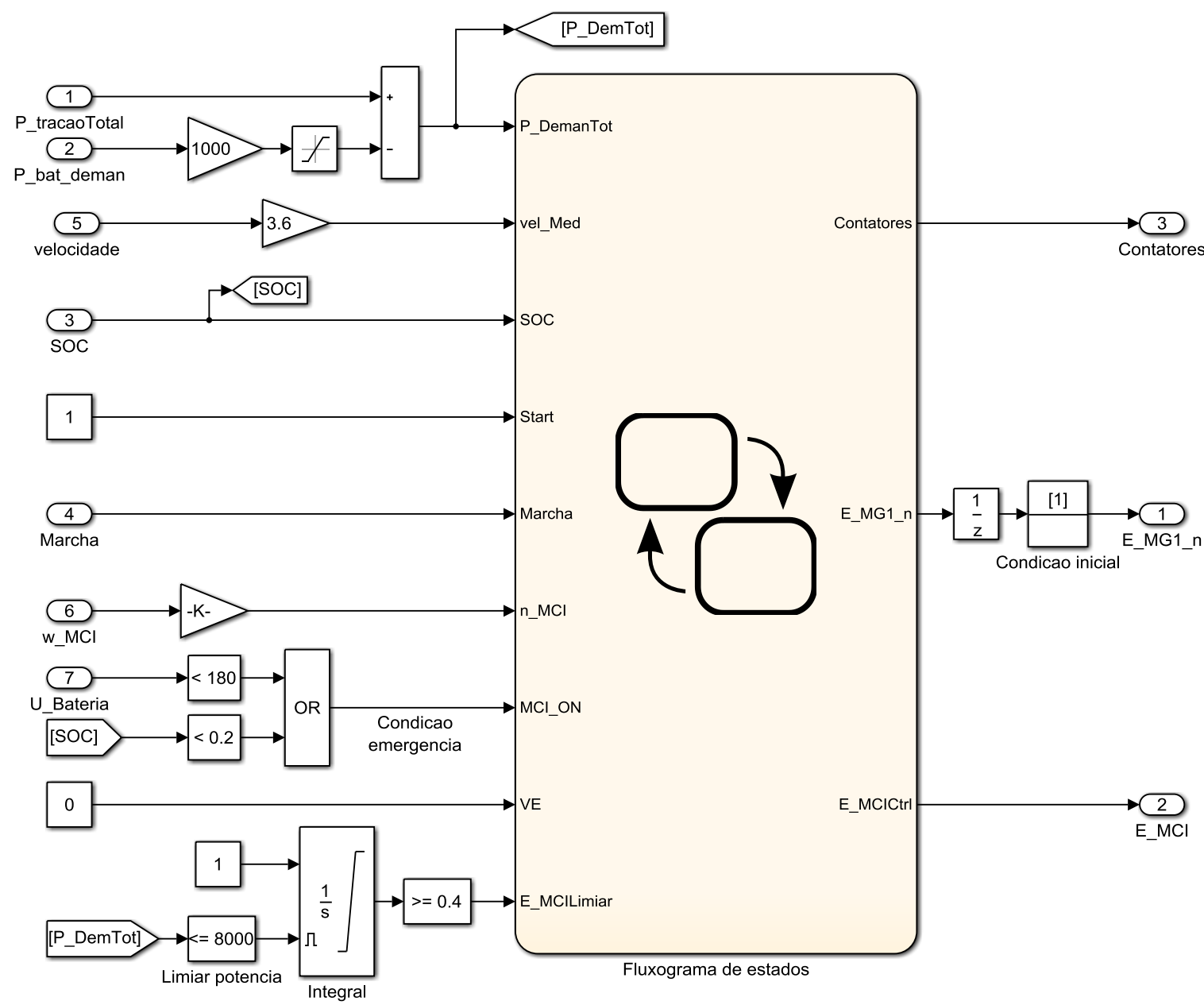

Figura B.2 - Diagrama do sub-módulo de estados de operação do sistema. 


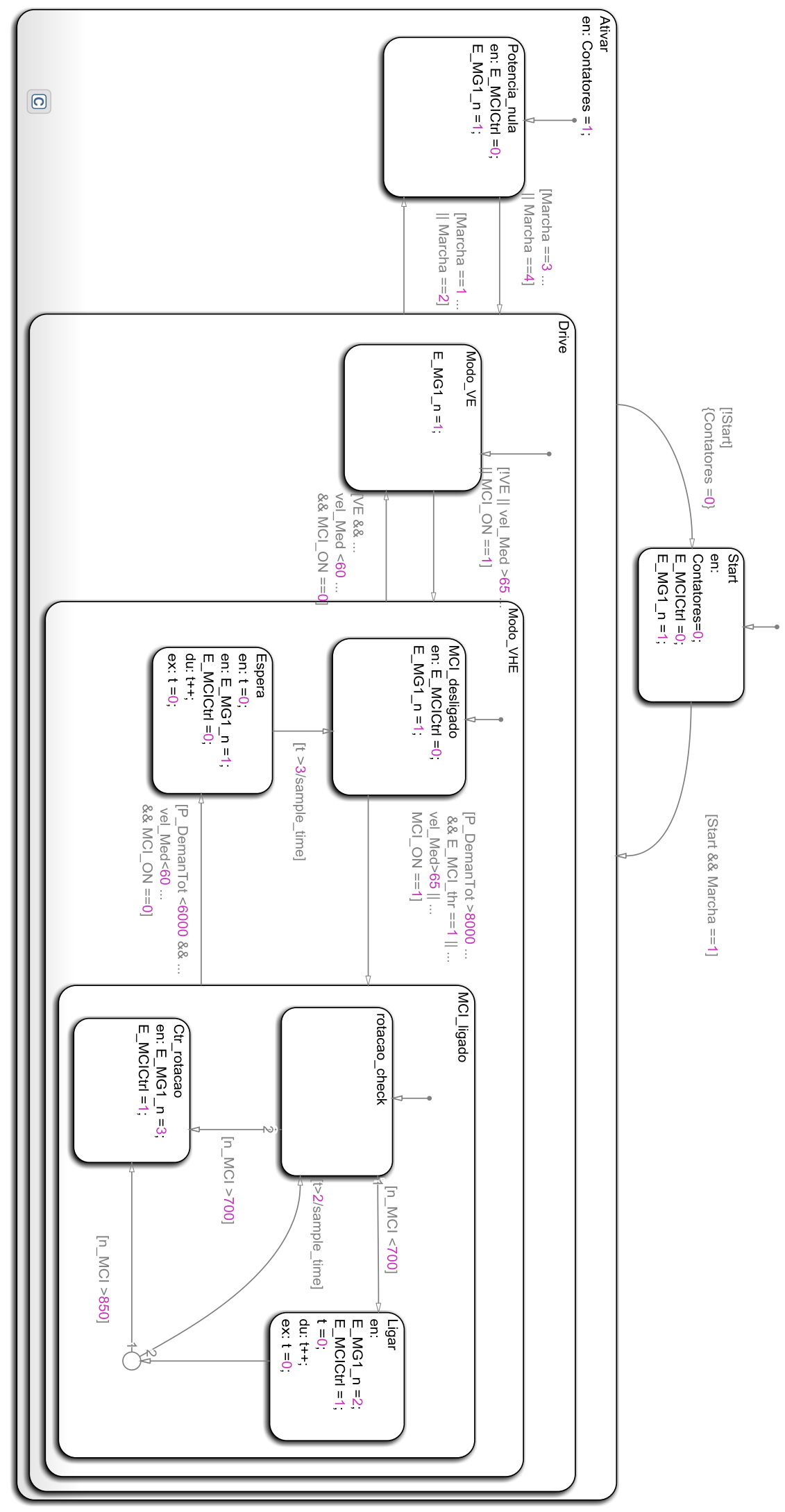

Figura B.3 - Diagrama da máquina de estados do sub-módulo de estados de operação do sistema. 


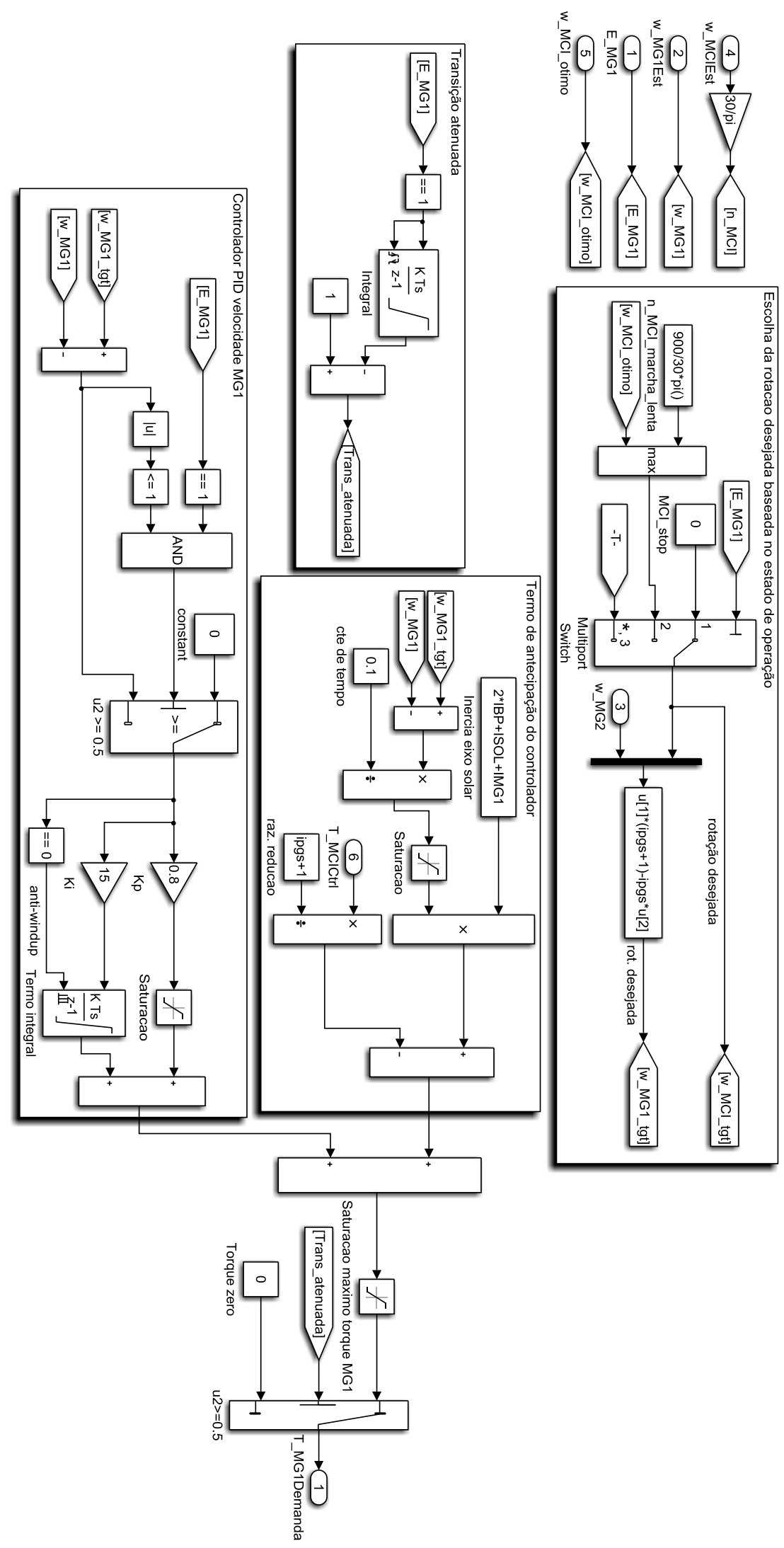

Figura B.4 - Diagrama do sub-módulo do sistema de controle do MG1. 


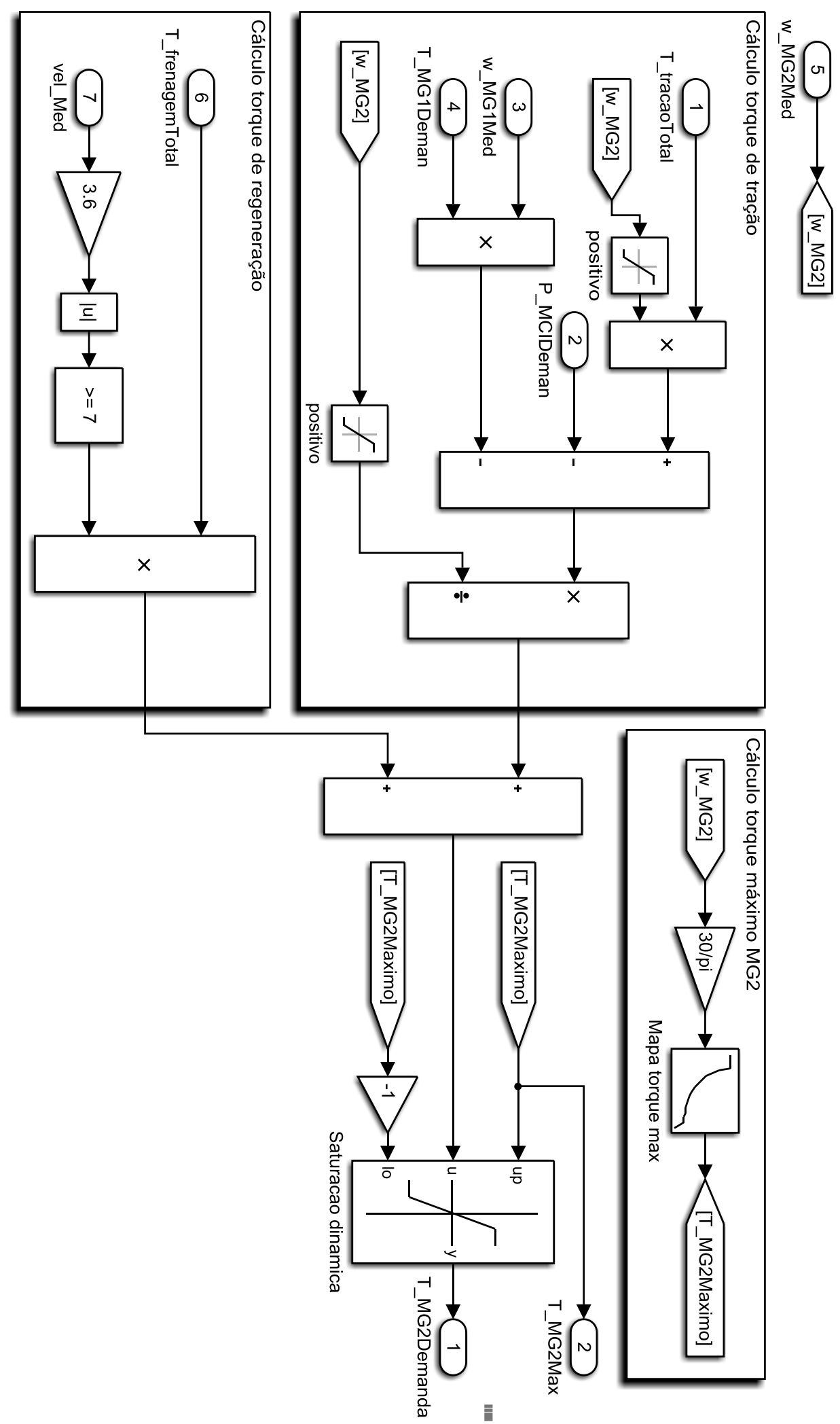

Figura B.5 - Diagrama do sub-módulo do sistema de controle do MG2. 


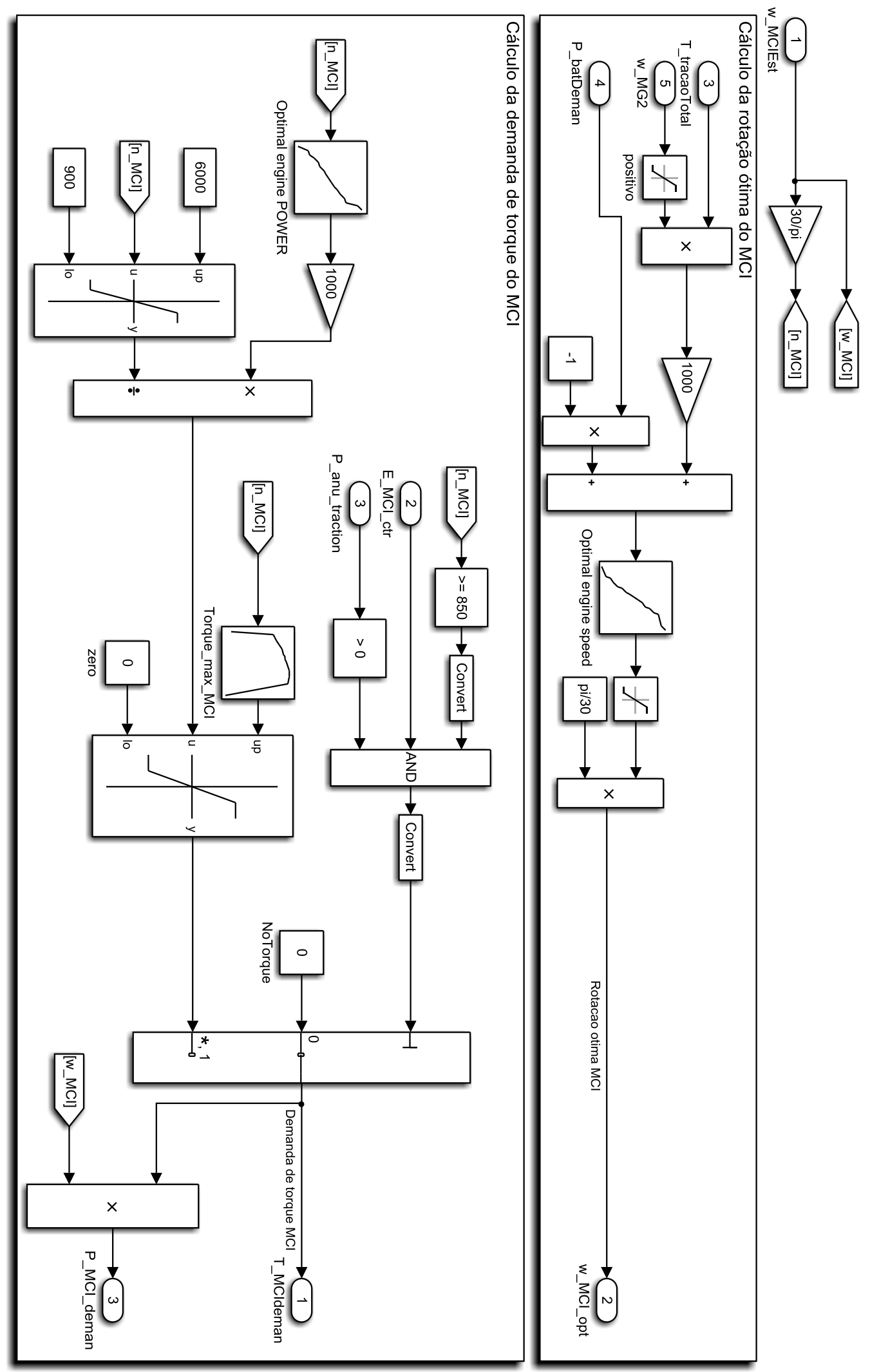

Figura B.6 - Diagrama do sub-módulo do sistema de controle do MCI. 


\section{APÊNDICE C - DADOS DO CICLO DA NORMA NBR 6601}

Tabela C.1 - Dados estatísticos referentes ao ciclo de condução da norma NBR 6601.

\begin{tabular}{lc}
\hline Parametros & Valor \\
\hline \hline Velocidade máxima $[\mathrm{km} / \mathrm{h}]$ & 91,25 \\
Velocidade média $[\mathrm{km} / \mathrm{h}]$ & 42,17 \\
Aceleração máxima $\left[\mathrm{m} / \mathrm{s}^{2}\right]$ & 1,48 \\
Aceleração máxima de frenagem $\left[\mathrm{m} / \mathrm{s}^{2}\right]$ & $-1,48$ \\
Distancia total $[\mathrm{km}]$ & 11,9 \\
Tempo com veículo parado $[\mathrm{s}]$ & 357 \\
Tempo total $[\mathrm{s}]$ & 1375 \\
\hline
\end{tabular}




\section{APÊNDICE D - RESULTADOS DE SIMULAÇÃO DO MODELO COM CONTROLE NÃO-ÓTIMO}
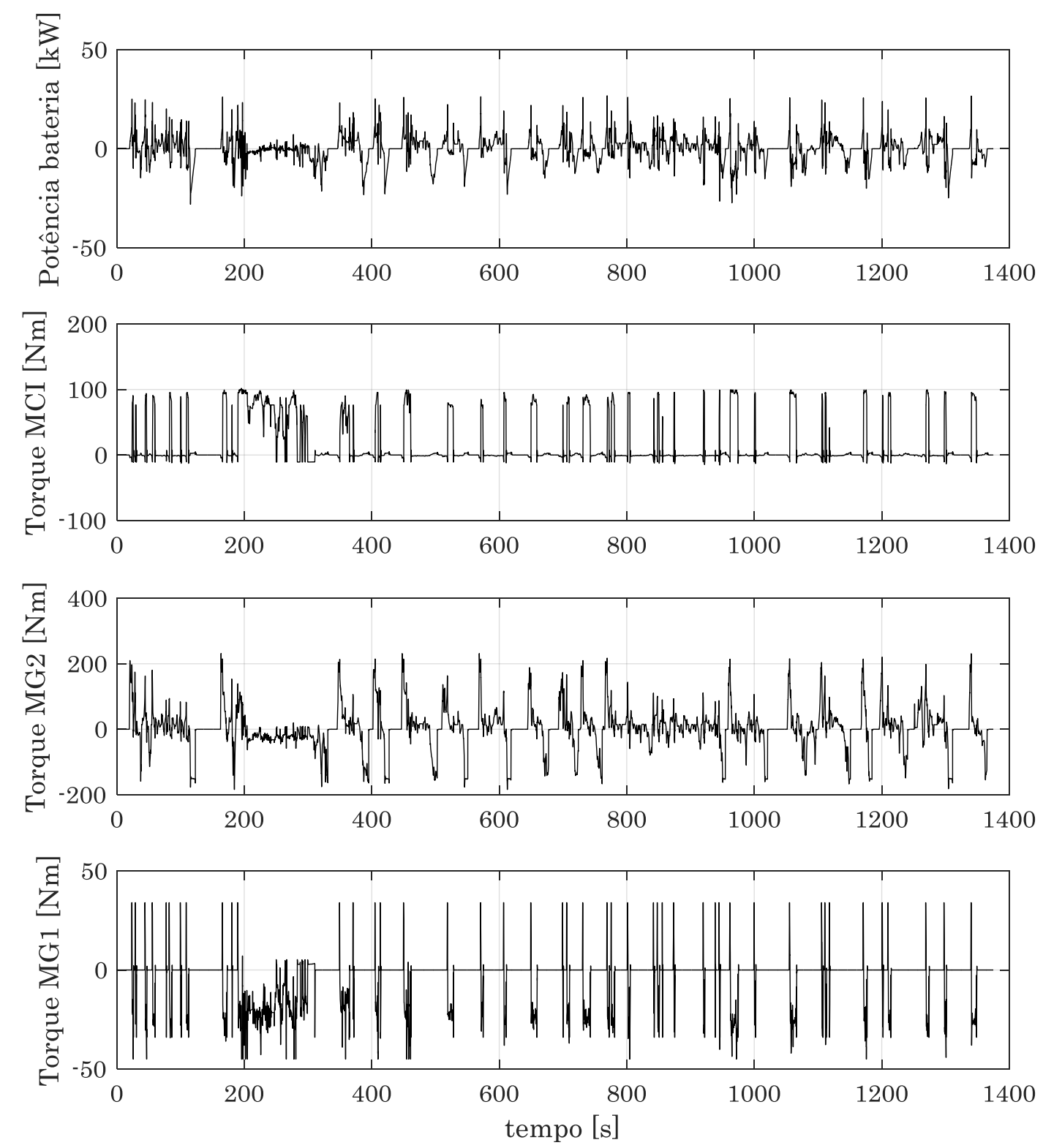

Figura D.1 - Resultados adicionais para a simulação do modelo com controle não ótimo. 


\section{APÊNDICE E - RESULTADOS DA PROGRAMAÇÃO DINÂMICA}
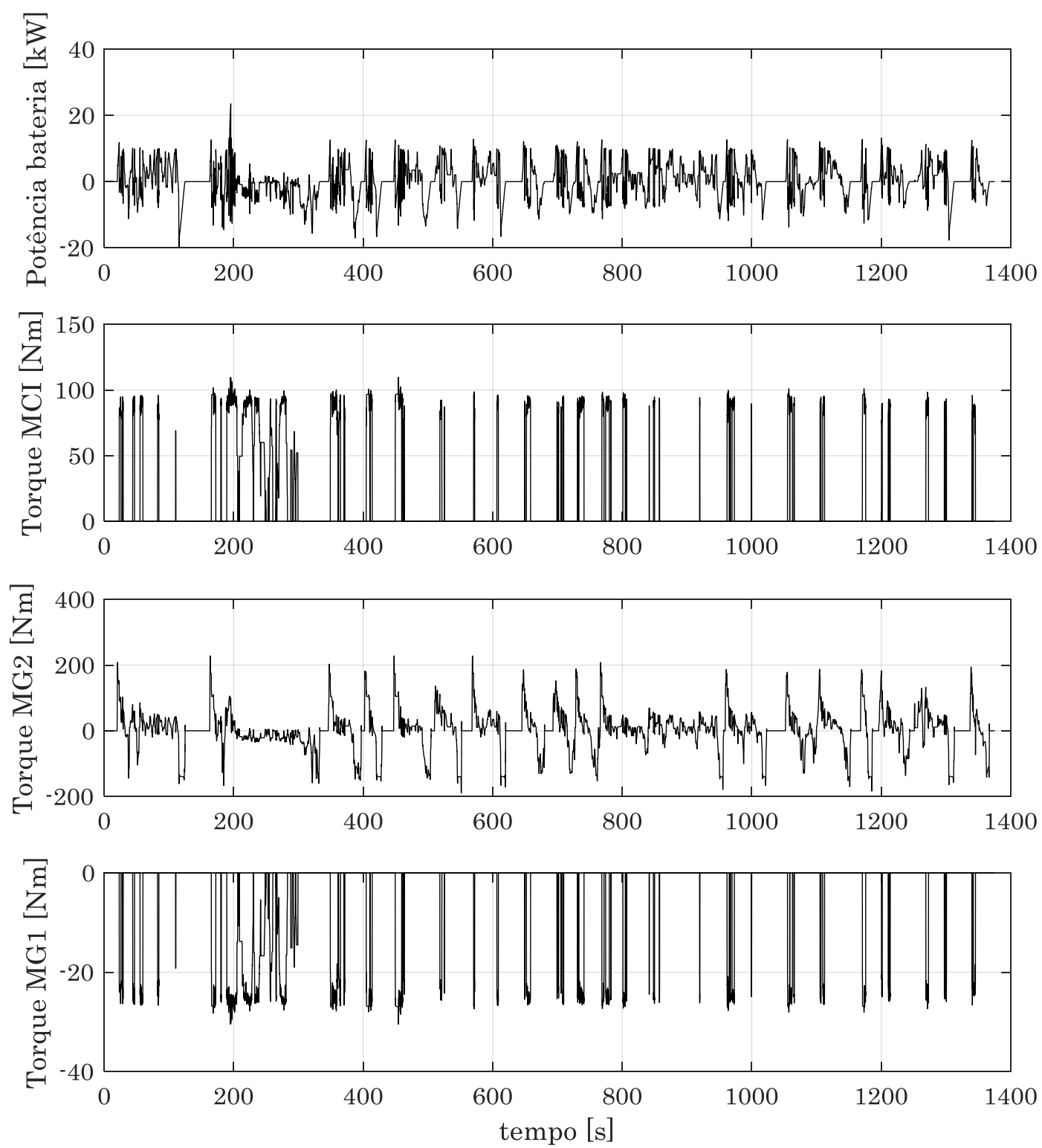

Figura E.1 - Resultados adicionais do caso 1 da programação dinâmica. 

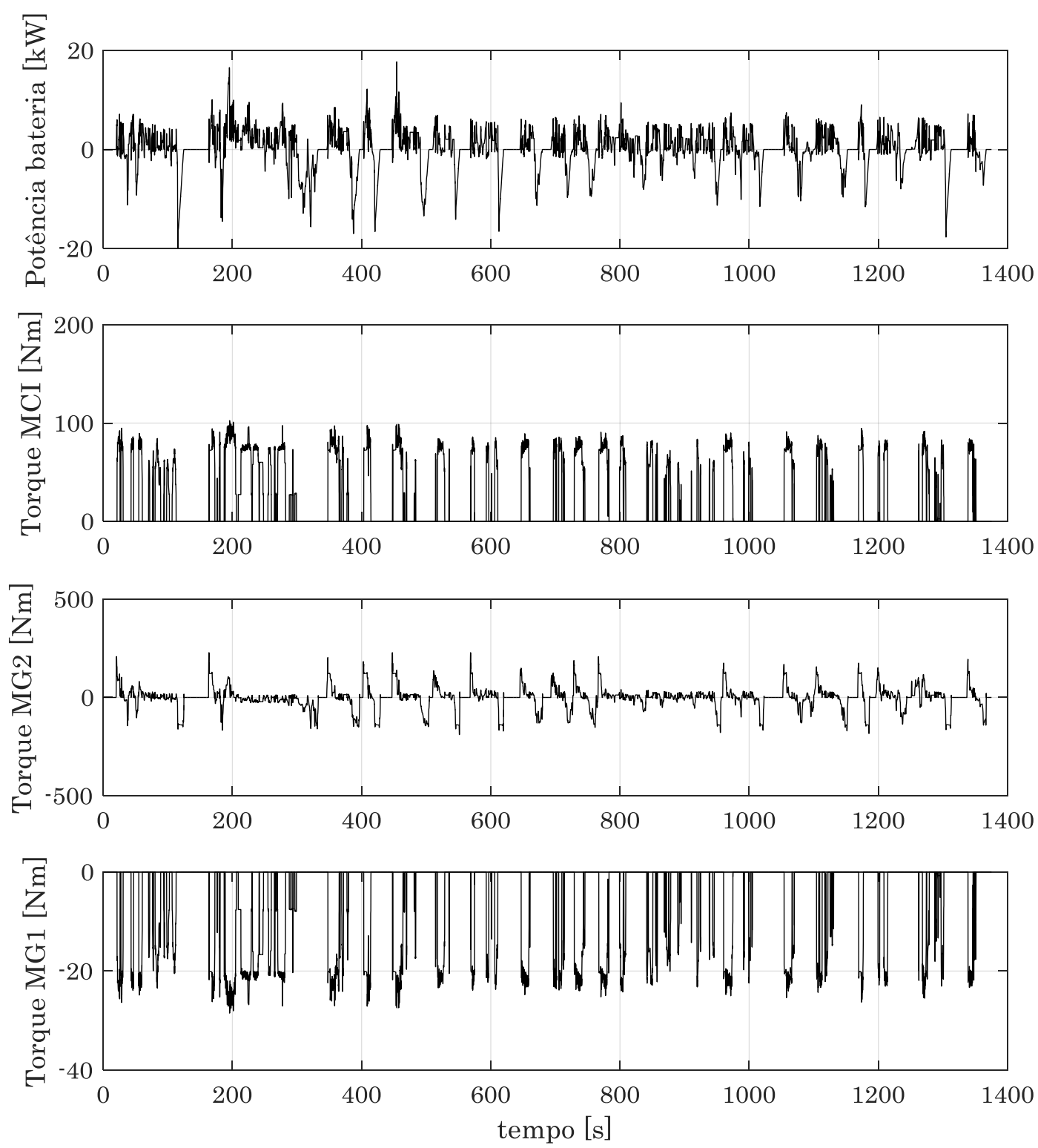

Figura E.2 - Resultados adicionais do caso 2 da programação dinâmica. 